\title{
THE ROLE AND IMPLICATIONS OF CITIZEN ENVIRONMENTAL BOARDS IN STATE-LEVEL POLICY-MAKING: DOES AGENCY STRUCTURE MATTER?
}

\author{
A Dissertation \\ presented to \\ the Faculty of the Graduate School \\ at the University of Missouri-Columbia \\ In Partial Fulfillment \\ of the Requirements for the Degree \\ Doctor of Philosophy \\ by \\ MATTHEW B. ARBUCKLE \\ Dr. Sean Nicholson-Crotty, Dissertation Supervisor
}

JULY 2013 
The undersigned, appointed by the dean of the Graduate School, have examined the dissertation entitled

THE ROLE AND IMPLICATIONS OF CITIZEN ENVIRONMENTAL BOARDS IN STATE-LEVEL POLICY-MAKING: DOES AGENCY STRUCTURE MATTER?

presented by Matthew B. Arbuckle

a candidate for the degree of Doctor of Philosophy, and hereby certify that, in their opinion, it is worthy of acceptance.

Professor Sean Nicholson-Crotty

Professor Guy Adams

Professor Jill Nicholson-Crotty

Professor Lael Keiser

Professor David Konisky 


\section{ACKNOWLEDGEMENTS}

I would like thank Dr. Sean Nicholson-Crotty for taking me on as a student, and for his advice, support, and instruction over the last three years. I have learned a great deal about research and classroom presentation through his guidance, and for that I am grateful.

I would like to thank Dr. David Konisky for helping me adjust to life as a Ph.D. student and, perhaps more importantly, for continuing to advise me after leaving the University of Missouri. His guidance in research and the environmental policy field have been very helpful to me, and I value his friendship.

I would like to thank Dr. Guy Adams for his instruction, advice, and calming presence during my four years at the Truman School. I would also like to thank him for serving on my dissertation committee. I am pleased to have that additional bond.

I would like to thank Dr. Lael Keiser for serving on my dissertation committee. I value her insight and encouragement, and am glad to have her support.

I would like to thank Dr. Jill Nicholson-Crotty for stepping in to fill a last minute vacancy on my dissertation committee. She also helped me prepare for the Comprehensive Examinations, and was a source of timely practical advice.

Last, but certainly not least, I would like to thank Drs. Diamond and Wechsler for believing in me, and for their advice and support along the way. In addition, I would like to thank the rest of the faculty and staff at the Truman School of Public Affairs. I have appreciated all of their support more than I have probably expressed, and am grateful for all of their help and guidance during the last four years. 


\section{TABLE OF CONTENTS}

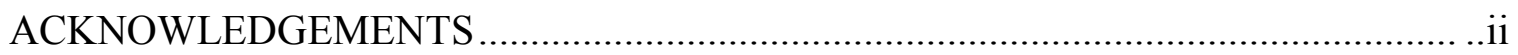

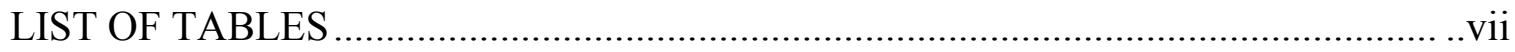

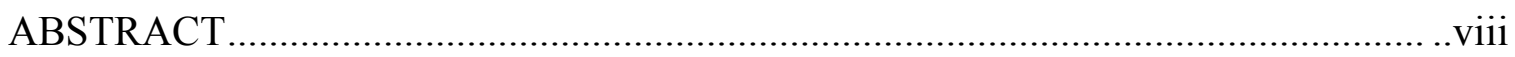

\section{Chapter}

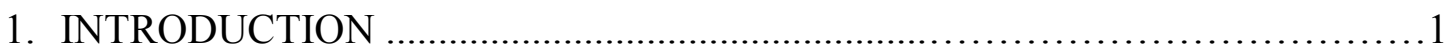

Origins of Modern Environmental Governance...............................4

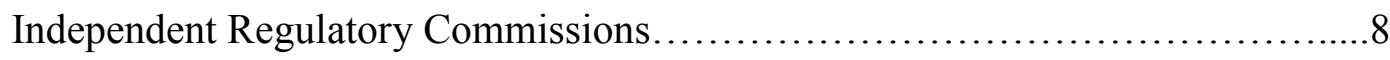

State Environmental Boards............................................ 12

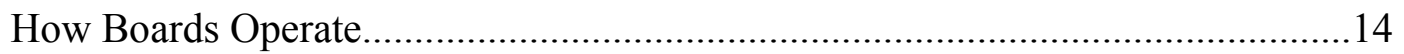

Perceived Benefits of the Board Structure......................................18

Political Independence

Deliberative Governance

Democratic Oversight

Perceived Disadvantages of the Board Structure .............................22

Barriers to Effectiveness

Interest Group Influence

Inefficient

2. DETERMINANTS OF STATE REGULATORY STRUCTURE................29

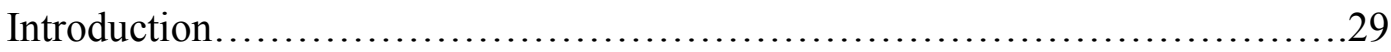


Predicting Board Adoption.

Political Preferences and Agency Structure................................... 32

Interest Group Influence........................................... 35

Constructing a Board Typology..........................................39

Model Specification..............................................43

Dependent Variable...................................................44

Explanatory Variables................................................45

Control Variables................................................48

Results........................................................... 48

Discussion and Conclusion............................................ 55

\section{BOARD MEMBERS' PERCEPTION ABOUT THEIR ROLE IN POLICY}

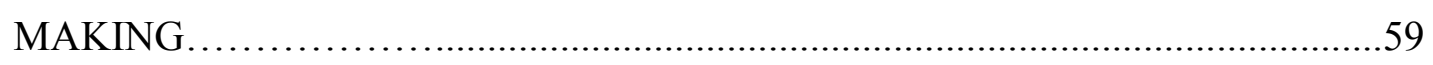

Introduction......................................................... 59

Data and Methods..................................................63

Public Participation..................................................64

Oversight.......................................................68

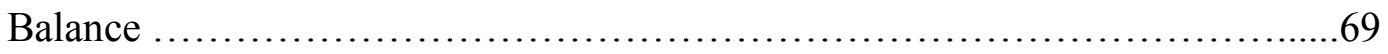

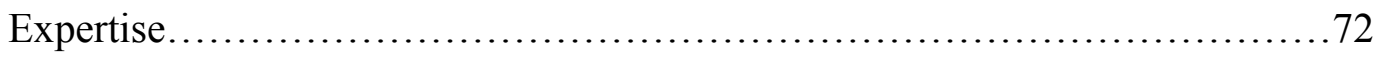

Resource Bias.................................................73

Independence.................................................. 77

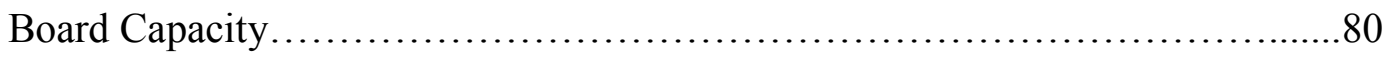


Efficiency v. Transparency............................................ 83

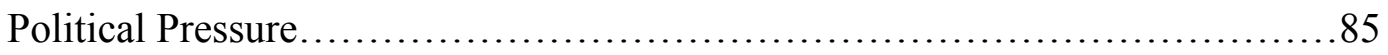

Discussion and Conclusion................................................. 87

4. ENVIRONMENTAL BOARDS AND ENVIRONMENTAL

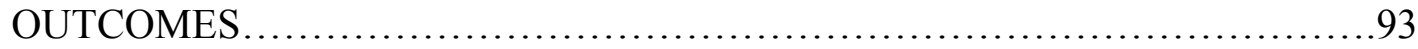

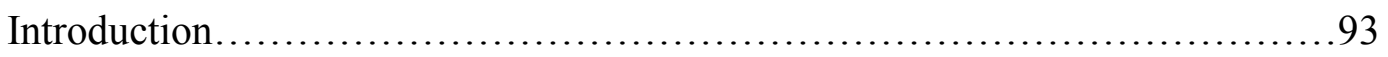

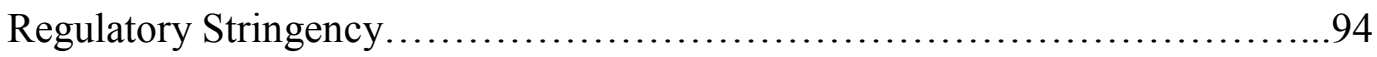

Regulatory Stringency and Agency Design................................98

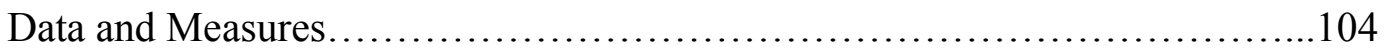

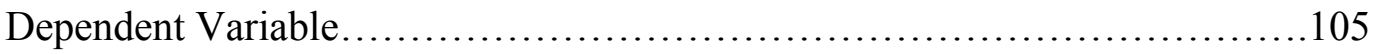

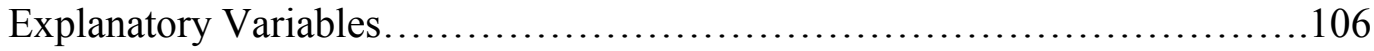

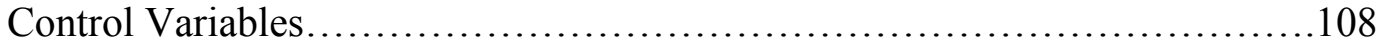

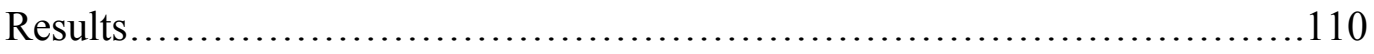

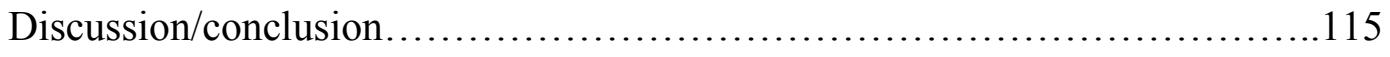

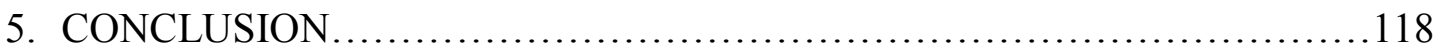

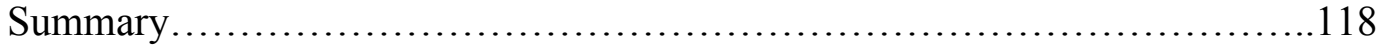

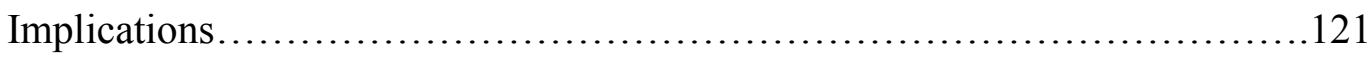

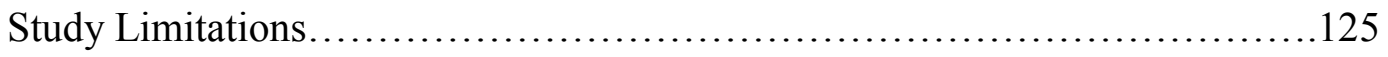

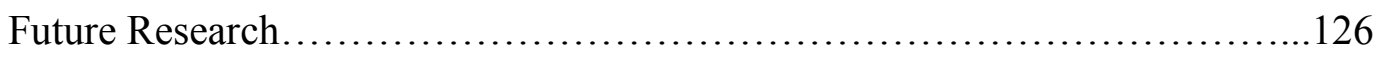

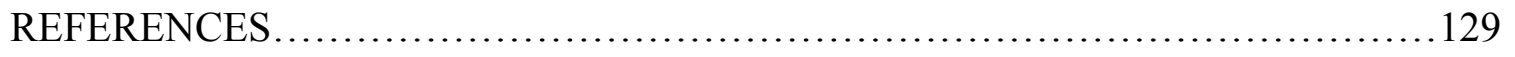




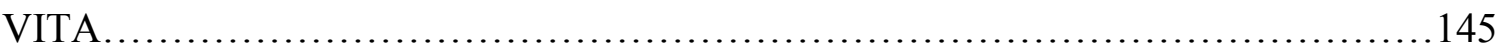




\section{LIST OF TABLES}

Chapter 2

2.1. States with Policy-making Boards, Year Created, and Board Type as of 2000.....41

2.2. States with Single-Administrator Agencies and Year Created as of $2000 \ldots \ldots \ldots . . .42$

2.3. Summary Statistics..................................................46

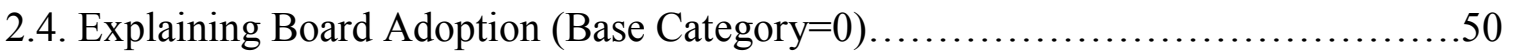

2.5. Explaining Board Adoption relative to Single Administrator Agency Adoption

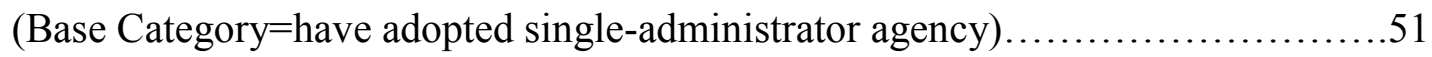

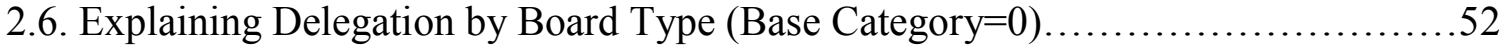

2.7. Explaining Environmental Board Adoption by Type

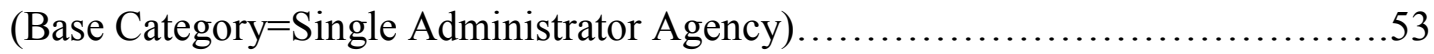

Chapter 4

4.1. Summary Statistics............................................... 106

4.2. Environmental Boards and the Levinson Index........................ 109-110

4.3. Boards and Enforcement Intensity...............................112-113

4.4. Boards and Inspection Intensity .................................113-114 


\begin{abstract}
Environmental regulation is widely considered among the most impactful regulatory fields, as it is both scientifically and technically complex and carries diverse and far-ranging implications for society. Because of this, environmental policy has developed as a highly controversial and contentious policy area, which has led to significant challenges to policy formulation and implementation, as stakeholders fight for their perspective, often at great expense of time, resources, and perceived policy legitimacy.
\end{abstract}

The environmental policy board emerged early in the development of regulatory governance in this area as a tool to ensure that regulatory processes and decisions are fair and representative of the public interest. These part-time citizen boards have been delegated significant decision-making and/or oversight authority in several states, with the promise that deliberative decision-making structures are better equipped to integrate multiple, varied perspectives and therefore enhances the probability of legitimate and successful policy outcomes. Critics of this governance model argue that it impedes effective and decisive decision-making by weakening accountability, dividing authority, and making the policy process more vulnerable to interest group influence.

Given their prominence and the current salience of collaborative strategies and institutions, it is surprising that very little scholarly attention has been paid to the contribution state-level environmental boards make to environmental regulation. This study seeks to fill this gap by studying boards' origins, experiences, and impacts on environmental processes and outcomes. It is proposed here that state policymakers and their constituencies use boards to gain leverage over environmental policy. It is further 
anticipated that variation in institutional features can be linked to variation in the outcome preferences of these actors. 


\section{Chapter 1}

\section{Introduction}

Environmental regulation is widely considered among the most impactful regulatory fields, as its costs and benefits affect large segments of the population. It is both scientifically and technically complex and carries diverse and far-ranging implications for society. For example, in a survey of stakeholders for its analysis of its state's Pollution Control Agency (PCA) Citizens Board, the Minnesota State Legislative Auditor's office found consensus among respondents from regulated entities that the PCA affects their companies more than any other state agency (State of Minnesota Office of the Legislative Auditor 1991). Conversely, voluminous sources describe the implications of air and water pollution, resource depletion, and other threats to the natural environment's ability to sustain life, and several environmental and other public interest groups have entrenched themselves in the environmental regulatory process on all levels of government. Because of this, environmental regulation has developed as a highly controversial and contentious policy area, which has led to significant challenges to policy formulation and implementation, as stakeholders fight for their perspective, often at great expense of time, resources, and perceived policy legitimacy.

The environmental policy board emerged early in the development of regulatory governance in this area as a tool to ensure that regulatory processes and decisions are fair and representative of the public interest. These part-time citizen boards have been delegated significant decision-making and/or oversight authority in several states, with the promise that deliberative decision-making structures are better equipped to integrate multiple, varied perspectives and therefore enhances the probability of legitimate and 
successful policy outcomes. Critics of this governance model argue that it impedes effective and decisive decision-making by weakening accountability, dividing authority, and making the policy process more vulnerable to interest group influence.

Given their prominence and the current salience of collaborative institutions, it is surprising that very little scholarly attention has been paid to the contribution state-level environmental boards make to environmental regulation. Nearly as old as environmental regulation, itself, citizen environmental boards are fully integrated deliberative bodies that enable direct citizen participation in policy-making like few other public policy areas. In most cases, board members are selected to represent a specific constituency, area of expertise, and/or geographic region or political jurisdiction, which promotes deliberative decision-making.

In light of this, and the ongoing discussion regarding the efficacy of deliberative decision-making, ignoring their ample experiences potentially constitutes a significant gap in the literature, as they may offer further insight into benefits and costs of collaborative environmental regulatory decision-making. This study seeks to fill this gap by studying boards' origins, experiences, and impacts on environmental processes and outcomes. It is proposed here that state policymakers and their constituencies use boards to gain leverage over environmental policy. It is further anticipated that variation in institutional features can be linked to variation in the outcome preferences of these actors.

After a brief description of the origin and characteristics of environmental boards that will follow in this introduction, this project will proceed in three parts to study the role boards play in state environmental policy-making. I use the Interest Group, 
Institutional Design, and Collaborative Governance theoretical frameworks to better understand the role boards play in state-level environmental governance systems.

Specifically, this manuscript will unfold as follows: First, the second chapter uses an Event History Analysis approach to study the adoption of State Environmental Boards and single-administrator agencies. The design is loosely modeled on Volden's (2002) effort to predict delegation to welfare boards, where he used binary and multinomial logistic analyses to identify the effect of an array of state-level political and economic variables on legislatures' willingness to establish a welfare board.

This analysis will use a competing and repeating-risk survival approach, such that agency adoption and reorganization are studied over time to evaluate the effects of the variables of interest on type of boards/institutions adopted. A central premise of this chapter is that dominant political coalitions design boards to best implement their policy preferences, based on expectations for subsequent policy outcomes. Identifying the relationships between preferences and structural choice is expected to reveal expectations concerning their effects.

Chapter 3 uses semi-structured interviews to identify board members' perceptions about their role in the regulatory process. The interview protocol includes queries about biographical information to deepen knowledge of board composition, but primarily focuses on board members' experience engaging in board activities. This line of questioning is most concerned with perceptions about their board's mission(s) and effectiveness, their perceived contribution(s) to their state's environmental decision- 
making, the quality and inclusiveness of board discourse, and the board's relationship with (and perceived influence on and from) political principals and stakeholders.

The fourth chapter will attempt to build on the previous chapters by identifying the empirical implications choice between agency models and distinctions between board types. Using a random-effects regression model, this chapter will study the effects of board type on several environmental outcome variables. Specific sources include the Levinson Index, a popular measure of state regulatory stringency that spans from 19771994 and two measures of stringency, standardized enforcement actions and standardized inspections, gathered from the Environmental Protection Agency's Enforcement History and Compliance Online (ECHO) data system. I conclude with a summary of findings and their implications, study limitations, and plans for future research.

\section{Origin of Modern Environmental Governance}

In an effort to balance state sovereignty and state incentives to export externalities of environmental pollution, environmental regulation evolved as a top-down model in which the Environmental Protection Agency (EPA) establishes minimum standards and gives states the opportunity to assume primacy for policy implementation (Kettl 2002; Kraft and Vig 1997). As a result, state governments have historically taken a lead role in implementation and management of environmental programs and early regulatory policies were designed along these lines.

The Federal Air Pollution Control Act of 1955 can be considered a catalyst for the development of state-level regulatory infrastructure. Enacted on the heels of the "First U.S. Technical Conference on Air Pollution," held in 1950 and several attention-grabbing 
environmental events (for a comprehensive account of the history of environmental regulation in the US, please see Stern 1983), the Act became the first federal effort to control air pollution. Specifically, it mandated federal research into the health effects of air pollution, and authorized federal grants to states for the purpose of research and development of abatement programs (Stern 1983). This Act served to increase awareness and the technical knowledge base, but perhaps more importantly, incentivized states to develop the capacity to process and implement this new funding stream.

The Clean Air Act of 1963 was the precursor to more stringent regulation down the road, but in its own right propelled the development of state regulatory capacity. This law authorized and provided leadership in the establishment of stationary source emissions standards, and authorized federal enforcement intervention upon receipt of court order in cases where public health was perceived to be at risk (Edelman 1968; Kramer 1983). These actions were accompanied by a significant increase in federal funding for states, including matching grants for development of air pollution abatement programs (Muskie 1968).

The Air Quality Act of 1967 enhanced the federal government's role by increasing its regulatory capacity and oversight authority over states. Specifically, it directed the Secretary of Health, Education, and Welfare to create nine pollution control regions, develop metrics of health effects from pollutants, and create a catalogue of recommended pollution control techniques and technologies (Sabatier 1975). States were then required to develop standards for pollution abatement, and commit to achieving them through enactment and implementation of State Implementation Plans (SIP). By 
this point, states were required to develop regulatory infrastructure for air pollution control.

Although the federal government strengthened its role in the late 1960s and 1970s, with far-reaching amendments to the Clean Air Act and other major legislation, the prevailing governing philosophy remained the same: the federal government establishes performance standards, and the states are expected to implement, maintain, and enforce them. While the EPA exercises oversight at several points during standard setting and enforcement processes, EPA intervention in these matters is considered an option of last resort. As a result, there is wide variation in the way environmental management programs within the states are organized and managed.

Due in part to the role of the judicial system in agenda setting and policy formulation during the early stages of environmental regulation (O'Leary 1993), the initial regulatory paradigm was constructed and characterized as a "top-down, command and control" system. Almost since its inception, this approach, defined most by the Clean Air Act of 1970 and Clean Water Act of 1972, has been challenged as inflexible, excessively prescriptive, and therefore unnecessarily adversarial and inefficient. Critics of the conventional paradigm acknowledge successes such as substantial reductions in point source emissions, but argue that second and third order environmental problems are too complex to address in this manner; the uncertainty surrounding the causes, effects, and the appropriate remedy for many environmental problems imposes a significant barrier to effective policy-making (Portney 2002; Fiorino 2006), especially when it poses a significant financial cost (Gibson 2005; Jaffee et al 1995; Repetto 1995; Palmer et al. 1995). 
As a result, newly regulated industries felt unfairly burdened by financial penalties and what they considered intrusive operating constraints and technology requirements. At the same time, affected citizens and environmental advocates believed public officials were not moving fast enough on environmental protection measures (O’Leary 1993). This contributed substantially to a highly adversarial policy environment, where, for example, upwards of eighty percent of EPA rules were contested in the 1970s and early 1980s (National Performance Review 1993; Weber and Khademian 1997).

In response, calls came quickly for a more integrated, deliberative approach, and stakeholder participation emerged as a popular strategy to achieve this goal. EPA's regulation-negotiation program, for example, began in the late 1970s. Negotiated rulemaking, which remains in force on the federal level as well as in several states, allows relevant interest groups to participate in rulemaking in order to develop a mutually agreeable standard (National Performance Review 1993; Harter 2000).

In practice, there has been some debate concerning the efficacy of negotiated rulemaking. A proponent, Harter found that negotiated regulations are less time consuming and less costly to enforce than those promulgated by the traditional "review and comment" method (2000), while Coglianese, a particularly vocal critic, controversially refutes these conclusions, claiming that findings to this effect are based on incomplete data and inflated litigation rates for conventional rulemaking, and optimistic litigation rates for collaborative rulemaking (1997).

Regardless, since their emergence on the public policy agenda in the 1970s, this policy area has relied heavily on deliberative strategies such as negotiated rulemaking, 
reporting and public comment requirements, community-based stakeholder engagement, and other practices designed to "democratize" environmental decision-making. Engaging affected parties in the policy process is thought to produce public policy that best represents their interests, therefore enhancing probability for success (Santos et al 2005; Kathi and Cooper 2006; Irvin and Stansbury 2004; Paehlke 1988; Dryzek 2005). Critics argue that deliberative decision-making impedes effective and decisive decision-making, weakens accountability by dividing authority, and make regulators more vulnerable to disproportionate influence or "capture" by interests groups (Haskell and Price 1973; The President's Council on Executive Organization 1971; Noll 1971; Bernstein 1955).

The state-level environmental board is one such deliberative governance strategy several states have used to oversee environmental regulatory policy. While some states concentrate authority in agencies with single, professional administrative executives, others elected to implement a multi-headed governance structure, where environmental regulatory policy is overseen by boards populated by part-time "citizen administrators." In cases where boards are empowered, these boards perform rulemaking and/or binding oversight over the rulemaking process.

\section{Independent Regulatory Commissions}

The modern environmental boards generally resemble the Independent Regulatory Commissions established in the mid to late $19^{\text {th }}$ century to help legislatures regulate the railroad industry, and the emerging need for economic regulation (Glaeser and Scheifler 2003; Fiorina 1982; Cushman 1972), and I, therefore, rely on their commonalities to help develop expectations regarding citizen boards. 
The multi-member commission arose from a perceived need to address very complex issues and a simultaneous distrust of government and the businesses they needed to regulate (Noll 1971; Cushman 1972). Congress wanted a regulatory body that could develop and apply expertise to regulate the industries that were emerging from the industrial revolution, but operate free from bias from political officials and regulated interests (Cushman 1941; Noll 1971; Kaufman 1969; Johnson 2003). .

Congress and state legislatures believed they could achieve this by implementing a system of "checks and balances" into administrative agencies. As a governance structure, the multi-membered commission was initially preferred by Congress because it divides authority among multiple board members rather than concentrating it into the hands of a single administrator (Cushman 1941). This was desirable from a "separation of powers" standpoint, as the commission structure was considered to be less autocratic and less vulnerable to political pressure than the single-administrator format.

Some lawmakers at the time also advocated for separation of powers within agencies, proposing that that agency executives not be vested with authority to legislate, administer, and adjudicate regulatory policy (Cushman 1941). Thus, a popular agency model that emerged adopted a board and administrative executive to divide these duties. Mostly this entails boards performing quasi-legislative and/or quasi-judicial functions, while the executive and his/her staff perform the day-to-day administrative tasks.

It was also believed that, given the complexity of regulatory issues, the board structure is useful for dividing labor and integrating multiple, independent perspectives into regulatory decision-making (Cushman 1941; Rossi 1997). As Leiserson notes (1942, 
100) "it is well-recognized that the plural-headed form of administrative authority permits a representation of more than one viewpoint in the formulation of policy."

Furthermore, the IRC structure was influenced by an early preference for "amateur" administrators. According to Cushman, the most common form consisted of "able laymen" working through issues with the help of expert staff (1972). In these cases, part-time panels of non-experts appointed by the governor meet periodically to complete delegated tasks, and in the process develop the necessary expertise. This style was designed, in large part, to prevent bias from industry and/or government experts (Cushman 1972). This format is also grounded in the idea that generalists are better policy decision-makers than specialists because they have a better understanding of the "big picture" (Paehlke 2005).

The multi-member structure that emerged in which members are typically appointed by the president (for national-level boards) or governors (state-level boards) and confirmed by their respective legislative bodies, were viewed as a mechanism to increase the representativeness of government. The independent commission (IRC) was neither fully in the executive branch, nor fully in the legislative branch, and was protected by measures that limited influence on their activities once they were appointed. As opposed to the single executive model where decision-making is ultimately centralized in the hands of a single administrator, multi-member commissions are said to create a forum for deliberation of multiple viewpoints, which provides opportunity for more moderate, consensus-based decision-making (Breger and Edles 2000). 
Subsequently, important components of the national and state policy-making infrastructure were given this form. The Securities and Exchange Commission, the Federal Trade Commission, and the Federal Elections Commission are three examples of federal regulatory agencies that possess this authority structure. State Boards of Health and Public Utility Commissions are two prominent examples from the state-level. I will revisit subsequent studies of some of these organizations in a literature review below.

Due to the punitive nature of environmental regulatory policy, there was an additional push to design environmental agencies with this "separation of powers" in mind. Some early observers of environmental regulatory agency development expressed concern that concentrating too much power (e.g., "judge and prosecutor" of enforcement cases) in one institution unfairly violates due process rights (Endris and Penrod 1997; Scher 1962). Here, boards can provide the mechanism for a relatively-low cost way to appeal agency decisions.

This trend began to reverse on the national level in 1960s and 1970s, when Congress began to favor the single administrator structure because of concerns about industry capture (Wilson 1989; Noll 1971; Moe 1989; Barkow 2010). As Wilson notes: "[i]f there were no commission, there would be neither opportunity nor justification for having the overseers of the agency be representative of affected interests. The job of a single administrator was not to represent but to decide, and in a way that would fix responsibility upon him or her (Wilson 1989, 85).” The Environmental Protection Agency was one of many subsequent agencies created in the Executive Branch, with a single administrator. However, boards remain prominent on the state-level, playing a significant role in environmental regulatory decision-making in thirty-two states. 


\section{State Environmental Boards}

State environmental boards generally mirror the structure of the independent regulatory commissions, with, perhaps, the most notable exception being that most environmental boards are housed within their state government's executive branch. While the modern environmental boards are structurally less independent than IRCs, most of the similarities remain, providing ample basis for drawing parallels. Environmental boards typically consist of part-time members appointed by their states' governor (with confirmation by the State Senate) to fixed and staggered terms, and meet periodically throughout the year (formally, typically once a month) to deliberate on delegated matters. Environmental boards vary in size from three (Texas) to twenty (Pennsylvania), but most commonly range from seven to thirteen members. They also vary in function, but most commonly engage in quasi-legislative activities such as rulemaking and standard setting, and/or quasi-judicial duties such as administrative review.

State Environmental Boards also vary in composition in several important ways. Most are unpaid, "citizen" boards. These are part-time, usually meeting no more than once per month, and are minimally compensated for their time and expenses. A few, like in Illinois, Texas, and California are more professionalized in terms of compensation and qualification. California's Air Resources Board and State Water Control Board, for example, are salaried and require a portion of the board to possess verifiable expertise in a specialty area relevant to board responsibility. It should also be noted that Texas' Commission on Environmental Quality is the state's sole administrative agency, while other boards share authority with a single-headed administrative agency. 
Some states also legislatively mandate stakeholder representation on environmental boards. This model grants representation to stakeholders such to resemble a pluralist approach to environmental decision-making. For example, Oklahoma's state legislature provides thorough instruction on the representation required on its thirteenmember Environmental Quality Board. The ODEQ contains five members from various industry sectors including one each from the petroleum, agriculture, hazardous waste, and solid waste industries, three citizen members from the environmental non-profit sector, and one each from local government, the state conservation districts, a rural water district, a certified environmental professional (non-governmental), and a person knowledgeable in water usage.

Ex-officio representation is another form of stakeholder model utilized by some states. In these instances, state and local officials are designated to serve on their state's board based on their position in state or local government. The ex-officio representation requirement was designed to facilitate interagency collaboration on issues with complex jurisdiction (Cushman 1941). This approach was often proposed during the formation of new agencies as a way to tap into existing expertise in the various issues that might be affected by regulations produced the board or commission. For example, Nevada's Environmental Commission statutorily requires representation from six state agencies, including the Department of Wildlife, Agriculture, Forestry, and the Board of Health, The State Engineer, and the Commission on Mineral Resources. Similarly, Pennsylvania's Environmental Quality Board consists of representatives from eleven state agencies: the Departments of Environmental Protection (Chair), Agriculture, Health, Community and Economic Development, the Public Utility Commission, the Fish and Boat Commission, 
the Game Commission, Labor and Industry, the Governor's Office of Policy, the Historical and Museum Commission, Transportation; five members of the state's Citizens Advisory Council; and two members of each branch of the state's legislature. An exofficio member interviewed for this project insisted ex-officio representation adds value in his/her state's regulatory process because "ex-officio members represent different areas of the administration to make sure we're all talking and communicating with each other."

Initially, this format was often criticized for introducing vulnerability to partisanship and political control, which were considered threats to its independence and consistency (Cushman 1941). This format has subsequently drawn criticism for overrepresenting those sympathetic with regulated interests. In a case study of Illinois' current Pollution Control Board, Haskell and Price (1973) described the state's predecessor board as overloaded with agencies whose primary constituencies are groups responsible for pollution, e.g, Economic Development, Agriculture, or Mineral/Natural Resources. As a consequence, according to the authors, conservation interests were frequently outvoted by representatives on behalf of these constituencies. In addition, according to one of the interviewees in this study, local government representatives are also responsive to the needs of economic development sources.

\section{How Boards Operate}

Gelpe (1990) categorizes boards into three models that more or less describe the different roles boards can play in state environmental governance. In one model, agency 
staff develops proposals and presents them to the board for consideration. In this most common model, agency staff completes most of the work towards policy formulation, and the board's role is to approve or reject agency proposals. In the state of New Mexico, for example, in most issue areas, interested parties can petition the Environmental Improvement Board for a new rule or rule change, and the board facilitates the review and public discussion about the proposal, and ultimately approves or rejects the petition. In the case of the latter, the petitioner can abandon the petition, revise and resubmit the proposal, or appeal the ruling to the State Court of Appeals. In many states, like New Mexico and Utah, the board's decision is final unless overturned by legislation or litigation. In other states, like Idaho and Florida, however, rules are submitted to the legislature for final approval.

In these instances, boards are not designed to initiate or actively engage in policy formulation, but instead act as an oversight mechanism to regulate the regulatory agency staff (Gelpe 1990). New York's State Environmental Board is designed along these lines, as the State's Department of Conservation is required to gain approval from this body before enacting rules and standards. Similarly, Florida's Environmental Regulation Commission represents the last line of technical review before rules and standards are submitted to the state legislature for final action.

In the second model, the board is primarily a quasi-judicial body. In Montana, West Virginia, and Wyoming, for example, boards are not vested with policymaking authority, but instead serve as a forum to adjudicate disputes stemming from agency decisions. Depending on the state, affected parties may appeal agency actions on standards, rulemaking, permitting, and/or enforcement, and boards adjudicate these 
disputes. Again in this model, boards are not the primary policy-making body, but instead influence environmental regulation through its ex-post oversight capacity.

In the third model, the board plays a more active role in environmental policy formulation. In states like Alabama, Arkansas, and North Carolina, boards are considered the head of their state's environmental agency, and agency staff, including the Executive Director, is considered subordinate to the board on issues where it has jurisdiction. The boards are charged with developing environmental policy through standard-setting and rulemaking, and are also involved with other agency activities, to varying degrees, such as permitting, enforcement, variance hearings, and appellate review. In Alabama, California, Georgia, and Oregon, environmental boards are further responsible for appointing the agency's director.

This model takes the "separation of powers" objective a step further, often dividing authority along legislative/executive lines. Like the typical power arrangements among federal and state governments, these boards serve as the "legislative" arm of environmental governance, while the agency director and staff implement these directives via permitting, monitoring, enforcement, and other administrative tasks. In North Carolina, for example, the Environmental Management Commission delegates many of the technical tasks to the state's Department of Environment and Natural Resources, but according to one board member, the commissions "sets the direction" and "takes a very active role in origination, development, drafting, and editing of regulations." The EMC also issues and reviews air and water quality permits, and takes the lead role in long range planning for the agency in these program areas. In this case, board members 
reported spending upwards of 50 to 60 hours per month between board meetings preparing for meetings, reviewing data, and meeting with stakeholders and agency staff. Many of the more active states have committee systems in which board members are assigned to smaller, more specialized panels where issues are discussed in depth. The aforementioned EMC, for example, has seven committees: a steering committee that works on general policy planning, agenda setting, and committee jurisdiction, as well as committees specializing in the National Pollution Discharge Elimination System program, air quality, water quality, groundwater, water allocation, and renewable energy. Proposed rules and permits are assigned to these committees according to relevance, and members with expertise in these areas work with stakeholders and the public to develop recommendations for the full committee. North Carolina also has a Civil Penalties Remissions committee that develops recommendations regarding enforcement appeals.

While environmental boards have been around for more than fifty years, very little scholarly work has studied their performance. In light of this, I use related literature to supplement existing literature on boards to enhance discussion of their contribution to the policy process, and help generate expectations about their performance. Independent Regulatory Commissions and Federal Advisory Committees, for example, have been heavily used and studied nearly since the birth of the nation, and, therefore, their experience can be used to provide insight on deliberative governance and interest group influence. Research on collaborative governance and deliberative democracy is also consulted to gain additional insight into the strengths and weaknesses of the collaborative decision-making one would expect from a multi-member policymaking board. 


\section{Perceived Benefits of the Board Structure}

\section{$\underline{\text { Political Independence }}$}

Political independence is one of the reported benefits of the board structure. Board members are selected to fixed and staggered terms, and most commonly only removable for cause. As a result, board members often carry over from previous regimes and are protected for removal for political reasons, which reduces their need to be responsive to current political officials. In addition, part-time, "amateur" status is believed to enhance this independence by preventing board members to rely on state government for employment (Gelpe 1990; Cushman 1942). Theoretically less beholden to political officials, board members are argued to be better situated to make objective and consistent decisions than single administrators appointed by the Governor.

In addition, the board structure is argued to promote decision-making that is free from bureaucratic influence. According to this argument, agency staff may have narrow or technical perspectives, or may act in the best interests of the agency rather than the general public (Gelpe 1990). The part-time citizen board is said to provide oversight of technical experts such that environmental decision-making also reflects a "common sense" orientation.

This independence is considered beneficial for overcoming policy complexity and conflict. In a study of monetary policy, Waller (2001) concluded that policy-making boards can provide a stabilizing force in volatile policy areas. According to the author, their fixed and staggered terms insulate policy from shocks caused by "regime change," and thus "smooths" monetary policy and substantially reduces policy uncertainty. This policy smoothing is thought to be enhanced by the cooperative bargaining produced by 
this model, as board members are appointed at different points in time, and are therefore likely to represent diverse perspectives.

\section{Deliberative Governance}

The collaboration literature commonly cites collaborative arrangements as beneficial for representative governance. Coming mostly from case-study analyses, collaborative, participatory modes of environmental governance have been linked to increased opportunities for stakeholder input (Innes et al 2006; Koontz and Thomas 2006; Weber 1998), increased compliance rates (Rogers and Weber 2010; Newig and Fritsch 2009), and lower compliance costs (Harter 1982). These findings are grounded in the argument that the establishment of shared goals and frequent and ongoing interaction towards achieving these goals breaks down barriers between competing stakeholders, and thus produces more favorable outcomes for all involved.

Likewise, the deliberative democracy literature describes the deliberative decision-making enabled by multi-member organizational bodies as having several advantages over single-administrator agencies. One perceived benefit is the enhancement of proficiency through policy learning. This perception is partly based on the argument that the "technocratic" approach constrains administrative capacity to learn by excluding perspectives and sources of expertise that could contribute to more efficient and sustainable policy outcomes (Torgerson and Paehlke 2005). According to this argument, integrating diverse viewpoints enhances the amount and diversity of information

considered, and, as a result, produces more ecologically rational decisions (Smith 2005; Dryzek 1987). Learning is also believed to be enhanced as these divergent perspectives 
persistently challenge existing ways of thinking, thus enhancing capacity for adaptation (Torgersen 2005).

Indeed, one commonly cited advantage of including a board in the regulatory process is that it provides a high-level forum for discussion of difficult issues. According to a survey of stakeholders associated with Minnesota's Pollution Control Agency Citizens Board, both regulatory and public interest advocacy groups expressed a preference for the decision-making board over leaving decision-making to agency staff (State of Minnesota Office of the Legislative Auditor 1991). Of the regulated stakeholders surveyed, 51 percent of respondents agreed with the statement that the MPCA Citizens Board enhances the environmental decision-making in the state, while only 27 percent disagreed with this statement (22 percent reported "no opinion"). Additionally, 45 percent of this cohort agreed that the board holds the agency accountable for decisions on rules, permits, and enforcements while only 23 percent disagreed (32 percent no opinion).

Of the public interest group respondents, 61 percent agreed that the board enhances the state's environmental decision-making, while only 27 percent disagreed with this statement. In addition, 58 percent expressed a belief that the board holds the agency accountable for its actions, and 60 percent agreed that the board ensures that agency decisions are made in a public forum.

\section{$\underline{\text { Democratic Oversight }}$}

Boards are also said to be beneficial for exercising oversight of environmental agencies. The aforementioned technical complexity and disagreement over the 
appropriate balance of economic and environmental values, and the high stakes perceived on both sides, causes wariness of environmental decision-making (Gibson 2005). External oversight panels are said to enhance normative legitimacy by applying societal norms and values to policy deliberations (Torgerson 2005). Oversight boards provide a mechanism by which technical knowledge can be filtered by human judgment from multiple perspectives, thus, it is believed, leading to enhanced normative and technical legitimacy (Torgerson 2005).

The demand for democratic oversight is also fueled by a widespread skepticism of technocratic expertise on both sides. Each argues that technocratic expertise undervalues the social and economic implications of proposals (Hahn 1990; Zywicki 1999). Environmentalists are commonly concerned that regulatory agencies are disproportionately influenced by regulated interests (Andrews 1980), while business interests frequently complain that regulators take regulation beyond what is necessary or feasible, imposing unnecessary costs (Kraft and Kamienecki 2007; Layzer 2007; Jaffee et al 1995; Repetto 1995). Oversight panels provide a mechanism by which technical knowledge can be filtered by human judgment, thus, it is believed, leading to enhanced normative and technical legitimacy.

Coming at the question from a very different perspective, the bureaucratic control literature views boards as tools political principals can use to influence agency behavior. According to this line of literature, forcing agencies to consult a board of politically accountable individuals before adopting policies improves principals' ability to steer choices towards their preferences (Potoski 1999). It is also argued that administrative procedures can help structure agency decision-making (Potoski and Woods 2001). By 
controlling interest group access - both public and private - through board appointments, for example, political principals can influence agency behavior in the desired direction.

\section{Perceived Disadvantages of the Board Structure}

\section{Barriers to Effectiveness}

The division of labor achieved through the separation of agency powers is also cited by critics as a significant limitation on regulatory effectiveness. In a report now commonly known as the "Ash Council Report," an advisory council commissioned by President Nixon to evaluate the existing federal commissions was highly critical of their collegial structure, noting that "[ $[$ ] he collegial structure is today inappropriate for regulating highly complex ever-changing areas of the economy (The President's Council on Executive Organization 1971, 20)," and that "collegial bodies are inefficient mechanisms for formulating and implementing specific policy in a timely manner (34)." The report, which focused on seven major federal commissions, determined that requiring multiple executives to form agreement causes several problems that limit the potential for regulatory effectiveness. Out of the seven studied, the commission recommended six be placed inside the executive branch, and that the multi-membered decision-making panel be replaced by a single administrator.

Primarily, the commission found that the deliberative format inherently has a tendency to produce weak and time-consuming regulatory output, as co-equal decisionmakers often have difficulty reaching agreement on new policy planning. The Ash Council described this as especially problematic, as it causes a tendency to defer major policy decisions to adjudication. This occurs as indecision leads to individual cases 
emerging that force ad-hoc rulemaking. According to the Ash Council, this case-by-case form of policy formulation delays administrative action, overburdens commissioners and staff, and imposes high litigation costs.

McCloskey (1999) similarly criticized the need for agreement via consensusbased decision-making, arguing that this favors policy outcomes resembling the "lowest common denominator." Coglianese shares this view, arguing that "consensus-building shifts the ultimate goal away from reaching a quality decision and moves it toward reaching a merely agreeable one (1999)." In addition, Wood and Bohte (2004) state that multi-membered leadership arrangements bias policy outcomes toward the status quo, because a consensus is necessary to produce change.

\section{$\underline{\text { Interest Group Influence }}$}

Other literatures take this criticism a step further, arguing that deliberative approaches open the door for improper influence from regulated interests. Beyond the weakened capacity for decisive decision-making, several researchers have argued that deliberative bodies are more easily "captured." Bernstein (1955) argues that the structure of the Independent Regulatory Commission, particularly that providing for its independence, enables industry capture by insulating them from political influence while leaving them open to interest group pressures.

Even while criticizing Ash Council findings and proposals, Noll (1971) offers frequent support for the Council's claim that the deliberative approach favors regulated interests. The author specifically argues that, due to appointment process dynamics, in situations where public and private interests are in conflict, the median board position 
will more commonly lie closer to the strong pro-regulated position, inevitably leading to an outcome that favors that side. Haskell and Price (1973) found this to be the case in their nine case study, concluding that, especially when business and industry groups are able to stack the boards with representatives and allies, they are able to leverage this input into favorable output.

Information asymmetry is commonly cited as a primary source of industry influence on regulators (Coglianese 2007; Kerwin 2003; Eisner, Worsham, and Ringquist 2000). Whether for information about firms themselves, or technical knowledge in general, regulators rely heavily on regulated interest groups for the expertise necessary for environmental policy-making. Input is provided through comments on proposed rules, participation in public hearings and advisory committees, and other formal and informal contacts (Furlong 2007; Coglianese 2007). This leverage over regulatory agencies is argued to provide equal or greater advantage to regulated interests than political pressure on lawmakers (Coglianese 2007; Furlong 2007). Indeed, Kerwin (1994; 2003) found strong evidence that regulated interest groups consider this engagement in the rulemaking process as an important mechanism for influencing public policy.

Historically, the interest group literature has commonly given the information advantage to regulated interest groups in terms of volume and influence because of their resource advantage. However, studies have increasingly determined that institutional factors can moderate the balance of power within policy subsystems. Institutional mechanisms such as citizen suits (Zinn 2002), notice and comment provisions (Cropper et al 1992), and other transparency measures can balance power by increasing access for disadvantaged stakeholders. In the commission context, specifically an analysis of rate- 
setting decisions made by State Public Utility Commissions, Teske (1991) found that embedded institutional factors such as commission professionalism can attenuate interest group influence by enabling commissioners to make more informed, independent decisions. Berry (1984) similarly found that transparency and participation by a public advocate lead to lower rates, indicating responsiveness to public, rather than private, interests. In each case, reducing information asymmetries reduced industry dominance of the policy subsystems.

Scholars also argue that, especially in the case of the "lay commission," board members are particularly vulnerable to this information asymmetry. According to Cushman's seminal account of the evolution of Independent Regulatory Commissions (1941), the part-time, "lay commission" has from the beginning been considered particularly vulnerable to information asymmetry, as board members often lack the time or expertise to collect and analyze independent information, and are thus more dependent on information provided by external sources.

In an early case study of nine states' environmental management programs, Haskell and Price (1973) noted that many boards are heavily reliant on agency staff for information and guidance. With a few exceptions, boards act on proposals that are presented to them by their state's environmental agency, and perhaps more importantly, rely on agency staff for technical and/or legal expertise.

\section{$\underline{\text { Inefficient Use of Scarce Resources }}$}

A related criticism of the board process is that it forces agency staff to spend a considerable amount of time preparing for and participating in board meetings. In their 
survey of Minnesota Pollution Control Agency staff, the state's Office of the Legislative Auditor reported that agency staff spend an estimated 11,000 hours per year (6 staff years) preparing for board meetings (1991). Agency staff must present technical information in clear, convincing arguments to persuade board members and other stakeholders to make policy decisions based on their findings and/or recommendations. One perspective views this as an opportunity for the board to serve as a "sounding board" for agency proposals, which, in theory, enhances agency performance. It is also argued that the time required by board review, both in terms of staff time and delays caused by the infrequency and time between board meetings (most part-time boards meet one or two days per month, at most) imposes a drag on efficiency and scarce agency resources (Gelpe 1990; Haskell and Price 1973). In the MPCA analysis, 53 percent of regulated respondents, 58 percent of MPCA staff, and 53 percent of members of government surveyed for the project agreed that the "board process results in delaying issuance of permits and rules."

However, it is worth noting that citizen groups surveyed for the MPCA study were split on this issue. Only 42 percent of citizen group respondents agreed with the statement that the "board process results in delaying issuance of permits and rules," while 44 percent disagreed with this statement. This suggests that public interest advocates value the input they have through discussions facilitated by the board process over the expedience that might be gained by delegating decision-making to the agency executive and staff.

In addition, boards, especially those populated by part-time, unpaid members, are criticized for impeding the environmental policy process because they lack the necessary 
expertise to keep up with modern environmental challenges. In a survey of Minnesota Pollution Control Agency (MPCA) staff, 55 percent agreed with the statement that "environmental issues are becoming too complex for volunteer board members." 40 percent (compared to 30 percent who disagreed) agreed that the MPCA board lacks the experience and expertise to make sound decisions (State of Minnesota Office of the Legislative Auditor 1991). A similar trend is observed among surveyed members of the state's government. A plurality (46 percent) of respondents agrees with the statement that "environmental issues are becoming too complex for volunteer board members." 41 percent, also a plurality, agree that the MPCA board "does not have sufficient expertise and experience to make sound decisions," and 47 percent believe the board is "inconsistent in its decision-making process."

As noted in this chapter, multi-member regulatory boards have been attributed with several advantages and disadvantages. On one hand, they provide an opportunity for transparent, collaborative, and representative decision-making. But on the other hand, the board process is time and resource consuming, and depends greatly on the quality of participation, both in terms of board members and the public(s).

This paper argues three main points. First, boards are often adopted to provide opportunity for direct stakeholder and public input in environmental regulatory decisions. Rather than delegate the authority to agency staff to formulate and implement environmental policy, many states have chosen to maintain a permanent oversight body to make sure environmental rules and regulations are "balanced" and reflect public interests. The second point I will argue is that some actors have a greater interest in maintaining a balanced approach to environmental regulation, and boards are more 
prominent in states where these interests were more powerful at the time of agency enactment. Third, it is expected that points one and two will have implications for environmental performance outcomes. Specifically, it is argued that granting oversight authority to boards, especially those that institutionalize stakeholder participation, has a moderating effect on environmental performance. 


\section{Chapter Two}

\section{Determinants of State Environmental Regulatory Structure}

\section{Introduction}

In an ideal world, one might expect design decisions regarding new political institutions to be driven by problem/task-specific context, where civic-intentioned officials make decisions about new public agencies based on the nature of the problem being addressed, and select the appropriate structures to do the job. However, issue complexity, competing values, and the state-centered evolution of policy design and implementation complicate environmental policymaking, producing wide variation in preferences regarding environmental policy choice. According to McCubbins et al (1989), Huber and Shipan (2002) and many others, these preferences are most often baked into agency design; decisions are made to enact and preserve the preferences of winning coalitions, and, therefore, vary according to social, political, and economic contexts in which they were created.

One significant point of variation among states is the structure chosen to develop regulatory capacity. Several states have opted for the single-administrator, hierarchical decision-making structure, while others have established multi-member policy boards to oversee environmental programs.

Despite their long-standing prominence in state environmental policymaking, very little empirical scholarly attention has been paid to the role environmental policy boards play in environmental governance. Proponents of deliberative decision-making argue that these structures are better equipped to integrate multiple, varied perspectives into the policy-making process, which is thought to enhance capacity for policy learning, 
normative and technical legitimacy, and, therefore, probability for success (Santos et al 2005; Paehlke 1988; Dryzek 2005). Critics argue that collegial decision-making impedes effective and decisive decision-making, weakens accountability by dividing authority, and make regulators more vulnerable to disproportionate influence or "capture" by interests groups (The President's Council on Executive Organization 1971; Noll 1971; Bernstein 1955). Given the disparity of these predicted outcomes, and implications of each, it is important to learn more about the role boards play in environmental governance.

Neo-institutional theory argues that structure is purposefully selected in the agency design phase in order to embed the preferences of political actors in subsequent policy-making (McCubbins, et al 1989; Hammond and Bender 2010; Potoski 1999; Moe 1980; Holburn and Vanden Burgh 2006). This literature views agency design as the product of "interest group politics (Moe 1989);" where design choices such as agency scope (Sinclair and Whitford 2012; Haskell and Price 1973) operating procedures, and oversight mechanisms (Potoski 1999) are believed to be implemented to influence future policy and implementation choices in the desired direction. Therefore, this chapter seeks to take a first step towards understanding boards' role(s) by studying the conditions surrounding choices regarding air pollution regulatory agency structure. Identifying social, economic and political conditions that give rise to environmental boards is expected to reveal something about expectations concerning how they perform.

Existing literature offers multiple claims about the implications of citizen boards for state-level public policy, but little in the way of empirical support for these claims. As a first step towards assessing these arguments, this study will use event history 
analysis to attempt to identify societal conditions that influence the choice of this regulatory structure. The study proceeds in two steps to test a set of hypotheses regarding social, political, and economic influences on agency organization. First, beginning in 1957 when New York, Delaware, and Florida became the first states to regulate air pollution with a policy board, and ending in 2000 when Idaho made the last substantive change to its board structure, I evaluate factors in the choice between single-administrator and board-led environmental regulatory agencies. In the second step, I expand the analysis to observe determinants of the type of board selected.

The primary expectations are two-fold: first, political factors such as ideology and party-identification are expected to influence the design of environmental decisionmaking structures. Second, guided by interest group theory, industry strength is expected to increase the likelihood that a state will favor a policy board over a single-administrator agency, especially when that board institutionalizes stakeholder representation. Finally, it has been suggested (but rarely demonstrated empirically) that the board structure, by virtue of its appointment and tenure characteristics, is commonly used by legislatures to insulate administrative agencies from their chief executive. As such, I expect to find evidence that boards are formed and modified during periods of divided government. By understanding the conditions in which state environmental boards were formed, it is hoped that we can gain a better understanding of their role in environmental policymaking and regulation

\section{Predicting Board Adoption}

What dictates the choice of boards over other authority structures? McCubbins, Noll, and Weingast (1989) are widely cited for their work on the role of structure and 
process in public policy implementation. According to the authors, lawmakers have three fundamental goals in designing agency structure: first, structure is designed to replicate the political environment at the time of enactment. Second, lawmakers seek to "stack the deck" in favor of favored constituencies at the time of enactment, and, third, agency structure is designed to be adaptable so as to accommodate changing preferences without new legislation. At its core, this framework argues that policy-makers design institutions to bias regulatory policy in their preferred direction (McCubbins et al 1989; Holburn and Vanden Bergh 2006).

Furthermore, this framework views agency design as a collective choice process (Hammond and Bender 2010). Disparate interests vie over structural design decisions in order to embed structures and processes that best serve their interests (Moe 1989). As a consequence, agency design choices most often reflect the preferences of those with political power at the time of agency creation (McCubbins et al 1989; Moe 1989; Holburn and Vanden Bergh 2006).

Sinclair and Whitford (2012) similarly stressed the importance of initial social conditions in agency design, arguing that path dependent nature of public organizational behavior allows the preferences associated with these initial interests to become "sedimented" in agency behavior. In studying the adoption decision concerning agency type: a combined health and environment model, environmental superagency or independent environmental protection agency, the authors found that initial conditions such as political ideology predict the type of agency chosen, and path dependence explains why, in their view, agency structure does not always necessarily match current needs and conditions. 


\section{Political Preferences and Agency Structure}

Political factors such as ideology and party-identification are considered critical influences on agency design choices. As McCubbins et al (1987), Moe (1989), and others note, structural choices such as administrative processes fundamentally influence the type of outputs and outcomes produced. They are a primary mechanism by which legislators (and the executive) attempt to exercise control, both short and long term, as they help reduce monitoring costs and steer public policy toward the preferences of policy-makers and their favored constituencies.

Thus, political factors should be strongly influential on the types of administrative structures that are adopted. Indeed, several scholars have observed this to be the case, including Holburn and Vanden Bergh (2006), who found that Democratic legislators have a stronger tendency to incorporate consumer advocacy measures into Public Utility Commission processes, and Figueiredo (2003) who observed that Republicans were more likely to enact line-item vetoes on the state level. Potoski (1999) describes oversight boards as a type of "fire alarm" procedure that allows policy makers to monitor environmental agencies, providing additional reason to expect that political contexts at the time of enactment are expected to be important influences on the choice of regulatory structure.

While the literature does not offer explicit guidance regarding ideological preferences vis-à-vis environmental boards, specifically, or the multi-member governing structure, more generally, I draw upon what is known to shape expectations regarding these relationships. In terms of governing philosophy, the conservative ideology and the 
Republican party are widely associated with a preference for less and decentralized governance (Campbell et al 1960; Rudolph and Evans 2005; Farnsworth 1999). This preference extends to a predisposition against excessive public intrusion into the private sector (Dunlap 1975). The liberal ideology, conversely, has historically favored centralized and robust governance structures. Indeed, in his account of the genesis of the EPA, Moe (1989) describes Republican President Richard Nixon as supportive of a commission structure, before being overruled by a Democratic Congress.

Furthermore, liberals and conservatives possess distinct preferences on environmental issues. Liberals and Democrats are widely considered to be more proenvironment, while conservatives are less likely to take an aggressive position on environmental issues (Konisky 2001; Potoski 2001; Woods 1988). This is especially true when environmental regulations are perceived to impose costs on private businesses (Dunlap 1975). With this in mind, since the board structure represents a form of diffused, even privatized decision-making (Weimer 2006), liberal ideology should be expected to correlate positively with single-administrator agency adoption, and negatively with board adoption, as conservative and republican-majority states favor the decentralized decisionmaking associated with the board structure over a system that isolates decisions in a single bureaucratic agency.

Sinclair and Whitford (2012) provide additional confidence in these expectations in their study of agency scope. The authors found that states with liberal citizenry favored independent environmental protection agencies over environmental "superagencies" or those that combined public health and environmental protection functions. Conversely, when the authors studied heath agencies adopted over roughly the 
same time period, they found that liberals demonstrated a preference for a larger "superagency" rather a smaller independent heath agency. While these did not speculate on the reasons for this trend, presumably, this is rooted in a preference among liberals for an environmental agency with a clear focus on environmental protection rather one that is also tasked with duties such as natural resource and/or public health management that may conflict with, or dilute the mission of environmental protection (Haskell and Price 1973). It is not a stretch of the imagination, therefore, to expect liberals to prefer a more centralized agency decision-making structure.

Partisan makeup of state government is also expected to be an important politically-driven influence on the choice of governing structures. Commissions historically have been celebrated for being less partisan, and less beholden to ruling political principals (Heady 1949; Bates 2005). Their fixed and staggered terms are believed to limit political influence, especially governors, because they ensure holdover from previous, possibly less ideologically aligned administrations (Waller 2000; Cushman 1941 Bernstein 1955; Gelpe 1990). Therefore, boards are anticipated in periods of divided government, as legislatures tend to try to limit Governors' authority when the executive is controlled by the opposing party (Volden 2002).

\section{Interest Group Influence}

Structural design choices are also said to be highly influenced by affected interest

groups. As Moe (1989) points out "structural politics are interest group politics." While interest group theory has evolved well past theories of "capture (Stigler 1971; Bernstein 1955)" to identify institutions that can manipulate the balance of power in regulatory 
subsystems (for a comprehensive discussion of these, see Culhane 1981; Teske 1991; Zinn 2002; Cropper et al 1992; Gormley 1983; Berry 1984), research still commonly reports a "bias towards business." (Yackee and Yackee 2006). Such studies show that regulated interests still have significantly more success than other groups in influencing environmental policy, especially on the state level. As recently as a study conducted by Nownes, Thomas, and Hrebenar in 2006-2007, general business interests (e.g., state and local chambers of commerce), utility companies and associations, and manufacturers were considered three of the top four most influential interest groups at the state level. This dynamic is enhanced by the reality that these interests are often important sources of economic development within states and are much more likely to be well- organized and resourced than competing interests (Olsen 1965; Klyza and Sousa, 2008; Nownes, Thomas and Hrebenar 2007). Environmental interest group influence, conversely, was believed to ebb and flow with the fortunes of Democrats in state government (Nownes, Thomas and Hrebenar 2007).

Therefore, pro-business interest groups are expected to have significant influence on the choice of regulatory structures. One emphasis of this paper lies in determining the relationship between regulated industry influence and board adoption. There is limited empirical data on industry preferences regarding agency structure; we know they have preferences regarding environmental regulation and advocate strongly and convincingly on their behalf, but do not know if and how this influence extends to the structural design of agency decision-making. The literature offers mixed theoretical guidance regarding expectations, so various literatures are consulted to explore potential explanations. 
One argument suggests that regulated interests disfavor the board structure because it potentially opens the process to competing stakeholders. As Rossi (1997), Culhane (1981), (Yackee and Yackee 2006), and others note, a group's influence is a function of its access to decision-makers. A primary premise of Bernstein's work (1955) asserts that "industry capture" occurs through a "cycle of decay" in which the attention span of regulated interest groups outlasts that of supporters of regulation, such that they are able to increasingly monopolize and dominate policy-subsystems over time. Therefore, industry groups might oppose efforts to open the regulatory process, especially to those representing competing interests, which would be reflected in a negative relationship between industry strength and board adoption.

An alternative and increasingly prevalent perspective suggests that regulated interests prefer regulatory systems in which they have more input into their regulation because they are more flexible, more efficient, less contentious, and less costly (Randolph and Bauer 1999; Weber and Khademian 1997). According to this argument, integrating diverse viewpoints enhances the amount and diversity of information considered, and, as a result, produces more ecologically rational and technically feasible decisions, and thus reduces costs (Smith 2005; Dryzek 1987).

Additional literatures identify more reasons to expect regulated interest groups to favor the board structure. One argument criticizes multi-membered structures for having a moderating effect on policy-making, a dynamic that would seem appealing to regulated interests. McCloskey (1999) argues that consensus-based decision-making requires participants to form agreement, which favors policy outcomes resembling the "lowest common denominator." Coglianese shares this view, arguing that "consensus-building 
shifts the ultimate goal away from reaching a quality decision and moves it toward reaching a merely agreeable one (1999)." Additionally, Wood and Bohte (2004) argue that multi-membered leadership arrangements bias policy outcomes against policy change, because a consensus is necessary to produce change.

Critics of collaborative governance also describe co-option of stakeholder approaches as a form of "policy containment" strategy (Hoberg and Phillips 2011; Pralle 2006; Oliver 1991). According to this characterization, actors pressured by the prospect of regulation embrace collaborative alternatives in order to slow the momentum toward policy change. By reaching out to stakeholders, regulated firms can enhance legitimacy in the eyes of regulators and competing stakeholders, and at the same time limit the scale of conflict and maximize their ability to control their policy environment (Selznik 1966; Hoberg and Phillips 2011).

One area where stakeholder participation programs have been empirically investigated is Negotiated Rulemaking, a collaborative rule-making program designed as a less adversarial alternative to the traditional "notice and comment" system. In a survey of participants in conventional and negotiated rulemaking, Langbein and Kerwin (2000) found that participants were more satisfied with the process and outcome of the latter than the former. In further investigation of the same data, Langbein (2002) found that participants perceive a more pronounced disproportionate influence on negotiated rules by big-business interests relative to that of small-business and public interest counterparts than rules formed in the conventional process. This suggests that the negotiated regulatory process is more vulnerable to influence from regulated interests, lending 
support for the hypothesis that collaborative regulatory processes are likely to be more prevalent in states where regulated industries are strong.

In summary, the literature offers compelling theoretical support for the hypothesis that regulated interests prefer collaborative regulatory processes because they offer potential for greater flexibility, lower costs, and greater potential for co-opting competing stakeholders.

\section{Constructing a Board Typology}

Contemporary environmental boards and commissions also contain variation in form and function that could influence results. To test the implication of this variation, I construct a typology that categorizes policy-making boards by their major compositional distinctions. The contemporary, state-level environmental board falls into one of three categories: citizen, stakeholder, and professional boards. "Citizen boards" serve parttime, receive minimal compensation, and their selection is not constrained by legislated eligibility requirements. Extant literature describes this distinction as a measure to promote independent oversight (Gelpe 1990; Cushman 1972); limiting compensation is believed to make boards less beholden to state government, and thus more likely to express objective judgment.

Stakeholder boards also serve part-time and are minimally compensated, but this subset also institutionalizes stakeholder representation with legislatively mandated constituency representation requirements. While federal law requires that a majority of board members "represent the public interest" (PL 95-95, 1977), several states legislatively mandate representation to stakeholders such to resemble a pluralist approach 
to environmental decision-making. In these instances, legislation requires that a certain number of members be chosen to represent specific stakeholder groups, so that policymaking reflects deliberation among diverse, and sometimes competing, interests.

These are often selected by requesting designated stakeholder groups to submit lists of recommended names, from which the Governor fills the position(s).For example, Oklahoma's Environmental Quality Board contains five members from various industry sectors including one each from the petroleum, agriculture, hazardous waste, and solid waste industries, three citizen members from the environmental non-profit sector, and one each from local government, the state conservation districts, a rural water district, a certified environmental professional (non-governmental), and a person knowledgeable in water usage. As noted above, research suggests that such representation on governing boards moves board consensus further toward the regulated industry position (Noll 1972). Therefore, I expect a tendency toward stakeholder boards where regulated interests are more economically important.

"Professional" boards consist of full-time, salaried members. Currently, there are three states: California, Texas, and Illinois that fall into this category. "Ex-officio boards" draw a majority of membership from state government through legislatively designated agency representatives. There are currently three of these: New York, Nevada and Pennsylvania, Cushman (1941) described this strategy as promoting an integrated approach (e.g., public health and economic development perspectives) to solving public policy problems with complex jurisdiction. 
In an analysis of Public Utility Commission (PUC) policymaking, Gormley (1983) describes government representation in administrative policymaking as an important source of expertise and public interest representation in PUC policymaking and suggests that the institutionalized presence of state government representatives balanced private utility influence, and produced more consumer-friendly utility rates. Conversely, Haskell and Price (1973) argued that ex-officio boards often contain a majority of exofficio members from agencies that are sympathetic to economic interests, like Departments of Agriculture and Economic Development, which they claim tilts the decision-making arena towards economically interested constituencies. However, like with "professional boards" the perceived vulnerability to government influence is expected to reflect preferences more aligned with single-administrator agencies than stakeholder or lay boards.

Ex-officio and professional boards are linked to bias towards economic interests, which presumably appeals to economic interest groups, but they also clearly involve additional government participation, which may also affect this preference. Ex-officio representatives, by definition, are accountable to the governor as a political appointees, and serves at his/her pleasure.

Professional board members are also considered more vulnerable to political pressures because, as full-time employees, they are more dependent on government for financial well-being (Gelpe 1990). In light of this, I expect these board types will be less favorable among economic interests and during periods of divided government, as they are less independent and more vulnerable to current political pressure, especially from the governor. 
Table 2.1 contains a list of states, board type, and year created. As of 2012, there are 14 citizen boards, 13 stakeholder boards, and 5 professional boards.

Table 2.1 - States with Policy-making Boards, Year Created, and Board Type as of 2000

\begin{tabular}{|c|c|c|c|c|c|}
\hline State & Year & Type & State & Year & Type \\
\hline \multirow[t]{2}{*}{ Alabama } & 1969 & Citizen & North & 1974 & Stakeholder \\
\hline & & & Carolina & & \\
\hline Arkansas & 1965 & Citizen & Oklahoma & 1967 & Stakeholder \\
\hline California & 1967 & Professional & New Mexico & 1973 & Citizen \\
\hline Colorado & 1970 & Citizen & New York & 1957 & Stakeholder \\
\hline Florida & 1969 & Stakeholder & Oregon & 1969 & Citizen \\
\hline Georgia & 1972 & Citizen & Pennsylvania & 1959 & Ex-officio \\
\hline \multirow[t]{2}{*}{ Idaho } & 1959 & Citizen & South & 1965 & Citizen \\
\hline & & & Carolina & & \\
\hline Illinois & 1963 & Professional & South Dakota & 1970 & Citizen \\
\hline Indiana & 1961 & Stakeholder & Tennessee & 1967 & Stakeholder \\
\hline Iowa & 1967 & Stakeholder & Texas & 1967 & Professional \\
\hline Maine & 1967 & Citizen & Utah & 1967 & Stakeholder \\
\hline Minnesota & 1967 & Stakeholder & Virginia & 1966 & Citizen \\
\hline Mississippi & 1966 & Citizen & West Virginia & 1964 & Stakeholder \\
\hline Missouri & 1965 & Stakeholder & Wisconsin & 1970 & Citizen \\
\hline Montana & 1971 & Citizen & Wyoming & 1976 & Stakeholder \\
\hline Nebraska & 1969 & Stakeholder & & & \\
\hline Nevada & 1971 & Ex-officio & & & \\
\hline
\end{tabular}


Table 2.2- States with Single-Administrator Regulatory Agencies and Year Created

\begin{tabular}{llll}
\hline State & Year & State & Year \\
\hline Alaska & 1971 & Michigan & 1991 \\
Arizona & 1973 & New Hampshire & 1986 \\
Connecticut & 1971 & New Jersey & 1967 \\
Delaware & 1970 & North Dakota & 1976 \\
Hawaii & 1959 & Ohio & 1971 \\
Kansas & 1974 & Rhode Island & 1977 \\
Kentucky & 1979 & Vermont & 1970 \\
Louisiana & 1979 & Washington & 1991 \\
Maryland & 1969 & & \\
Massachusetts & 1969 & & \\
\hline
\end{tabular}

\section{Model Specification}

This analysis uses the Event History Analysis approach to study the evolution of State Environmental Boards from the first adoptions in New York, Delaware, and Florida in 1957 to the last major change in Idaho in 2000. Specifically, the model is estimated using a modification of multinomial logistic regression analysis proposed by Beck et al (1998) as an effective alternative to Cox and other EHA approaches. This strategy has subsequently been implemented by Volden (2002), Holburn and Vanden Berg (2006) and others to account for competing multiple and competing events 
This study addresses temporal dependence by incorporating a series of temporal dummy variables to control for the non-linearity of the relationship between time and the dependent variable. While Beck et al (1998) proposed several techniques for accomplishing this objective; the procedure used here is the natural cubic spline procedure, which is favored by these and other researchers (Volden 2002; Meinke et al 2006). Splines correct for non-linearity by breaking the time-series into segments, and controlling for the influence of time during these periods. This is considered preferable to time increment dummies because it accomplishes the same goal without the loss of degrees of freedom.

In line with Beck et al (1998), Volden (2002) and other multiple-event studies, "events" are defined here as substantive reorganization of environmental regulatory systems. These are most commonly enacted by state legislation, and can entail major changes in scope, e.g., from single to multiple media jurisdiction, major changes in composition and/or selection requirements such as the addition or removal of stakeholder representation requirements like Florida and or Maine undertook in 1975, respectively, or a reorganization of agency structure, as Michigan completed in 1991 when decisionmaking authority was transferred to the director of the new Department of Environmental Quality.

\section{Dependent Variable}

The dependent variable of interest in the first set of models is a multinomial indicator of whether the state legislatively delegates rulemaking authority to an 
environmental board or single-administrator agency. In this analysis, delegation decisions are treated as "events," such that a state is coded as " 1 " if it has adopted or modified a policy-making board in that year, " 2 " if the single executive structure, or " 0 " during years of inactivity. The results are presented two ways. In table 2.4 , " 0 " is the reference category so that adoptions of both regulatory structures are compared against periods of inactivity. In order to facilitate comparison, for each model I perform an additional analysis in which " 2 " is set as the reference category in order to compare the likelihood of adopting a board or single-headed agency.

The second step expands the analysis to study adoptions of the various board types, to determine whether support for the hypotheses vary by composition type. For this classification, events are coded as " 1 " if a citizen board without qualification is adopted, "2" if a "stakeholder" board is adopted, " 3 " if the board is "professional" or majority exofficio, "4" if a single-administrator agency is adopted or reorganized. " 0 " remains indicative of no adoption event.

Over the studied time period, forty-four states adopted policy-making boards, twenty-four made substantive adjustments multiple times, twelve states changed from board-led to single administrator agencies, six states adopted single administrator agencies without first having a board in place, and, one, California, adopted a policy board after first having delegated regulatory authority to a single administrator-led agency. As of 2012, thirty-two states have boards with oversight authority, while the balance leave decision-making to a single administrator.

\section{Explanatory Variables}


Summary statistics for these variables are listed in Table 2.3. Political variables are considered important influences, and are fairly straight-forward. To measure state ideology, I employ the Berry et al (2006) citizen ideology measures. The citizen measure is an average of congressional district ideology scores that aggregate the ideologies of congressional incumbents and their most recent challengers. ${ }^{1}$ In this index, "liberal" is the high value.

The partisanship measures include a variable identifying the governor's political party affiliation. Democrats are coded as "1," while non-Democrats are coded as "0." This coding strategy accounts for the periods in which Connecticut, Maine, and Minnesota were governed by independent governors by including them in the comparison group. I also create two variables to measure party alignment. "divided branches" uses a binary indicator to identify whether states' legislative and executive branches fall under unified or divided party control, respectively, and "Republican legislature" and "Democratic legislature" are each coded as "1" when the respective political party controls both chambers of the state legislature. Nebraska is coded as missing for these variables, as its legislature is unicameral and officially non-partisan.

\footnotetext{
${ }^{1}$ Since the Berry ideology begins in 1960, it does not cover the period of analysis. To compensate, the earliest value is used to fill these values for 1957, 1958, and 1959. While the stability of citizen ideology over time remains an open question in the literature (Brace et al 2004; Berry et al 20007), it is believed here that its stability from year to year enables this estimation with some confidence. While admittedly not an ideal solution, omission does not produce substantively different results.
} 
Table 2.3. Summary Statistics

\begin{tabular}{llllll}
\hline Variable & Observations & Mean & $\begin{array}{l}\text { Standard } \\
\text { Deviation }\end{array}$ & Min & Max \\
\hline Citizen Ideology & 2198 & 46.44 & 16.58 & .96 & 93.91 \\
Value Added by & 2198 & 7.46 & 4.51 & .62 & 16.87 \\
Manufacturing & & & & & \\
Per Capita Income & 2198 & $25,247.93$ & $7,243.23$ & $8,194.56$ & $53,083.09$ \\
Governors' Party & 2198 & .56 & .49 & 0 & 1 \\
Divided Government & 2198 & .56 & .50 & 0 & 1 \\
Democratic Legislature & 2198 & .53 & .50 & 0 & 1 \\
Republican Legislature & 2198 & .25 & .43 & 0 & 1 \\
Population (in & 2200 & 4476.73 & 4850.32 & 224 & 33987.98 \\
thousands) & & & & & \\
\hline
\end{tabular}

The second set of explanatory variable of interest measures regulated industry strength. The concept is measured in terms of "value added" by the manufacturing industry. Specifically, this measure is derived by subtracting the cost of materials, supplies, containers, fuel, purchased electricity, and contract work from the estimated value of shipments. The Census Bureau considers this the best measure of relative economic importance because it captures employee compensation, taxes on production and imports, subsidies, and proprietor income on activities performed within the state (Census Bureau, Annual Survey of Manufactures). These data were acquired from various years of the Census Bureau's Statistical Abstract, which sourced it from the Annual Survey of Manufactures, and were reported in units of millions of dollars. The 
measure was standardized by obtaining their per capita values (per thousand residents, forming a variable in units of millions of dollars per thousand residents. It is also adjusted to reflect value in 2010 dollars.

\section{Control Variables}

To protect against omitted variable bias, I also control for additional variables that may influence structural design choices and environmental policy more generally. While the design lacks a measure of environmental degradation, which could affect structural choices, I use state population as a rough proxy for environmental demand, considering population has been commonly observed to correlate with pressure on natural resources. Population is measured and reported in number of residents. Personal Per Capita Income is also included as a measure of economic conditions. Per Capita Income data also come from the Bureau of Economic Analysis, and were originally derived from Bureau of Labor Statistics' Quarterly Census of Employment and Wages. PCI is reported in 2010 dollars. Finally, since partisan identification has been observed to carry different meaning in the South, I control for this region in order to minimize misinterpretation. To this end, a binary indicator reflects whether states fall within the South region, as defined by the US Census Bureau.

Results

Table 2.4 reports results from the first set of analyses, which study delegation of rulemaking authority to boards and single-headed agencies. The table shows that ideology, population, and per capita income are significant influences on these delegation 
events. Addressing the control variables first, per capita income is significant for both board and single-headed agency adoption, with relative risk ratios of .99 and 1.001 respectively. This indicates that increases in per capita income decreases the odds that a state will delegate rulemaking authority to a board and increases the likelihood that it will delegate to a single administrator agency. This finding is not surprising, given the links between per capita income, and professionalized government and expectations for environmental performance. This relationship holds when the analysis is performed with "single-administrator" as the base category, as the rrr coefficient remains .999 and significant when compared to adoption of a single-administrator agency. The coefficient for population is significant, but statistically little different than 1 , indicating its impact is negligible.

Turning now to the variables of interest, ideology turns out to be an important predictor in the choice of authority structures, producing strong evidence that states with ideologically liberal citizenry are more likely to adopt environmental regulatory agencies without oversight boards. This is evident from significant coefficient of .97 for the board category and 1.04 for single-administrator agencies. Support for this conclusion is also found in the first step comparative model (which compares board and agency adoption directly) (table 4.5), where the rrr coefficient of .93 suggests that the odds of delegating to a policy-making board rather than a single administrator decreases significantly as citizen ideology increases. Again, this confirms our expectations that states with liberal citizenry are more likely to have robust environmental governance structures.

The secondary political variables offer mixed results. Divided government was expected to correlate positively with likelihood of policy board adoption, but instead 
produce evidence (though on the margins of significance) of the opposite effect. Governors' Party and Democratic legislatures were expected to produce results similar to that of ideology, but instead produce no discernible pattern in these models. The coefficient for Republican legislatures is 2.01 for board adoption, which suggests that Republican control substantially increases the odds of board adoption, but this does not carry over to the model that compares adoption of boards and single-administrator agencies directly. Turning now to economic interest group pressure, while the coefficient approaches significance $(p<.20)$ in the expected direction on both the base and comparative model, these significance levels prevent me from drawing conclusions based on these models. 
Table 2.4 Explaining Board Adoption (Base Category=0)

\begin{tabular}{|c|c|c|c|c|}
\hline \multirow[b]{2}{*}{ Variables } & \multicolumn{2}{|c|}{ Board (1) } & \multicolumn{2}{|c|}{ Single-Admin Agency (2) } \\
\hline & RRR & Coefficient & RRR & Coefficient \\
\hline & & $-.03 * * *$ & $1.04 * *$ & $.04 * *(.01)$ \\
\hline Citizen Ideology & $.97 * * *$ & $(.01)$ & & \\
\hline \multirow[t]{2}{*}{ Manufacturing } & 1.06 & $.05(.04)$ & .95 & $-.05(5.47)$ \\
\hline & & $.0001 * *$ & $1.01 * * *$ & $.0008 * *(.00)$ \\
\hline Per Capita Income & .99 & $(.00)$ & & \\
\hline Governor's Party & 1.02 & $.029(.28)$ & 5.9 & $1.68(1.21)$ \\
\hline Divided Government & 1.07 & $-.41(.26)$ & .74 & $-.41(.52)$ \\
\hline Republican legislature & $2.02 * *$ & $.70 * *(.33)$ & 1.47 & $.39(.65)$ \\
\hline \multirow[t]{2}{*}{ Democratic legislature } & .94 & $-.063(.37)$ & .44 & $-.81(.65)$ \\
\hline & & $.0003 *$ & 1.00 & $.0000(.000)$ \\
\hline \multirow[t]{2}{*}{ Population } & $1.00 *$ & $(.000)$ & & \\
\hline & & $-3.18 *$ & $4.93 \mathrm{e}-$ & $-16.32 * * *$ \\
\hline Constant & $.07 *$ & $(1.77)$ & 06 & $(4.12)$ \\
\hline Observations & 2153 & & 2153 & \\
\hline
\end{tabular}

Robust standard errors in parentheses

$* * * \mathrm{p}<0.01, * * \mathrm{p}<0.05, * \mathrm{p}<0.1$ 
Table 2.5. Explaining Board Adoption relative to Single Administrator Agency Adoption

\begin{tabular}{lll}
\hline VARIABLES & $\begin{array}{l}\text { Board (1) } \\
\text { RRR }\end{array}$ & Coef \\
\hline Citizen Ideology & & \\
Manufacturing & $93 * *$ & $-.072 * * *(.015)$ \\
Per Capita Income & 1.11 & $.11(.07)$ \\
Governor's Party & $.99 * *$ & $.00001(.0000)$ \\
Divided Government & .04 & $.43(.49)$ \\
Republican legislature & $.39 *$ & $-.94 *(.55)$ \\
Democratic legislature & 1.37 & $.31(.73)$ \\
Population & 2.21 & $.75(.75)$ \\
& 1.00 & $.00(.86)$ \\
Constant & & $9.03 * * *(2.02)$ \\
Observations & $8393 * * *$ & \\
\hline
\end{tabular}

Robust standard errors in parentheses

$* * * \mathrm{p}<0.01, * * \mathrm{p}<0.05, * \mathrm{p}<0.1$

The second set of analyses evaluates board adoption by type, and its results are reported in tables 2.6 and 2.7. The control variables perform similarly on the second set of analyses. Interestingly, while its coefficient is similar across board types, the effect of per capita income appears most prominently through adoption of stakeholder boards. An rrr coefficient of .99 suggests that the odds of delegation to a stakeholder board decrease as per capita income increases. This trend is also evident in the comparative analysis (where single-administrator agency adoption is the base category) as a coefficient of 99 for stakeholder boards indicates that states are more likely to adopt single-administrator agencies as per capita income increases. 
Table 2.6. Explaining Delegation by Board Type (Base Category=0)

\begin{tabular}{|c|c|c|c|c|}
\hline \multirow[b]{3}{*}{ VARIABLES } & \multicolumn{3}{|c|}{ (Stakeholder } & \multirow{2}{*}{$\begin{array}{l}\text { (Single } \\
\text { Admin) }\end{array}$} \\
\hline & (Citizen) & ) & (Professional) & \\
\hline & 1 & 2 & 3 & 4 \\
\hline Citizen Ideology & $\begin{array}{l}0.971 \\
(0.0174)\end{array}$ & $\begin{array}{l}0.976^{* *} \\
(0.0108)\end{array}$ & $\begin{array}{l}0.955^{* *} \\
(0.0173)\end{array}$ & $\begin{array}{l}1.045^{* * *} \\
(0.0122)\end{array}$ \\
\hline Manufacturing & $\begin{array}{l}1.009 \\
(0.112)\end{array}$ & $\begin{array}{l}1.161 * * \\
(0.0750)\end{array}$ & $\begin{array}{l}0.875 \\
(0.121)\end{array}$ & $\begin{array}{l}0.948 \\
(0.0416)\end{array}$ \\
\hline Per Capita Income & $\begin{array}{l}1.000 \\
(5.79 \mathrm{e}-05)\end{array}$ & $\begin{array}{l}1.000^{*} \\
(8.94 \mathrm{e}-05)\end{array}$ & $\begin{array}{l}1.000 \\
(0.000108)\end{array}$ & $\begin{array}{l}1.000 * * \\
(3.22 \mathrm{e}-05)\end{array}$ \\
\hline Population & $\begin{array}{l}1.000 * * \\
(9.42 \mathrm{e}-05)\end{array}$ & $\begin{array}{l}1.000^{*} \\
(3.42 \mathrm{e}-05)\end{array}$ & $\begin{array}{l}1.000 * * * \\
(4.32 \mathrm{e}-05)\end{array}$ & $\begin{array}{l}1.000 \\
(3.61 \mathrm{e}-05)\end{array}$ \\
\hline Governor Party & $\begin{array}{l}0.699 \\
(0.443)\end{array}$ & $\begin{array}{l}1.286 \\
(0.426)\end{array}$ & $\begin{array}{l}0.413 \\
(0.336)\end{array}$ & $\begin{array}{l}0.664 \\
(0.265)\end{array}$ \\
\hline Divided Government & $\begin{array}{l}0.338^{* *} \\
(0.179)\end{array}$ & $\begin{array}{l}0.820 \\
(0.256)\end{array}$ & $\begin{array}{l}0.246 \\
(0.274)\end{array}$ & $\begin{array}{l}1.704 \\
(0.798)\end{array}$ \\
\hline Democratic Legislature & $\begin{array}{l}0.582 \\
(0.396)\end{array}$ & $\begin{array}{l}1.334 \\
(0.643)\end{array}$ & $\begin{array}{l}1.461 \\
(1.646)\end{array}$ & $\begin{array}{l}0.439 \\
(0.286)\end{array}$ \\
\hline Republican Legislature & $\begin{array}{l}1.396 \\
(0.778)\end{array}$ & $\begin{array}{l}2.993 * * \\
(1.419)\end{array}$ & $\begin{array}{l}0.463 \\
(0.597)\end{array}$ & $\begin{array}{l}1.466 \\
(0.949)\end{array}$ \\
\hline Constant & $\begin{array}{l}0.0441 \\
(0.0904)\end{array}$ & $\begin{array}{l}0.152 \\
(0.523)\end{array}$ & $\begin{array}{l}0.000480^{*} \\
(0.00207)\end{array}$ & $\begin{array}{l}4.93 \mathrm{e}-06^{* * *} \\
(1.03 \mathrm{e}-05)\end{array}$ \\
\hline Observations & 2,153 & 2,153 & 2,153 & 2,153 \\
\hline
\end{tabular}

Robust standard errors in parentheses

$* * * p<0.01, * * p<0.05, * p<0.1$ 
Table 2.7: Explaining Environmental Board Adoption by Type (Base Category Single Administrator Agency)

\begin{tabular}{|c|c|c|c|c|}
\hline VARIABLES & $\begin{array}{c}\text { (Inactivity) } \\
0\end{array}$ & $\begin{array}{c}\text { (Citizen) } \\
1\end{array}$ & $\begin{array}{c}\text { (Stakeholder) } \\
2\end{array}$ & $\begin{array}{c}\text { (Professional) } \\
3\end{array}$ \\
\hline \multirow[t]{2}{*}{ Citizen Ideology } & $0.957 * * *$ & $0.930 * * *$ & $0.934 * * *$ & $0.914 * * *$ \\
\hline & $(0.0112)$ & $(0.0209)$ & $(0.0166)$ & $(0.0200)$ \\
\hline \multirow[t]{2}{*}{ Manufacturing } & 1.055 & 1.064 & $1.225 * *$ & 0.923 \\
\hline & $(0.0463)$ & $(0.130)$ & $(0.114)$ & $(0.136)$ \\
\hline \multirow[t]{2}{*}{ Governor Party } & 1.507 & 1.053 & 1.938 & 0.622 \\
\hline & $(0.603)$ & $(0.835)$ & $(1.025)$ & $(0.559)$ \\
\hline \multirow[t]{2}{*}{ Divided Government } & 0.587 & $0.198 * *$ & 0.482 & 0.144 \\
\hline & $(0.275)$ & $(0.138)$ & $(0.283)$ & $(0.178)$ \\
\hline \multirow[t]{2}{*}{ Democratic Legislature } & 2.277 & 1.325 & 3.039 & 3.326 \\
\hline & $(1.484)$ & $(1.114)$ & $(2.632)$ & $(4.227)$ \\
\hline \multirow[t]{2}{*}{ Republican Legislature } & 0.682 & 0.952 & 2.042 & 0.316 \\
\hline & $(0.442)$ & $(0.793)$ & $(1.626)$ & $(0.458)$ \\
\hline \multirow[t]{2}{*}{ Per Capita Income } & $1.000 * *$ & 1.000 & $1.000 * *$ & 1.000 \\
\hline & $(3.22 \mathrm{e}-05)$ & $(7.32 \mathrm{e}-05)$ & $(9.58 \mathrm{e}-05)$ & $(0.000112)$ \\
\hline \multirow[t]{2}{*}{ Population } & 1.000 & $1.000 *$ & 1.000 & $1.000 * *$ \\
\hline & (3.61e-05) & $(0.000105)$ & $(6.05 e-05)$ & $(5.55 \mathrm{e}-05)$ \\
\hline \multirow[t]{2}{*}{ Constant } & $202,884 * * *$ & $8,952 * * *$ & $30,874 * *$ & 97.35 \\
\hline & $(424,272)$ & $(27,146)$ & $(126,699)$ & $(468.0)$ \\
\hline Observations & 2,153 & 2,153 & 2,153 & 2,153 \\
\hline
\end{tabular}

Robust standard errors in parentheses

$* * * \mathrm{p}<0.01, * * \mathrm{p}<0.05, * \mathrm{p}<0.1$

The second set of analyses also indicates that citizen ideology strongly influences the likelihood of delegating rulemaking authority to a single administrator, and significantly and negatively influences the likelihood of adopting two of the three board types in comparison. This set of results is consistent with the initial findings that ideology is strongly predictive of the choice of decision-making structures. More liberal states tend to adopt agencies headed by a single, professional administrator. 
Regarding the partisan variables, Governors' party and Democratic legislatures again failed to register a significant effect on delegation decisions. I do find a relationship between Republican legislatures and stakeholder boards; particularly, Republican legislatures appear substantially more likely to choose divided or Democratically-controlled legislatures in the base model. However, this trend does not extend to the model in which adoption of a single-administrator agency is the base category.

I also find significant results for "divided government." Somewhat surprisingly, both the base and comparative models suggest that citizen boards are much less likely during periods of divided government. This trend is not observed among the other board categories. Turning to value-added by manufacturing, while this variable performed poorly in the base model analyses, the expanded analysis does produce evidence that this measure of economic importance correlates with adoption of stakeholder boards.

Statistically significant coefficients of 1.16 and 1.22 indicate that value-added by manufacturing increases the odds of delegation to a stakeholder board. Interestingly, this trend does not extend to the other board types.

\section{Discussion and Conclusion}

Part-time, multi-member environmental policymaking boards occupy a prominent place in the rule-making processes of thirty-two states, yet little is known about their role in environmental regulatory policy formulation and implementation. A large body of research argues that power and other institutional arrangements at the time of policy 
enactment can reveal a lot about how it operates in the present (McCubbins, Noll, and Weingast 1989; Sinclair and Whitford 2012).

This study finds strong patterns in the relationship between citizen ideology and agency structures. Across the board, citizen ideology is negatively associated with board adoption and positively related with single-administrator regulatory agencies. These findings offer strong evidence that the single administrator agency is more likely to be adopted in states with more liberal citizenry. This is significant because it offers support for the theory that agency structures can produce organizations with different missions and potentially different outcomes.

Specifically, given liberals' widely observed preference for increased environmental activism, it is reasonable to surmise that their apparent preference for single-administrator agencies reflects a preference for a technocratic approach to environmental decision-making, where technical decisions are made by a single, professional administrator rather than panels of political appointees. It is also reasonable to conclude that this finding suggests that ideological conservatives are more committed to institutions that moderate agency output.

The fact that this relationship is particularly strong among stakeholder boards offers reason to believe that the presence of environmental policy boards with rulemaking authority reflects a desire to balance economic and environmental interests and/or keep the environmental technocracy in check; a goal attributed by a subsequent evaluation of Minnesota's Pollution Control Citizens Board to the legislature that created it in 1967. 
This is significant because in both cases, the choice of agency structure appears to reflect different preferences regarding agency mission.

Ideology's importance may also explain why secondary political variables performed weakly and inconsistently. Political party preferences were expected to mimic the ideologies to which they are roughly aligned, but produced little support for these expectations. This is not altogether surprising, when one considers the ideological differences within political parties within different parts of the country, especially in the South where policy-making boards have been prevalent.

I also found support for the hypothesis that economic pressures influence the choice of regulatory structure. Per capita income is negatively associated with stakeholder board adoption and positively associated with single-administrator agencies, which is consistent with previous findings that political principals are more sensitive to economic concerns when state fiscal conditions are weaker (Konisky, 2007). Economic drivers have more leverage under these conditions as state officials value economic development.

More importantly, the analysis provides empirical evidence that regulated industry strength influences the choice of regulatory structures. While value-added by manufacturing performed weakly in the first set of analyses, results from the expanded analyses estimate that value added by manufacturing increases the likelihood that the sector's concerns will be represented on a stakeholder board, and decreases the likelihood that policymaking authority will be delegated to professional administrators. This finding indicates that industry preferences vary according to board type. This suggests that 
regulated firms do not have significant preferences for one structure over the other (unilateral v. collective decision-making), but do have preferences regarding their role and proximity to decision-making, and are influential in institutionalizing them as their importance to the state economy increases. Whether directly or implicitly influenced, policymakers appear to prefer agency structures that enhance the access regulated firms have to environmental decision-making.

These findings make significant contributions in two ways. First it begins to shed light on the role boards play in the environmental process. We now know that ideology and manufacturing industry strength are strong predictors of agency structure, which is attributed to expectations concerning how each form will affect agency decision-making. Second, these results also contribute to interest group theory by providing empirical evidence that regulated interest group strength influences environmental policy-making through agency design. In places where they are strong, regulated industries are able to gain institutionalized representation in the decisions that affect their industries.

These findings introduce a number of questions regarding the implications of composition differences for policy outcomes. Do these composition differences predict mission variation? Do single-administrator agencies produce comparatively stringent regulations? Does stakeholder participation in regulatory decision-making improve or compromise policy outcomes? Unfortunately, these questions exceed the scope of this analysis. Later chapters of this manuscript will introduce process and outcome variables to further clarify the contribution boards make, both collectively and as subgroups, to environmental policy-making 


\section{Chapter 3}

\section{Board Members' Perceptions about their Role in Environmental Policy-making}

\section{Introduction}

In the previous chapter, I found empirical support for arguments that ideology and manufacturing industry strength predict preferences for one structure of environmental decision-making over the other. Specifically, the analysis revealed that states with more liberal citizenry are more likely to implement the single-headed agency model over the multi-member design, and conversely, states where the manufacturing industry has a greater impact on the economy are more likely to regulate environmental decisionmaking with a part-time citizen board, particularly one that enables direct stakeholder participation. What the analyses cannot explain, however, are the implications of these preferences for process and outcomes. The following section, in large part, attempts to answer these questions by utilizing semi-structured telephone interviews to gain insight into board members' perspectives on their role in their states' environmental policymaking process.

As previously noted, neo-institutional literature argues that agency structure has important consequences for policy outputs: it controls access to the regulatory process, agency scope, operating procedure, and discretion, and ultimately shapes agency performance (McCubbins, et al 1989; Hammond and Bender 2010; Holburn and Vanden Burgh 2006). Therefore, knowing that states with higher levels of manufacturing intensity and/or conservative citizenry prefer citizen boards is supposed to tell us 
something about expectations concerning how they perform. From what is known about both interests, for example, it can be reasonably predict that boards promote greater contemplation of the economic costs of regulation, as well as their related impacts on society.

However, the implication for the environmental regulatory process and outcomes remains unclear. Does the board process fulfill expectations? Is this desirable for public policy? While we readdress empirical effects in the next chapter, they cannot be expected to fully explain the linkage between process and outcomes. The goal of this chapter, therefore, is to use board member interviews to provide a rare glimpse into the environmental policy making process from the board member's perspective. Specifically, the interview protocol is designed to build theory by capturing their sense of purpose in their state's environmental process, the nature of their relationships with public and private stakeholders, perceptions about the strengths and weaknesses of the board process, and institution-level factors that appear to moderate performance. In short, this chapter seeks to supplement the quantitative analyses by adding context to the results, as well as increase the comprehensiveness of understanding of how and why boards operate.

To briefly summarize previous literature, boards were initially preferred because they were viewed as a way to generate unbiased, balanced expertise in order to address the emerging complex problems in a way that is transparent and representative of the public interest. Because of the perceived complexity and invasiveness of regulation, policymaking in this area was believed to require a representative, deliberative approach in order to make sure the regulation's impacts on the multiple interests at stake are 
adequately raised and considered, and output reflects the jurisdiction's interests. This sentiment was captured by a board member interviewed for this study who, when asked whether s/he believes the board enhances environmental decision-making in his/her state, said "yes, it is the only real avenue to produce codes that people have to comply with." This format is also grounded in the idea that generalists are better policy decision-makers than specialists because they have a better understanding of the "big picture (Paehlke 2005)."

Once the EPA was established as a single-administrator agency in 1970 and regulatory expectations grew more advanced, some states shifted authority away from environmental boards and/or created new administrative agencies more similar to the EPA model. Massachusetts, Maryland, New Hampshire, and Louisiana are a few among this latter group. An agency managed by a full time, singularly accountable, professional administrator was (and continues to be) viewed by many as the most appropriate way to address complex and salient environmental problems. However, at present time, thirtyfour states ranging from California to Alabama retain the multi-member administrative form to develop rules and standards, take administrative action to enforce regulations, adjudicate environmental disputes, and/or otherwise oversee formulation and implementation of environmental regulatory policy. A few even have the power to appoint their state's environmental agency director.

The choice between administrative structures is often framed as a choice between reliance on technocratic expertise on the one hand, and the inclusiveness and transparency that is commonly associated with participatory structures on the other. The former emphasizes scientific rationality, and is characterized by expertise-driven problem 
solving (Mashaw 1985). This model is praised for its comprehensive, methodical approach to policy-making, but is also criticized for ignoring the inherent role of value judgments in most public policy decisions, and is considered particularly less appropriate for managing competing values (Rossi 1997). The deliberative structure is considered legitimacy-enhancing for its openness, transparency, and purported ability to generate policy outcomes that represent the preferences of diverse interests. (Randolph and Bauer 1999; Paehlke 2005; Dryzek 1987). On the other hand, critics contend that deliberation impedes effective and decisive decision-making, weakens accountability by dividing authority, and make regulators more vulnerable to disproportionate influence by interests groups (The President's Council on Executive Organization 1971; Noll 1971; Bernstein 1955).

Deliberative structures, citizen participation, in particular, are also linked to "lopsided pluralist decision-making (Rossi 1997. 240)." This argument, also presented by Mashaw (1980) and Rosenbaum (1976), states that while the participatory approach is often utilized as a more inclusive, transparent alternative to technocratic decision-making, the opposite is more likely the case. As Mashaw (1980) notes "it seems rather more likely that, with respect to many areas of administrative policy formulation, certain interests, because of their intensity, resources and organization, will come to dominate even an open decision making process. Or to put the point somewhat differently, interests that are substantially affected might, because of lack of resources or organization, fail to participate effectively in administrative forums." In sum, while policy processes that emphasize participatory strategies are often granted a stamp of legitimacy through their 
promise for openness and transparency, asymmetries of resources, time, and interest limit their capacity to fulfill this promise.

This study contributes to the literature by probing these questions through the experiences of board members. The semi-structured interview protocol includes queries about biographical information to deepen knowledge of board composition, but primarily focuses on board members' experience engaging in board activities. This line of questioning is most concerned with perceptions about their board's effectiveness, the quality and inclusiveness of board discourse, and the board's relationship with (and perceived influence on and from) political principals and stakeholders.

\section{Data and Methods}

Some states' boards are more accessible than others in terms making contact information for individual board members available to the public, so sampling was limited to those who I could reach, either via e-mail or through their listed contact. Of the thirty-two states with active citizen boards, fourteen were contacted for interviews. These consist of five Western states, five Midwestern states, one Northeastern state, and three Southern states. In total, approximately one hundred twenty-three board members were asked to participate in this study, and twenty-seven participated in interviews, for a response rate of about twenty-one percent. At least one member was interviewed in eleven states. The highest number of interviews from any one state was seven, which constituted roughly fifty percent of that state's board members. Of these eleven states, six use stakeholder boards, four have unaffiliated citizen boards, and one is predominantly an ex-officio board. Furthermore, the interview sample consists of thirteen Democrats, eleven Republicans, two liberal-leaning independents, and 1 
conservative leaning independent. It should be noted that in a couple of cases where states did not post e-mail contact information for board members, the posted board contact was relied upon to provide access to members. In one case, the board's executive secretary suggested that I limit my contact to the board's chair, a request that I honored.

Board members were asked approximately forty questions. All interviews were conducted via telephone, and their average length was approximately 45-50 minutes. These calls were not recorded, but instead data were collected via note-taking. Board members were questioned about their perceptions about of their board's contributions to environmental decision-making in their state, as well as their response to points raised in the literature concerning proposed advantages and disadvantages associated with governance by policy-making boards. The protocol specifically proceeds as follows: the first set of questions inquires about education and professional background, including previous public service experience. The second set of questions relates to perceptions about board members' role in the environmental policy-making process, and inquires about perceived contributions and importance to environmental decision-making, and strengths and limitations. The next set of questions addresses the board's internal dynamic, and relationships with state administrative and political officials. The final set

of questions inquires about personal political background, and perceptions about changes, if any, in the character of board deliberations over time.

\section{Public Participation}

Facilitating public participation was a commonly cited value-added by boards to the regulatory process. As one board member noted: "that is the whole point [facilitating 
public participation] we are [interviewee's emphasis] the public, and the public testifies at our meetings." Members almost unanimously cited this role as their most important contribution to environmental policy-making. One Mid-Atlantic board member described his/her board's most important role as providing the public with direct representation in environmental rulemaking. By virtue of their positions as "citizen representatives" and the inherent transparency of public, deliberative decision-making, the board, according to this board member, "brings the public perspective into the process," as compared to an environmental agency that lacks the same direct line of accountability to citizens and stakeholders.

One perceived benefit of formally opening policy-making to public participation is that it enhances the quality of regulation. A board member in a western state reported that one of his/her board's primary roles "is to subject agency rules to public discussion." $\mathrm{S} /$ he described his/her board as "very diverse in perspective, which forces agency staff to consider multiple perspectives when developing rules, State Implementation Plans, and compliance schedules." S/he particularly remarked that the "business perspective" forces agency staff to clarify compliance requirements, which often leads to adjustments that make compliance more feasible.

Several board members similarly cited diversity of perspective as a significant contribution to environmental decision-making in their state. A board member from a state with stakeholder representation requirements cited this diversity as important for the viability of environmental regulations. According to this member, "agency staff writes rules from their perspective and often don't realize their impacts." In his/her state, everybody on this board represents a constituency and therefore review proposed rules 
from a different perspective. Stakeholders have the opportunity to express their concerns, which in his/her view, leads to production of more viable rules.

Relatedly, several board members also cited their ability to facilitate dialogue among stakeholders as an important contribution to state environmental policymaking. Many expressed a belief that boards are much better suited for enabling representative, deliberative decision-making than administrative agencies without boards. A representative from the medical profession on a stakeholder board viewed his/her board's role as "to represent the public more directly and bring the public perspective into the regulatory process so it's not such a direct line for the agency."

Many members, from stakeholder boards and non-stakeholder boards alike, cited their ability to engage and incorporate stakeholder input as a key contribution to environmental policy-making in their state. A Western board member shared his/her views that his/her state's environmental agency "has trouble reaching out to stakeholders while the board is well equipped to make sure the right stakeholders get to the table." A Midwestern member selected to represent the general public insisted that this constituency representation "helps get groups involved that don't normally participate in environmental rulemaking." A Southern board member similarly stated that "it is difficult for agency staff to put themselves in the position of their customers. The board identifies conflicts with other state regulations and brings an outside perspective."

When asked about the value the board adds to the state's environmental regulatory process, a Midwestern ex-officio board member said: "part-time board members bring important feedback on how the public or regulated community will respond to regulation, I don't know if you could fairly do it [regulation] otherwise." A 
Northwestern board member selected for expertise similarly stated that one of the board's most important contributions is that it "provides a good sounding board for industry, and gives good perspective on impacts of regulations promulgated by DEQ." Another Midwestern board member argued that "Having diversity brings different ways of looking at problems together. It is good to have all walks of life on the board because there is a better chance different perspectives will be aired."

A member of a board that selects on area of expertise rather than constituency reported that his/her board has the same type of commitment to stakeholder engagement. This board member described a "collaborative assessment" process in which the board works with stakeholders, particularly the regulated community, on proposed rules. In this state, the board participates facilitates in a "negotiated rulemaking" approach to regulation in which stakeholders negotiate the details of rulemaking and implementation. The board and regulatory staff enter deliberations with an "endgame" in mind, and work with stakeholders to develop a workable solution. This member further reported that litigation has decreased significantly since the collaborative assessment process has been implemented.

Another contribution cited by board members is their reported enhanced ability to promote collegiality with and among stakeholders. Especially among members of the "stakeholder boards," it was commonly expressed that frequent stakeholder discussions produced additional understanding of others' perspectives and mutual respect among stakeholders. A Midwestern member went so far as to say that s/he believed the collegiality among stakeholders within the board and regulatory subsystem has yielded better relationships among stakeholders in the state at large. According to this board 
member, this collegiality "fosters communication and cooperation among business and environmental groups throughout the state." A Western member also noted that the board improves collegiality among stakeholders in his/her state, identifying an instance where the board brokered agreement between the environmental agency and regulated community on a new rule after the two sides had reached a protracted impasse.

\section{Oversight}

Boards are also frequently described by board members as important for maximizing transparency of environmental regulation. Forcing agency staff to present proposed rules to a citizen panel is believed to improve the quality of regulation. Board members from multiple states reported that their boards enhance environmental decisionmaking in their states by providing a venue for a "public vetting" of environmental rules and other agency actions. A Southern board member described his/her board's most important role as providing a "first airing of agency proposals." S/he described the board as a "diverse group" that channels public input both directly through its representation requirements and indirectly through public testimony at board meetings, which provides "good input" into policy development. A Western board member noted that "the board makes sure all deliberations are public. We can explain what we're thinking, and why we're voting the way we are. I think this makes us more accountable to the public."

A Southern board member described his/her board as "a platform for public input to vet and understand regulatory changes." According to this member, this forum forces the state's environmental regulatory agencies to "drill down" into the details of proposed changes to clarify their impacts on the environment and affected stakeholders. S/he 
described this role as very important to policy formulation in the state. Another Southern board member referred to his/her institution as a "panel of citizen judges that provides a place where people can say what they think and the process is opened up," and continued to express his/her belief that "most times when problems come up, it's because people feel like they haven't heard about it."

A Northwestern board member insisted that "you can't have too much transparency and oversight in rules and regulations, and the board provides that oversight." S/he continued to warn that "you need to stay on top of them [environmental regulatory staff] or they'll get away from you." A more frequent expression of this view cited the need for consideration of its impacts when developing a rule, and boards' value in providing this perspective. A board member from the Pacific Northwest described his/her board's role as providing oversight on how rules are written. In this state, the environmental agency drafts proposed regulations, and the board either approves or rejects them.

\section{Balance}

Several board members identified this inclusiveness as important for providing balance to environmental regulation. A Mid-Atlantic board member argued that "board members have worked in the private sector more than [agency] staff and can see the bigger picture. Staff sometimes gets bogged down in issues and agendas." An ex-officio representative from a Midwestern state said one of her board's primary contributions is "utilizing the diverse expertise on the board to make sure regulations are science-based and promote, to the extent possible, economic development." Another Midwestern board 
member said: "on certain issues there are fuzzy lines. The board's job is to find the sharp point in the fuzzy areas." When asked to elaborate, this member explained that many target-based emissions standards, for example, can be implemented using multiple approaches that might affect different industries and/or individuals. One of the board's goals, therefore, is to balance the impacts of regulatory impacts across constituencies in a way that is fair. A Southern board member similarly discussed the importance of making sure regulation is evenly applied such that no parties are disproportionately harmed or benefitted from its implementation.

Several additional board members also cited the importance of balancing environmental and economic interests. When asked what s/he believed to be his/her board's most important contribution, a citizen member from a Southern board whose membership is split between citizens and ex-officio representatives said his/her board's most important role is to "balance industry needs and protect the environment."

When asked specifically about the importance of balancing environmental and economic effects of regulation, a citizen board member from the Southwest reported that this is the potential economic impacts of the proposed regulation is one of the things they spend the most time discussing. Part of the reason for this is they are statutorily required to consider the economic impacts, but s/he also cited the board's ability to "bring the common person's perspective to how regulations will affect people" as one of its most important contribution to the state's regulatory process. A local government representative on a Midwestern board said: "over the years, a large set of regulations has been established; the point of the board is to make sure they are in the best interests of the people [of the state], are fair to business, and protect the environment." 
A board member from the South responded that "it's not something we try to do, but it comes up, we do have an important role in balancing those two things." $\mathrm{S} / \mathrm{he}$ continued to say that this affects timing of implementation rather than substantive effect of regulation, and cited an example in which timing of compliance requirements was adjusted to reduce the economic effects on the regulated businesses.

A Midwestern board member similarly stressed that an important part of his/her board's role "is to help environmental and economic interests to find a way to coexist." $\mathrm{S} / \mathrm{he}$ continued to state the belief that "it is very important to consider the economic impacts of environmental regulation, and develop good policy that promotes economic development." A Southern board member expressed a similar sentiment, reporting that one of his/her board's most important contributions is its ability to "find the balance between clean air and water and a healthy economy." Yet another board member cited his board's most important contribution as "making sure there is a balance between the need for regulation and its impacts on the community being regulated."

Several board members asserted that this public dialogue enhances the "implementability" of environmental regulations in their states. One reported way this is accomplished is by helping to ensure clarity and consistency of rules and regulations. A Northwestern board member expressed that an important contribution his/her board makes is "making sure rules and regulations are easily understood and not complicated." This member went on to say that simplicity and "common sense" is important for increasing ease of compliance, which increases the likelihood of compliance, and in the long run benefits regulated entities, resource-challenged regulators, and the environment. 
Another Western board member similarly identified one of his/her board's most important contributions as "providing consistency, and making regulations more understandable and readable." The board's role, according to this member, is to "ensure that new regulations are practical, and based on science and understandable to the public." S/he further expressed a belief that businesses in the state understand and support the need for environmental regulation, but want them to be scientifically sound, understandable, and fair.

\section{Expertise}

Board members also cite their expertise as a significant contribution to their state's environmental decision-making. Board members are frequently appointed for their expertise, through training, experience, and/or constituency affiliation, which is believed to add value to the regulatory process by contributing knowledge (often through private sector experience) in the practical application of law, science, and technology pertaining to environmental management. Board members commonly view their role as "checking the work" of environmental agency staff. A Western board member cited his/her board's primary contribution to the state's environmental decision-making is to "point out problems" with proposed policy changes, and work with agency staff to produce a more workable solution. His/her board institutionally represents several public and private stakeholder perspectives, which in his/her view, incorporates "a broad array of expertise." One example given where this is especially useful is in adjusting compliance schedules to reflect a more accurate level of technical and practical feasibility. 
A board member from a Southern state shared a similar view of his/her board's role in the state's environmental policy-making process. Appointed to the board for his unaffiliated technical expertise, this board member views the board's role, and his/her own particularly, as a "last line technical review" of agency proposals before they are submitted to the state's legislature. His/her board not only analyzes proposed policy changes through their respective expertise, but also helps process information so it is more accessible to affected stakeholders, including the general public.

An additional reported benefit of the public scrutiny produced through board processes is that it forces better staff work. Several board members interviewed for this project expressed a belief that this inspection enhances staff performance at and between meetings. Staff members are forced to anticipate the types of questions that might arise, which produces stronger, more transparent, and more thorough presentations. One western board member noted this being the case in his/her state, commenting that his/her board is diverse enough to produce interesting discussion. S/he further elaborated this point by stating that this scrutiny often forces the agency to clarify complex points, which in his/her view forces a level of introspection that might not otherwise occur. Another Western board member reported that agency staff members in his/her state have learned to anticipate the types of concerns that might be raised, and come into meetings with more thorough and concise information.

\section{Resource Bias}

However, the emphasis on public participation also appears to have its shortcomings. The model designed to promote representative collective action is 
vulnerable to the same problems inherent to most collective action scenarios (Olson 1965). Just as Olson predicted a bias in collective action toward the more committed and well resourced, I find evidence of a similar tendency in the board dynamic. While most claimed that their board provides equal opportunity for access and participation, many acknowledged that some are consistently better equipped to take advantage of this opportunity. The board process, through its pluralist, participatory orientation, appears biased towards stakeholders with greater tangible investment in policy outcomes. A Midwestern board member said "people with more to win or lose are going to put themselves into the process." One Western board member reported that stakeholders who "show up and talk get more attention than those who don't."

Several other board members acknowledged that well-resourced stakeholders have a decided advantage in board processes. A citizen member of a board with significant ex-officio representation in the South noted that legal expertise is an important criterion for understanding and participating in the regulatory process in his/her state. "Some have full-time lawyers that are looking at these issues and some do not. If you don't have a lawyer you're just out in the dark." Therefore, according to this member, those who can afford legal representation can participate more fully, and thus tend to be over-represented in board proceedings. S/he further noted that his/her state has a third party petition process that allows parties with standing to petition the board for a new rule or modification. However, in order to gain standing, interested parties must fund the studies and other briefing materials necessary to state the case for a policy change, thus contributing to the resource bias. 
A Midwestern board member similarly identified structural impediments to participation, noting the regulatory process in his/her state is complex and inflexible, which imposes additional barriers to citizen participation. S/he lamented that citizens have to be knowledgeable about bureaucratic processes in order to participate meaningfully in environmental rulemaking.

As a consequence, several board members reported that business and industry groups in their states are much more organized than other groups in terms of regular participation in meetings and workgroup/committee sessions, preparation of briefing materials and technical reports, and direct correspondence with the board. A MidAtlantic board member acknowledged that well-funded industry entities have a greater presence in his/her state than those with fewer resources. "Energy companies send more people, prepare more reports, and can do more with larger budgets while others can fund fewer people, surveys, and reports." An environmental representative from a Midwestern board commented that "business and industry are able to pay for professional lobbyists so industry expertise overwhelms citizen participation.” A board member appointed to represent the environmental advocacy constituency suggested that business and industry groups are far more organized towards representation than other stakeholder groups. In his/her state, one way in which this manifests is selection of board members - recruiting members to represent the business constituencies is described as far easier than finding volunteers to fill the public interest positions.

A Western board member added an additional perspective, reporting that wellfinanced environmental advocacy groups are over-represented in board proceedings. "I think a vocal minority has disproportionate input because of the legal representation from 
national groups. The media gravitates towards these groups and sensationalizes their cause. Meanwhile, the general public gets shut out." S/he continued to say the general public is additionally underrepresented because "it's hard to get them to care."

Several other board members corroborated this point about the general public being underrepresented. Another Western board member commented that "environmental quality problems have to get bad before the general public becomes active in board proceedings while business and industry groups maintain a constant presence." Yet another board member lamented that the general public is underrepresented in his/her state's environmental regulatory process because they "don't pay attention to that sort of thing." S/he continued to say that the issues they normally consider are complicated, and require regular attendance and attention to understand. She observed that casual observers attend, but rarely for long because of this complexity.

A Southern board member added to this point by remarking that the "average citizen" is also underrepresented in environmental decision-making in his/her state. According to this member, the "average person" is crowded out by strong industry voices on one side and strong environmental or public interest advocates on the other. As a result, according to this interviewee, environmental policy deliberations are most characterized by extreme positions, leaving the more moderate general public behind. Another board member from this state also concluded that the general public is underrepresented in their board's deliberations. S/he further blamed meeting location particularly the fact that meetings are always held in the state's capital - as being a barrier to more representative public participation. According to this member, always holding meetings in one part of the state limits accessibility for citizens, stakeholders, and 
board members from other more distant parts of the state. In his/her view, this biases the environmental policy making process towards stakeholders with the resources and/or commitment to participate. S/he suggested that rotating board meetings through different parts of the state might improve the policy process by increasing accessibility.

This also highlights the real potential that transaction costs influence participation-levels among board members, themselves. Several board members noted that participation also imposes significant transaction costs for members themselves in terms of time and resources needed to prepare for and travel to meetings, but offers minimal financial compensation for this effort. At the same time, several board members noted that board decisions only require a quorum in their states, in some cases only a simple majority. While it is beyond the scope of this chapter to empirically evaluate attendance patterns, several citizen and local government representatives noted that while special interest representatives are independently motivated to participate, these transactions cost pose significant challenges to civilian members that live and work relatively far from the state capital where board meetings are held.

\section{Independence}

Another criticism raised in the literature about state-level environmental boards characterizes them as a "rubber stamp" for agency proposals (Haskell and Price 1973). As noted above, boards have historically been considered advantageous for regulatory policy for their ability to remain "neutral" and unbiased in contentious policy debates. Instead, according to this criticism, boards tend to be underprepared to exercise 
significant independent authority. Haskell and Price described Wisconsin's Department of Natural Resource Board as a body established to promote "good governance," but concluded that "the board has evolved as basically a reactive body to the secretary. The board meets only once a month, often less than a day. Instead of initiating issues, it usually briefly discusses those raised by the department, gains consensus, and then signs of on the secretary's recommendations...As a matter of conviction, most members agree that the real expertise lies within the department, and they take for granted the merit and validity of its proposals $(1973,127) . "$

Modern environmental boards are commonly situated within the state's environmental regulatory agency, and depend on its staff to complete their work. This dependence results from time, resource, and expertise advantages commonly held by fulltime, professional agency administrators and staff. While a few board members reported spending as many as $40-60$ hours reviewing briefing materials and speaking with agency staff, stakeholders, and/or constituents to prepare for meetings, most reported spending about 10-12 hours on meeting preparation, and a few as little as 1-2 hours per month. In addition, most reported limited dedicated staff, and several acknowledged reliance on agency staff and external sources for scientific, technical, and legal information and expertise. As a result, in many cases, they hear only what is presented to them, and must rely on other sources for critical information.

In some cases, this appears problematic. A Western board member reported that in his/her state, board members frequently approach meetings with a submissive mentality. S/he reported a pervasive mentality that "it is easier if the board quietly passed everything without questions." S/he elaborated that, "by the time decision comes to a 
vote, there is a lot of momentum behind one position, and it is often too late challenge it." This member expressed a desire for board involvement earlier in the formulation process. Another board member from this state independently corroborated this point. When asked why the state had not replaced the board's dedicated lawyer since the last one retired 3-4 years ago, this member commented that "the AG's that currently work with DEQ seem unable to get their minds around the idea that the interests of the boards are not always identical with the staff's."

In most cases however, board members interviewed appeared to take their oversight role seriously. While most reported working closely with agency staff and some acknowledged some dependence on them for information (for example, a citizen board member from the Southwest acknowledged that the board depends on the agency for roughly 90 percent of the technical information they review), most also reported feeling a fiduciary responsibility to assert their authority when the two institutions disagree.

A Midwestern member appointed to represent the general public said: "Our staff is [the state's environmental agency]. Some say we should have staff independent of them, but I don't think that's necessary, the state agency is going to have to implement the rules so they need to be involved in their development." When asked if s/he believed this compromises the board's independence, this member said "I don't worry about that because we have the ability to call in outside experts. Our board is very bright and very educated, and each board member is going to listen to their constituency group because that is where their bread is buttered." A Northwestern board member commented that "sometimes the tail wags the dog [referring to a subordinate controlling a superior] but that's not the case in [his/her state]." 
An ex-officio member of a Midwestern state reported that his/her board approves roughly 90 percent of rules proposed by the state administrative agency. For most of the remaining 10 percent, the board has an established process for studying and working through the proposal with agency staff. A citizen member from a Southwestern state insisted that his/her board "works through proposals paragraph by paragraph, line by line." S/he continued to estimate that the board forces the agency to clarify or modify proposals roughly 40 percent of the time. Similarly, a citizen member from a Southern state estimated that his board challenges agency proposed rules about 20 percent of the time.

\section{Board Capacity}

Board members also largely disagreed with the notion that their part-time, "amateur" status limits their capacity to act on the issues they face. A board member appointed to be a citizen advocate from the Midwest said "the board's role is not so much about technical knowledge, but about regular people asked to impart their experience to make wise decisions. We incorporate the technical information and try to figure out the impacts the decision will have on [residents of the state]."

Some acknowledged the validity of this criticism in the abstract, but few acknowledged this as a problem for their own boards. A Southern board member representing his/her state's local government constituency, for example, represented this perspective. Citing a current review of water quality standards, $\mathrm{s} /$ he described the issues involved as "very, very complicated with a lot of assumptions," and acknowledged that 
the board has to "rely on state scientists to present their case for the levels they recommend." S/he further noted however, this might be challenging for a larger board with a broader scope, his/her board has a narrow scope (water quality standards) and gets "good briefings" that help overcome this barrier. Another board member from a different state acknowledged that "the voluminous reading materials between meetings can be overwhelming." However, s/he also noted, as many did, that rulemaking is not a fulltime job in his/her state, and the monthly workload varies widely.

Others also do not view this as a problem. A Southwestern board member acknowledged that "the issues they face can be complicated for lay people," but questioned whether the alternatives are any better. S/he continued to point out that "the legislature could handle this directly, but they are also a part-time legislature, and face the same limitations as the board." S/he also acknowledged that "state employees do have more time and expertise, but bureaucracy traps them in a bubble, and their actions do not necessarily represent the best interests of the state."

Some members cited board composition as a key factor for overcoming this challenge. Several board members noted that their board members are selected for expertise in relevant fields such as public health, engineering, and program areas like air, water, and solid waste management, which helps provide broad command of the issues they face. A Western board member offered a common response when s/he said his/her board "possesses a broad array of expertise. Usually someone on the board will know enough about the issue to brief the other board members and ask the right questions." Instead of imposing a drag on the system, these members claim their boards enhance 
environmental policy-making in their states through contribution of knowledge and experienced gained through practically applied expertise.

When asked about this, a citizen board member from a Southern state argued that the board helps the public process complex information. "Meetings can be a challenge to prepare for because of the time limitation, but those with expertise can normally understand, and those without technical training work hard to keep up." This member continued to say “there are things we don't know but if we do a good job of asking questions we can overcome it. The board has enough expertise to ask the right questions, and bridges the gap between citizens and regulation." A Midwestern board member appointed to represent his/her state's agricultural constituency said in response to this question: "we need to keep environmental issues at a level that they are manageable and understandable to citizens, and not just full-time bureaucrats."

Another Western board member suggested that information processing is an important part of his/her board's mission. S/he pointed out that, while not by required by statute, his/her board comes from diverse professional backgrounds, which, in his/her view, provides enough expertise to oversee the agency's technical experts. S/he continued to state that the "one of the board's biggest contributions is to review technical information produced by the state's environmental agency, and make sure it is understandable to the generable public. If it doesn't make sense to any of us, how will it make sense to the public? Our job is to make direct the state environmental agency to align state rules with federal rules and make them more consistent and understandable for industry and the general public." 
Two Western board members additionally reported that their board enhances the political feasibility of regulation in their state. In this state, once rules are approved by the board, they are submitted to the state's legislature for final approval. Both members emphatically stated a belief that their board's review processes significantly increases the rate of approval by the state legislature. One of them further noted that this saves a considerable amount of time because if the legislature rejects a rule, they send it back to the agency to be reworked.

A related claim was asserted by a general public representative from a Midwestern board, who insisted that the part-time citizen board is the only way to develop environmental regulation. "We are a conservative state; realistically there will never going to be money for a paid rule-making body." When asked about the possibility of delegating rulemaking authority to the full-time agency administrators, $\mathrm{s} /$ he said: "there would be a hue and cry in this state if we did that. The regulated community is very suspicious of [the state environmental agency]. They would rather the rules board be completely independent."

\section{Efficiency v. Transparency}

As one might expect, board members bristled at the criticism that their boards unnecessarily slow down then environmental policymaking process in their states. A few disputed the claim altogether. A board member from the Midwest reported that his/her board's timeliness is consistent with the rulemaking process prescribed the state's legislature in the Administrative Procedures Act (APA), and pointed out that barriers to efficiency are place on them by the state's legislature. S/he specifically noted on a couple 
of occasions during the interview that the APA requires extra steps in the rulemaking process that could be cut to promote efficiency. Others, like the Northwestern members cited above, insisted that they improve the process by cutting through some of the complexity, enhancing political feasibility, and reducing litigation.

However, most of the board members interviewed for this study challenged the legitimacy of efficiency as a desirable goal. Instead, most insisted that the process is necessarily slow in order to get it right. A Midwestern member said "rulemaking is a long process, but it should be slow to make sure the peoples' interests are represented. It's a pain in the butt, but I think it's there for a good reason." A Mid-Atlantic member acknowledged that it [the rulemaking process] is slower but delays are necessary for the kind of study these things require." S/he continued to say that "it is really important for the public to understand the issues, so it is worth taking the time on."

A Northwestern board member commented that "efficiency may be improved by a dictatorial system, but it is important to allow the public all the time it needs to make its points." He then added that a "public process enhances legitimacy," further speculating that the transparency gained by a public process has positive implications for long term policy viability. Not only does it enhance policy legitimacy among the public and stakeholders, in his/her view, but it also improves the likelihood the state's legislature will adopt the proposed changes.

According to a Southern board member, "the government process is inherently slow and in some instances for good cause to let the public process to completely unfold. Public involvement and vetting of issues is very important and thus I believe it does not unnecessarily slow the process down." Yet another board member agreed that the board 
process may delay environmental decision-making in his/her state, but also did not consider this a negative influence. S/he further argued that part of the reason for having a board is to ensure that proposed policies are subjected to a thorough review.

\section{Political Pressure}

The board structure is also believed to insulate members from political pressure from elected officials. When asked about their relationships with elected officials, the most common response indicated little to no contact or influence between boards and elected officials from either the executive or legislative branches. Several board members reported that representatives from the state legislature and governor's office occasionally make presentations at hearings or contact board members for information, but very few reported feeling pressured to vote one way or the other. When asked about the value his/her board adds to state environmental decision-making, a southwestern board member said "we are not necessarily beholden to anyone, we make decisions we feel are best for the people of [the state], outside of the political process." Some also noted that legislators often come down on multiple sides of an issue, and the body is thus not monolithic in terms of expectations. A rare exception, a citizen member representing the medical profession, expressed displeasure that legislators in his/her state lobby the board on behalf of industry constituents appealing enforcement actions, and speculated that some board members may be influenced by this pressure.

Most notably, the board structure appears effective in shielding board members from political influence from the executive branch. In contrast to single administrator agencies where agency executives are appointed by the governor, board members across the board reported little contact or influence from the governor's office. 
However, several board members acknowledged sensitivity to ex-ante and ex-post influence applied by state legislatures. They exert little influence during the rulemaking and implementation stages, but are extremely influential in both shaping the parameters of implementation and revising regulatory output they do not like. A Mid-Atlantic board said "most members are not beholden to political interests and work independently, but I'd like to see us have more independence. The legislature keeps a close eye on what we do, and can veto rules it doesn't like. The legislature makes our commission change more things than each of us would like." Two board members from a Western state pointed out, their legislature can (and does) influence board behavior by limiting their scope in targeted ways. This occurs preemptively, like through a state ban on regulations that are more stringent than federal standards and several additional specific limitations on scope and authority, and retroactively, as was the case when the legislature in this state overturned a ban on outdoor wood-burning boilers.

Evidence regarding the influence of (and on) ex-officio representatives is mixed. A board member from a Midwestern state complained that the four proxy members on his board always voted in a block and in favor of the agency position. S/he expressed concern that this compromises the board's independence by weighting board votes towards staff preferences. Others however, cite ex-officio staff as an important source of expertise. When asked about this, another member from this board partially corroborated this concern, stating: "Obviously they have a bias and I would expect they are expected to vote with the agency if there are disputes. However, I know there have been examples when the ex-officios have voted against agency wishes and passed more protective aspects of the rule." 
However, another non-ex-officio member of this board disputed this claim: "I do not think the ex-officio members lend a bias to the decision making process. Interestingly enough, our ex-o members rarely speak or ask questions at the meetings. That may be because our citizen members are very confident and not intimidated or threatened by them or their presence. I think the ex-o members do provide an administration perspective that the board would not have without them participating. Simply enough they have no effect on decision making." A citizen member from a Southern state with a significant ex-officio contingent observed that "state agency representatives understand legal and technical information and are harder to convince on something than civilian members." Others note that ex-officio members also come from diverse backgrounds like agriculture, natural resources, parks and recreation, and economic development, and bring perspective on how regulations will affect their program areas.

\section{Discussion and Conclusion}

This study adds to existing scholarly work by fleshing out some of the theoretical claims attributed to environmental boards specifically, and boards and commissions, more generally, to gain a better understanding of what they do in the modern environmental regulatory framework. Specifically of concern were three overarching questions: What value do environmental boards add to state environmental policy making, who benefits, and at what costs?

It is clear that most board members feel a fiduciary responsibility to exercise independent critical judgment, and seldom does the board appear to be merely an 
extraneous burden on already cumbersome regulatory processes, as is sometimes suggested. Many board members, indeed, consider themselves the primary decisionmakers on the agency level for areas within their scope.

Overwhelmingly, board members across the board cited their role in representing the public and facilitating dialogue about environmental problems and regulation as their most important contribution. Board members noted several positive implications of this public participation: It allows more direct public input into policy formulation, integrates a broader range of expertise, balances the needs of stakeholders, and promotes better staff work. In sum, board members viewed their role in large part as helping to legitimatize the input into environmental regulatory policy in order to produce viable, implementable, and less contentious regulation.

Board members also notably roundly rejected criticism of their capacity to keep up with the demands of regulatory issues. Most insisted that their boards contain a broad range of expertise and experience that can be applied to whatever issues they are confronted with, or at least have the capacity to develop the necessary expertise "on the fly" by asking the right questions. Members also almost unanimously disputed the notion that their board slows down the policy-making process. Most pointed out that the regulatory process is necessarily slow regardless of their contribution, and several pointed out externally imposed barriers to efficiency. Most also questioned whether efficiency should be an important goal, citing a greater need for maximizing public input and "getting it right." 
However, this study also offers reason to be concerned about the influence of resource bias by virtue of its dependence on public participation. While most board members noted the openness and transparency of environmental regulatory processes in their state, many also noted the presence of resource bias predicted by Rossi (1997), Mashaw (1980), and other skeptics of deliberative modes of governance. The interviews conducted for this study confirmed that barriers such as time, education, knowledge about the regulatory process, and financial resources, prevent many constituents from being full participants in the board process.

As a consequence, according to these board members, participation is often dominated by the same groups: those with the greatest incentive to participate. While in most instances, board members reported industry groups holding the advantage in terms of resources and participation, and others cited disproportionate representation from the environmental side, the general public was overwhelmingly identified as underrepresented in board deliberation, which may hold implications for policy outcomes.

I also investigated whether responses vary according to board type. While many board members noted that interest groups frequently dominate board proceedings, and several board members observed that some institutionalized stakeholder groups appear to be more organized than others, I found little evidence that board type predicts the quality of deliberation. Observations of resource bias came from every board type, indicating that this trend is at least identified with the participatory features of boards in general, if not the compositional distinctions among them. 
However, I did find individual level variation in perceptions about resource bias and participation. Particularly, Democrats and liberals were more likely to report the presence of resource bias in their state, while Republicans and conservatives were more likely to report a belief that interests are fairly balanced. Of the fourteen Democratic respondents, eight reported that better-resourced organizations are overrepresented in board deliberations and outcomes. In addition, five Democrats or liberal-leaning independents specifically identified business or industry groups as overrepresented in board deliberations, while eight expressed a belief that the general public is underrepresented. Conversely, only one Democratic board member expressed a belief that no one is consistently underrepresented or overrepresented in board deliberations in his/her state. Among the eleven Republicans and one conservative-leaning independent, five view their board's deliberative process as adequately balanced, four think the general public is underrepresented, one thinks the state's environmental agency is overrepresented, and one believes environmentalists are overrepresented. Only one identified business/industry interests as overrepresented in board deliberations.

Another notable observation that came out of this study is that members frequently viewed their role differently depending on board type. The members of stakeholder boards viewed their role as representing the interests of the constituencies they were chosen to represent, ex-officio and local government viewed their role as contributing expertise from their administrative perspectives, and unaffiliated board members most often reported a more holistic view of their role; a greater commitment to representing the state at large, rather than focusing on its component perspectives. A Midwestern board member acknowledged that "everybody represents a particular 
interest, which helps get non-participating groups involved." S/he also acknowledged that this changes the way members approach their role. Citing personal experience from serving on his/her board two different times representing two different constituency groups, $\mathrm{s} /$ he noted that his/her role changed from one appointment to the other as $\mathrm{s} / \mathrm{he}$ is now expected to approach his work from a different perspective.

Similarly, when asked about the board's dependence on the state's environmental agency for information, another Midwestern stakeholder board member insisted that "board members are going to listen to where their bread is buttered," suggesting that board members feel a strong sense of accountability to their constituency groups, While this may be deliberate in attempt to ensure that all interests are formally represented, the unaffiliated board members seemed to express a greater commitment to balancing the diverse needs of the state on the individual level, rather than trusting that the pluralist approach will yield the most equitable outcomes.

This is not to say that one is more effective or representative than the other, or even that this distinction is consistent across all policy boards; it is outside the scope of this chapter to answer these questions. Given the small sample size, it is difficult to identify systematic patterns, especially between board types.

This limitation is one of several imposed by the sample. Analysis is also challenged by the narrow sample. While it is useful for exploring board members' perceptions about their role in environmental policy-making in their states, it only presents one perspective. Other stakeholders may hold different assessments on their contributions, but these perceptions are unrepresented in the sample. Future research will 
enhance capacity to answer these questions and make other systematic comparisons by increasing the sample to include more and more representative board members, as well as other stakeholder perspectives such as agency staff and relevant public and private interest group representatives. The next chapter will take an additional step further by linking boards and their compositional types with environmental performance indicators. 


\section{Chapter Four}

\section{Environmental Boards and Environmental Outcomes}

\section{Introduction}

To briefly recap the project to this point, I have argued that agency structure has implications for environmental policy output. Particularly, I have endeavored to study the source and implications of the choice between single-administrator decision-making structures and part-time citizen boards. The analysis in Chapter 2 produced evidence that ideology and economic pressures significantly influence this choice; boards are more prevalent in states with ideologically conservative citizenry, Republican legislatures, and strong manufacturing industries. The latter is particularly correlated with likelihood of adopting boards that institutionalize stakeholder representation.

In Chapter 3, it was determined that boards are valued for their potential for inclusiveness. They are considered particularly well suited for incorporating public input into regulatory decisions, and ensuring thorough consideration of the impacts of proposed regulation. However, chapter 3 also provides reason for caution concerning their efficacy: while they offer the appearance of openness and transparency, they are also vulnerable to resource asymmetries that advantage certain stakeholders over others, and commonly underrepresent the general public.

Yet, it is not yet known whether these fundamental differences translate to empirically different environmental results. While other forms of collaborative governance like negotiated rulemaking and place-based public/private/non-profit stakeholder partnerships are gaining increasing attention and popularity as the next environmental regulatory paradigm, very little attention has been paid to the effects of 
environmental citizen boards, despite the fact that they are one of the oldest forms of collaborative governance.

This project attempts to fill this gap by examining the relationship between citizen boards and measures of environmental stringency. Questions sough to be answered here are: Does the board structure have implications for performance outcomes? Does board composition predict the outcomes produced? From the findings produced above, I argue that structure should matter as it is selected to produce certain outcomes.

However, it is unclear which direction the influence will take. One hypothesis argues that deliberative decision-making structures are better equipped to integrate multiple, varied perspectives and therefore enhances the probability of legitimate and successful policy outcomes. On the other hand, others claim that it produces inferior outcomes through weakened accountability and vulnerability to interest group influence.

\section{Regulatory Stringency}

A considerable amount of literature discusses the determinants of regulatory stringency. A significant initial strain argues that environmental stringency is a product of market competition that incentivizes policy-makers to make regulatory decisions on environmental protection along two parameters: economic development and quality of life for residents. This argument is rooted in the Tiebout model, which describes citizens as utility maximizing consumers that shop for the basket of goods that best matches their set of preferences (1956). According to the theory, this juxtaposition guides the “invisible hand" toward the most efficient mix of economic prosperity (capital) and environmental protection (taxes or standards) for each community. 
In the environmental context, therefore, regulatory stringency is thought to be a function of preferences along two parameters: capital stock and citizen's quality of life. The first pillar motivates policy-makers to base environmental policy decisions, in part, on their effect on the ability to attract and retain jobs and services for their community (Oates and Schwab 1998). This offers incentives to minimize compliance costs for the regulatory community. The second pillar adds an additional layer of competition that is supposed to balance the first; efforts to meet citizens' preferences for quality of life force jurisdictions to also consider quality of life issues, (e.g., public health), and set stringency levels - via standards, taxes, etc., that best reflect local preferences along these lines (Oates and Schwab 1988).

"Race to the bottom" theorists argue that policymakers are more responsive to economic motivations when establishing regulatory standard (List, McHone, and Milimet, 2003; Greenstone 2002). Greenstone (2002) is among many that have cited the negative impacts of environmental regulations on industry, a finding that has driven the assumptions about firm location decisions. This perspective argues that firms exploit variation among states to "shop" for the lowest regulatory burden when making siting decisions. States in turn, lower their stringency levels in order to compete for these firms on the basis that they will provide economic development. List, McHone, and Millimet (2003) found empirical support for this claim, noting that more stringent environmental regulations negatively influence plant location decisions.

Evidence concerning the direct influence of industry strength on regulatory stringency is mixed. Conventional wisdom argues that industry groups oppose stringent regulation because they must bear many of the costs directly (Wilson 1980; Hays, Esler, 
and Hays, 1996). However, empirical evidence is inconclusive. For instance, Ringquist (1993) has found that that states with powerful mining interests are more likely to produce less stringent water pollution regulations, but also that air pollution regulation tends to be more stringent in states with more economically important manufacturing sectors.

More recently, Potoski and Woods (2002) found that political context is an important determinant of stringency of ambient air quality standards. Industry group strength predicts a negative relationship with stringency, while public interest group membership appeared to have a positive effect in the absence of a strong industry presence. However, this dynamic did not hold for regulatory enforcement, where the authors found a positive relationship between regulatory industry strength and the number of monthly enforcement actions.

Konisky found further ambiguity regarding this question in his study of state level regulatory stringency (2007). He found a consistent negative relationship between manufacturing industry strength and number of enforcement actions related to the Clean Air Act, but found evidence of the opposite effect with Clean Water Act enforcements, and no apparent relationship when looking at Resource Recovery and Conservative Act enforcements.

Not surprising then, several scholars have challenged the "race to the bottom" theory. In an analysis of air quality regulation in the states, Potoski (2001) found no evidence that economic pressures are causing a race to the bottom in terms of regulatory stringency, but instead notes that many states choose to exceed standards prescribed by the US EPA. Vogel (1995) cited the "California effect" as an example where enhanced 
regulation can produce a "race to the top," as California catalyzed a national increase in emissions standards by implementing them on the state-level.

Others, like Konisky (2007) and Woods (2006) have found that, while environmental regulation is less important to site location than initially thought, states still behave as if they do. In a study of surface mining regulation, the latter found that states are responsive to regulatory stringency in other states, and adjust when they perceive their regulations are becoming comparatively more stringent than competitor states. Konisky (2007) found evidence that states are responsive to economic competitors in terms of regulatory stringency, but also found that states respond positively as well negatively. Specifically, he found that states also tend respond to increased regulatory stringency in competitor states with increases of their own.

Several state level economic and political conditions have also been found to influence regulatory stringency. Ideology and partisanship are commonly described as significant influences on regulatory stringency (Hays, Esler and Hays 1996; Hedge and Scicchitano 1993). Political ideology has been strongly linked to environmental attitudes and support for environmental regulation in general (Carley and Miller 2112; Dunlap 2008; Van Liere and Dunlap 1980), and several studies have observed elite and citizen ideology leading to more stringent regulation (Hays, Esler and Hays 1996; Hedge and Scicchitano 1993). Extant research is less conclusive concerning the influence of political party identification. While the expectations are that Democratic officials are more supportive of environmental regulation than Republicans, this is not readily apparent in state-level studies. Konisky (2007), for example, found that states with Democratic legislatures appeared to more stringently enforce Clean Air Act regulations, 
but also appeared less stringent for Clean Water Act and RCRA regulations. Findings concerning "Democratic Governor" were also inconclusive.

State-level individual and government economic conditions are also believed to influence environmental stringency and outcomes. State wealth, in terms of per capita wealth, and government resources are believed to influence regulatory stringency, as they, theoretically, affect demand for economic development and state government's capacity to implement and enforce environmental regulation, respectively. Research has commonly determined that commitment to environmental protection increases with per capita wealth (Ringquist 1993; Lowry 1992; Hays, Esler and Hays 1996), which seemingly supports the idea that government priorities shift according to per capita wealth.

Research on state government capacity is less clear; Woods (2009) found that legislative professionalism was associated with more stringent environmental programs, while Hays, Esler, and Hays (1996) found a negative, but insignificant, relationship between a state's debt burden and regulatory stringency.

\section{Regulatory Stringency and Agency Structure}

Scholars have also noted the salience of structure in agency design. To briefly summarize literature reviewed previously, a strong contingent view agency design as a collective choice process, in which policy makers attempt to design institutions to "steer" future policy outcomes towards their preferences (McCubbins et al 1989; Moe 1989; Holburn and Vanden Bergh 2006; De Figueiredo and Vanden Bergh 2004; Potoski 1999). 
According to this research, structure dictates who has access to the regulatory process, agency mission and discretion, and ultimately shapes agency output. Yet, little has been done to identify whether agency structure, particularly the delegation of oversight authority to citizen board or commission, has lasting effects on policy outcomes.

One objective of this chapter is to link these literatures to begin to identify whether the citizen board carry meaningful implications for state-level environmental performance. Relevant literature offers mixed guidance in terms of expectations. Coming mostly from case-study analyses, collaborative, participatory modes of environmental governance have been linked to increased opportunities for stakeholder input (Innes et al 2006; Koontz and Thomas 2006; Weber 1998), increased compliance rates (Rogers and Weber 2010; Newig and Fritsch 2009), and lower compliance costs (Harter 1982). These findings are grounded in the argument that the establishment of shared goals and frequent and ongoing interaction towards achieving these goals breaks down barriers between competing stakeholders, and thus produces more favorable outcomes for all involved. For example, in a case study of four "successful" public/private environmental collaborations, Rogers and Webber "find a series of positive steps toward sustainable communities that, although originally catalyzed by the demand for compliance with existing environmental mandates, move beyond compliance as stakeholders work collectively to integrate environmental, economic, and social/community needs into a sustainable whole $(2010 ; 550) . "$

However, while stakeholder engagement is touted is as a promising way to transform environmental regulation, empirical support for this claim is somewhat incomplete. Several studies also point out the pitfalls associated with collaborative 
approaches. In an Advocacy Coalition Framework guided analysis of a policy network based in the Lake Tahoe Basin, Weible and Sabatier (2009) highlighted the challenges inherent in the stakeholder bargaining model. Using questionnaire data collected in 1984 and 2001, the authors found evidence of some convergence on policy problems and proposals, but no more willingness to rely on empirical rather than normative beliefs. This, they assert, suggests that collaboration can move secondary beliefs, but is no more effective than the conventional paradigm in reconciling core values. This holds implications for the effectiveness of collaboration as a policy process - at least from the perspective of those supporting policy change - in that it supports the argument that collaborative processes tend toward the status quo.

Similarly, Lubell (2004) warns of the barriers that can block the path from collaborative intent to cooperative outcomes. In an empirical evaluation of participation in the National Estuary Program (NEP), an EPA-sponsored watershed management program that incentivizes local stakeholders to collaborate towards planning and implementing watershed management plans, Lubell found collaborative intent, but also found no difference in the levels of cooperation among NEP and non-NEP estuaries. While the stakeholders in NEP estuaries exhibited higher levels of consensus on collective action beliefs, this consensus did not translate into meaningful cooperation on policy outputs.

These findings are consistent with literature that describes co-option of stakeholder approaches as a form of "policy containment" strategy (Hoberg and Phillips 2011; Pralle 2006; Oliver 1991). According to Hoberg and Phillips (2011) analysis of Alberta's oil sands subsystem in the mid-2000s, when environment-based criticisms of 
oil shale mining emerged in the mid-2000s, the province of Alberta adopted several collaborative initiatives designed to incorporate external stakeholders into oil shale governance, rather than impose additional regulations. Stakeholders were asked to collaborate towards developing mutually acceptable environmental standards and practices. However, as the authors concluded, policy recommendations going against the oil shale industry were most often disregarded by the provincial government, and little changed in the distribution of power within the subsystem.

Other literatures take this criticism a step further, arguing that deliberative approaches open the door for improper influence from regulated interests. Beyond the weakened capacity for decisive decision-making, several researchers have argued that collegial mechanisms are more easily "captured." Bernstein (1955) argues that the structure of the Independent Regulatory Commission, particularly that providing for its independence, enables industry capture by insulating them from political influence while leaving them open to interest group pressures. Public land use planning policy serves as an example of how boards have been used to institutionalize economic interests in the policy making process. Championed by rancher-friendly, Western Congress members, The Taylor Grazing Act of 1934 created the United States Grazing Service (a division of the Department of Interior that ultimately merged into a new Bureau of Land Management), divided public range land into districts, and directed the Grazing Service to manage grazing rights in these districts in cooperation with local ranchers (Culhane 1981). District advisory boards - consisting of and appointed by range users -- were established to facilitate this cooperation, and were given broad authority in land-use permit allocation (to share with agency employed district managers). Their power was 
further enhanced in 1940, when Congress investigated and ultimately cut funding for the Grazing Service, which significantly hindered their management capacity.

As a result, for many years, grazing advisory boards dominated public land management subsystems, and were largely successful in resisting government efforts to increase grazing fees and reduce grazing levels (Culhane 1981; Foss 1960). Though the Grazing Committees were ultimately reigned in (Culhane 1981), and legislation was subsequently enacted to promote balance and transparency (Markham 1973), federal advisory committees in the BLM and other agencies were long after considered an important source of industry influence (Petracca 1994).

In his study of Public Utility Commissions in twelve states, Gormley (1983) also observed that regulated interests can be highly influential on commission proceedings. In nine of twelve states, Gormley found regulated utilities to be the most influential outside participants in commission proceedings. The author attributes this advantage to the leverage they enjoy as market monopolies and benefactors of large information and resource asymmetries. In sum, regulated utilities have the resources to maintain a strong presence in commission proceedings, and Commissions must rely heavily on utilityproduced information to inform decision-making. Furthermore, non-utility business groups were found to exert a "moderate" level of influence in ten of twelve states. However, Gormley is quick to warn that business interests are not always monolithic. While outside business interests may join utilities in opposing changing rate structures, they also often take an opposing position when their interests diverge. Conversely, Gormley (1983) found grass-roots advocates to be only moderately influential in six of 
twelve states, acknowledging that they are often limited by decisive resource disadvantages.

However, Gormley also found that "proxy advocacy," or the institutionalized presence of state government representatives (mostly the Attorney General or his/her representative), can provide an effective counterbalance to private interests. In all six states where they participate in PUC proceedings, proxy advocates were found to be either moderately or very influential in the regulatory process. However, Gormley also found that proxy advocates are reluctant to take a stand on issues with high levels of conflict and complexity (e.g., rate structure reform), thus reducing their influence where it is perhaps needed most.

In summary, the conventional environmental regulatory paradigm has drawn criticism for being inefficient, inherently confrontational and decreasingly effectively in the face of second and third order environmental problems (Ringquist 1993). These criticisms have led to experimentation with collaborative, stakeholder-focused governance strategies. The part-time citizen board is one tool some states have used to accomplish this end, seeking to promote efficiency, fairness, and balance in environmental regulatory processes (http://www.ipcb.state.il.us).

Despite being one of the oldest forms of collaborative governance, very little more than a few case studies have studied their performance. While some literature argues that this type of deliberative regulatory process shows promise for generating more legitimate and effective outputs, others identify significant barriers between 
collaborative processes and productive outcomes. I believe that the bulk of the literature falls in this latter category and suggests that:

H1: The board structure impedes effective and decisive decision-making by weakening accountability, dividing authority, and making the policy process more vulnerable to interest group influence. Therefore, states in which boards are active in environmental decision-making are expected to have weaker environmental records than states where decision-making authority is vested with a single administrator.

H2: Environmental regulatory boards that institutionalize stakeholder participation are vulnerable to capture and should, therefore, be more likely than non-stakeholder boards to produce a regulatory environment that is more favorable to regulated interests.

H3: State government representation has been observed to balance private interests in regulatory subsystems, and further enhance regulatory policy-making by contributing administrative expertise. Therefore, I expect states with environmental boards on which ex-officio representation constitutes a majority of membership to perform better on environmental performance metrics than states with citizen or stakeholder boards.

Data and Measures

The objective of this chapter is to evaluate the impact environmental boards have on state-level environmental outcomes. Since there is very little existing data that can measure board output, or otherwise captures what occurs in the "black box" of environmental decision-making, data were collected from multiple sources in hopes of triangulating a better understanding of boards' role(s). To analyze these data, I estimate a random-effects, cross-sectional time-series model, which, in conjunction with a number 
of important control variables, allows me to assess associations between boards and environmental outcomes compared to states without boards. The models discussed below also correct for diagnosed first-order autocorrelation in the dependent variable.

\section{Dependent Variable}

The first outcome variable is the Levinson index, a popular measure of environmental stringency collected between 1977 and 1994 (Keller and Levinson 2002; Fredriksson et al 2003; Millimet and Slottje 2002). Based on the premise that abatement costs correlate highly with regulatory expectations (Levinson 2001), Levinson's measure is a ratio of actual compliance costs to predicted costs (national industry average) based on the types of industries within the given state. Measured against a national average compliance cost figure, the index is greater than 1 if manufacturers in the state spend more on pollution abatement than predicted. These higher values suggest greater regulatory stringency within a state. Low values, conversely, indicate less stringency.

The next set of outcome variables also attempt to measure regulatory stringency on the state-level. While the states are inconsistent in terms of data availability and accessibility, especially going back in time, the EPA started aggregating and publishing environmental data early in the development of environmental regulation as a significant policy area. Therefore, much of the data used to construct this outcome variable comes EPA's Integrated Data for Enforcement Analysis database, which is an aggregation of several smaller databases like ICIS-FE\&C, the Permit Compliance System (PCS), the Toxic Release Inventory, and Air Facility System (AFS). 
Specifically, I use Konisky's measure of state-level enforcement effort that uses two indicators: 1) an annual number of state inspections for the Clean Air Act, and 2) an unweighted sum of formal and informal enforcements for these programs $(2007 ; 2009$; Konisky and Woods 20011). Both are collected for 1985-2000, and are standardized by the number of manufacturing establishments in the states. The suitability of this variable is based upon the premise that these measures of inspection and enforcement intensity, respectively, reflect the level of regulatory rigor in the given states.

\section{Explanatory Variables}

The key independent variable in this study is the presence and type of environmental policymaking boards in the states. While I am interested in their overall effects, I am particularly interested in the implications of compositional differences among them. The first source of variation is the formal power that the board has over environmental policymaking. I focus here on boards that are legislatively empowered to participate in standard setting and rulemaking in their respective states. At current count, boards in twenty-two states have significant authority in rulemaking and standard setting over the full range of program areas, and ten states delegate this authority to boards to media-specific boards.

The second key source of variation arises from legislatively mandated participation requirements. For example, Oklahoma requires that their Department of Environmental Quality board include representatives from the manufacturing, agriculture, and mining industries, as well representatives from local government, environmental groups, and the general public (http://www.deq.state.ok.us). Alternatively, the board in 
Mississippi is an example of a "citizen" board; they are unpaid, and only require that one member be drawn from each of the five congressional districts, along with two at large members. A third board design, such as Pennsylvania's Environmental Quality Board, emphasizes interagency collaboration and requires membership by representatives from multiple state agencies. The PA EQB consists of twenty members: eleven represent various state agencies including the Departments of Environmental Protection (Chair), Agriculture, Health, and Community and Economic Development, five are members of the Citizens Advisory Council, and four members come from the state's Senate and House of Representatives.

Table 4.1 - Summary Statistics

\begin{tabular}{lrrrrr}
\hline \multicolumn{1}{l}{$\begin{array}{l}\text { Observatio } \\
\text { Variable }\end{array}$} & \multicolumn{2}{l}{ Std. } & \multicolumn{2}{l}{ Min } \\
\hline Levinson Index & & \multicolumn{1}{l}{ Dev. } & \multicolumn{1}{l}{ Max } \\
State Enforcements & 864 & 1.02 & 0.37 & 0.23 & 2.59 \\
Standardized & & & & & \\
State Inspections Standardized & 760 & 0.02 & 0.02 & 0 & 0.15 \\
Citizen & 760 & 0.13 & 0.12 & 0 & .69 \\
Stakeholder Board & 1450 & 0.22 & 0.43 & 0 & 1 \\
Professional Board & 1450 & 0.32 & 0.47 & 0 & 1 \\
Ex-Officio Board & 1450 & 0.48 & 0.22 & 0 & 1 \\
State Total Expenditures Per & 1450 & 0.09 & 0.29 & 0 & 1 \\
Capita & & & & & \\
Manufacturing & 1450 & 4.32 & 1.84 & 1.95 & 18.84 \\
& 1450 & 0.17 & 0.08 & 0.02 & 0.38 \\
PCI & & & & 18.53 & \\
Citizen Ideology & 1450 & 31.15 & 6.08 & 1 & 53.74 \\
Government Ideology & 1450 & 47.55 & 15.33 & 8.45 & 95.97 \\
Population & 1450 & 49.37 & 23.55 & 0 & 97.92 \\
Governor Party & & 5101.3 & 553742 & 39736 & $3.58 \mathrm{e}$ \\
CAA 1990 & 1450 & 8 & 3 & 3 & +07 \\
South & 1450 & 0.55 & 0.52 & 0 & 1 \\
\hline
\end{tabular}


In order to capture these criteria, I created three dichotomous variables to measure environmental boards. "Citizen boards" are defined as policy-making panels that serve part-time, are minimally compensated, and have no representation requirements.

"Stakeholder boards" are those that have rulemaking/oversight authority, and do mandate stakeholder participation in the form of designated seats for particular constituencies. "Ex-officio boards" are those on which a majority of members are appointed to represent various state agencies. Finally, I also distinguish "professional boards," where board members draw a salary for their service. In each case, a dummy variable is created where "1" indicates category membership. The excluded category consists of states with boards that do not have formal standard setting or rulemaking authority and states with no board.

\section{Control Variables}

Compliance with environmental regulations and enforcement efforts can also be influenced by a multitude of factors other than environmental board presence. Therefore, the models also include numerous variables designed to capture these alternative explanations and reduce omitted variable bias.

First, I control for statutory changes during the frame of study. During our time frame, The Clean Air Act amendments of 1990 significantly enhanced the number of included toxins and penalties associated with the National Ambient Air Quality Standards (O’Leary 1993). Such statutory changes should be expected to cause changes in regulatory stringency, and I attempt to control for this by creating a dummy variable that is coded as "0" before 1990, and " 1 " thereafter. 
There are also several economic factors that also may affect environmental regulatory policy design and implementation. First, the relationship between manufacturing industry strength is estimated with a measure of the percent of Gross State Product produced by the manufacturing sector in a state, assuming that states with strong manufacturing sectors may design and enforce regulations less stringently than those with less manufacturing. These data were acquired from the Bureau of Economic Analysis' Regional Economic Accounts, and reflect their value in 2010 U.S. dollars.

State economic conditions can also influence political pressures on state officials to increase or decrease regulatory stringency. Regulators in states with poorer economic conditions may face pressure to relax environmental enforcement effort if citizens believe doing so will increase employment and economic prosperity (Konisky 2007; Woods 2006). Personal Per Capita Income is also included as a measure of economic conditions. Per Capita Income data also come from the Bureau of Economic Analysis, and were originally derived from Bureau of Labor Statistics' Quarterly Census of Employment and Wages. PCI is reported in 2010 dollars.

Regulatory effort can also be influenced by state and national political pressures. Ideology and partisanship are potentially significant influences on regulatory stringency (Konisky 2007; Potoski 2007; Woods 2006). Liberals are widely considered to be more pro-environment, while conservatives are considered more pro-business and opposed to regulation, a combination that contributes to a strong aversion environmental regulation (Boyd 1999; Vig and Kraft 1997 Dunlap 1975). To measure state ideology, I employ the Berry et al (2006) citizen ideology measures. The citizen measure is an average of congressional district ideology scores that aggregate the ideologies of congressional 
incumbents and their most recent challengers. On this index, "liberal" is the high value. I also include a variable identifying the governor's political party affiliation. Democrats are coded as " 1 ," while non-Democrats are coded as " 0. ."

State institutional capacity has also been linked environmental outcomes, as states with greater capacity are more likely to enact stronger environmental programs (Konisky and Woods 2011; Woods 2009). To approximate state government capacity I use a measure of state government spending per capita. These data were collected from U.S. Census Bureau's Annual Survey of State Government Finances and Census of Governments, and are reported in thousands of 2010 dollars. I also include state population to further approximate environmental demand, and this is reported in thousands of residents. Finally, since partisan identification has been observed to carry different meaning in the South, I control for this region in order to minimize misinterpretation. To this end, a binary indicator reflects whether states fall within the South region, as defined by the US Census Bureau.

Results

Table 4.2 Environmental Boards and the Levinson Index

(1)

VARIABLES

Lagged (Previous Year) Levinson

Citizen Non-stakeholder Board

Stakeholder Board
(2) Levinson

$0.63 * * *$ $(0.03)$ $0.12^{* * *}$ $0.05^{*}$ (0.03) 
$\begin{array}{lr}\text { Professional Board } & 0.02\end{array}$

$\begin{array}{ll}\text { Ex-officio Board } & -0.04 \\ & (0.04)\end{array}$

Total State Expenditures Per Capita (1000s) $\quad 0.02 \quad 0.03 *$

$\begin{array}{lll}-0.28 & (0.15) & (0.16)\end{array}$

Per Capita Income (1000s) $\quad-0.00^{* * *} \quad-0.00^{* *}$

$\begin{array}{lcc}\text { Citizen Ideology } & 0.00 & 0.00\end{array}$

$\begin{array}{lll}0.00) & (0.00) \\ & -0.01 & -0.01\end{array}$

$\begin{array}{lll}\text { Governor Party } & -0.01 & -0.01\end{array}$

CAA Amendments of $1990 \quad(0.02) \quad(0.02)$

CAA Amendments of $1990 \quad-0.01 \quad-0.02$

$\begin{array}{lcc} & (0.02) & (0.02) \\ \text { South } & 0.06^{* *} & 0.07 * *\end{array}$

Board $\quad(0.03) \quad(0.03)$

Board 0.02

$(0.03)$

$\begin{array}{lll}\text { Constant } & 0.50^{* * *} & 0.46^{* * *}\end{array}$

$(0.11) \quad(0.10)$

$\begin{array}{lcc}\text { Observations } & 816 & 816\end{array}$

$\begin{array}{lll}\text { Number of states } & 48 & 48\end{array}$

Standard errors in parentheses

$* * * \mathrm{p}<0.01, * * \mathrm{p}<0.05, * \mathrm{p}<0.1$

The results from the analyses using the Levinson stringency index, which measures actual against expected compliance costs, are reported in table 4.2. Looking first at model 1, I find that the lagged value of the dependent variable, the previous year's stringency score, proves to be the most significant predictor of regulatory stringency, as expected, with a coefficient of .66. To put this in perspective for the standardized dependent variable, this represents a correlation of about 1.8 standard deviations. Manufacturing as a percentage of Gross State Product is also found to correlate significantly with regulatory stringency. A coefficient of -.28 indicates a negative relationship between manufacturing GSP and the ratio of actual to expected compliance 
costs. Specifically, this suggests that compliance costs are lower than the national average when the manufacturing sector is more important to the state's economy. Similarly, per capita income is also inversely related to this compliance cost ratio at a rate of .01. These findings contradict those associating higher average incomes with greater demand for environmental quality (Grossman and Krueger 1995). Also, surprising, are findings for citizen ideology. While these are frequently found to influence environmental effort, this study shows very little effect on any of the stringency measures. Last among the control variables, "South" is also significant in Model 1, suggesting that Southern states experience higher than average compliance costs.

Looking now at the variable of interest, I find that "board" has no statistically discernible relationship with the Levinson index. This suggests that, when measured as a group, boards do not produce a discernible difference in terms of regulatory stringency.

However, when looking at board types, I find significant variation in terms of correlation with the dependent variable. Most notably, I find that citizen boards without constituency requirements are positively linked with a slight but significant increase (.10) in regulatory stringency over the comparison models, including single-administrator agencies. I did not find significant results among the other board types. Although, especially given the sample size, it might be worth noting for future exploration that the findings for stakeholder boards (positive) and ex-officio boards (negative) approach significance (.14 and .22 , respectively) suggesting these membership requirements may also have an effect.

The results from the standardized state enforcement models are presented in table 4.4. In As in the first table, model 1 presents the comparison of boards with single 
administrator agencies, while Model 2 categorizes boards by compositional type. Again, the previous year's enforcement level is by far the best predictor of state-level enforcement, with a coefficient of .59. Again, this equates to an impact of roughly 31 standard deviations of the dependent variable. However, unlike the first set of models, total state expenditures per capita is also found to correlate positively with this measure of regulatory stringency (.003), suggesting that state enforcement levels are higher among state governments that expend more resources.

Table 4-3 Boards and Enforcement Intensity Air Enforcements

Citizen Non-Stakeholder Board

Stakeholder

Professional

Ex-officio Board

Total State Expenditures Per Capita (1000s)

Manufacturing Percentage of GSP

Per Capita Income

Citizen Ideology

Population

Governors Party

Clean Air Act Amendments 1990

South
(1)

$0.59 * * *$

(0.03)

(2)

Air Enforcements

$0.61 * * *$

$(0.03)$

0.00

$(0.00)$

0.00

$(0.00)$

0.00

$(0.00)$

0.00

$(0.00)$

$0.002 * * *$

$(0.00)$

$-0.01$

$(0.01)$

0.00

$(0.00)$

$-0.00$

$(0.00)$

$-0.00 *$

$(0.00)$

0.00

$(0.00)$

0.00

$0.002 * *$

(0.00)

$-0.01$

$(0.01)$

0.00

$(0.00)$

$-0.00$

(0.00)

$-0.00$

(0.00)

0.00

(0.00)

(0.00)

0.00

$(0.00)$

0.00

0.00

(0.00) 
$\begin{array}{ll}\text { Board } & 0.00\end{array}$

$(0.00)$

Constant $\quad-0.00$

0.00

$(0.01)$

Observations

720

720

Number of states

48

48

Standard errors in parentheses

$* * * \mathrm{p}<0.01, * * \mathrm{p}<0.05,{ }^{*} \mathrm{p}<0.1$

The "board" variable also performed similarly in this set of models: the structural form in itself appears to have little impact on enforcement intensity in the states.

However, unlike the Levinson measure of stringency, board type also appears to have little effect on enforcement rigor. Again, besides the previous year's enforcement level, state expenditures were the largest predictor in the model.

Table 4.4 reports results from the standardized state inspections models. Again, the previous years' number of inspections predictably outperformed other predictors with a coefficient of .86. "South" is also significant and positive, indicating that Southern states inspect their CAA regulated facilities at a slightly higher rate than non-Southern states. Looking at the variables of interest, "board" and the board types again fail to reach statistical significance, preventing meaningful interpretation of their coefficients.

Table 4-4. Boards and Inspection Intensity

(1) Air Inspections

$0.84 * * *$

(0.02)
(2)

Air Inspections

$0.84 * * *$

(0.02)

$-0.00$

$(0.01)$

0.00 
$\begin{array}{lcc} & & (0.01) \\ \text { Professional Board } & & 0.01 \\ \text { Ex-officio Board } & & 0.02) \\ & & 0.01 \\ \text { Total State Expenditures (1000s) } & 0.01) \\ & & 0.00 \\ \text { Manufacturing Percentage GSP } & (0.00) & (0.00) \\ & 0.00 & 0.00 \\ \text { Per Capita Income } & (0.04) & (0.04) \\ \text { Citizen Ideology } & -0.00 & -0.00 \\ & (0.00) & (0.00) \\ \text { Population (1000) } & -0.00 & -0.00^{*} \\ & (0.00) & (0.00) \\ \text { Governors Party } & -0.00^{* *} & -0.00^{*} \\ & (0.00) & (0.00) \\ \text { CAA Amendments } 1990 & 0.00 & 0.00 \\ & (0.00) & (0.00) \\ \text { South } & 0.00 & 0.00 \\ & (0.01) & (0.01) \\ \text { Board } & 0.02^{* * *} & 0.02^{* * *} \\ \text { Constant } & (0.01) & (0.01) \\ & 0.00 & \\ \text { Observations } & (0.01) & 0.03 \\ \text { Number of States } & 0.03 & (0.02) \\ \text { Standard } & (0.02) & 720 \\ \end{array}$

Standard errors in parentheses

$* * * \mathrm{p}<0.01, * * \mathrm{p}<0.05, * \mathrm{p}<0.1$

\section{Discussion and Conclusion}

Boards and commissions, and stakeholder bargaining approaches to environmental regulation more broadly, has been the subject of much discussion regarding their strengths and weakness. Whereas proponents view this structure as way to balance competing interests, critics view it as a threat to effective policy-making. The multi-member structure is believed to weaken policy output by requiring multiple points of agreement, and is furthered argued to favor the status quo, especially when industry representation is formally institutionalized in board composition. This study attempts to 
fill this gap by studying the relationships, if any, between boards and several metrics used to evaluate environmental but rarely of empirical tests of their implications for environmental outcomes.

To validate criticisms, we would expect to see systematic and substantive differences in the environmental performance of states with boards vs. states without boards. In the comparison of management structures, I found marginal significance in only one of my models, hardly the "smoking gun" needed to justify these concerns. The only conclusion that can be drawn from these data is that the board structure in itself is not systematically related to regulatory stringency as measured by compliance costs and enforcement effort.

When boards were categorized and analyzed according to their composition types, the data show some indication that composition matters. In the Levinson model, citizen boards without stakeholder representation requirements appear to positively correlate with regulatory stringency. If stringency is the goal, one could conclude from this finding that this type of board has a positive impact on environmental performance. Of course, environmental policy is more complex than this conclusion allows, and there is far from consensus that stringency is an appropriate primary goal. However, this finding does contradict claims that non-expert boards are vulnerable to industry influence by estimating that expected compliance costs are greater, not less, in states where environmental regulatory policy is overseen by citizen boards.

The models utilizing the second and third measures of regulatory stringency, standardized state inspections and enforcements, did not confirm these results, which 
provides some reason for caution in their interpretation. However, I expect boards are more influential in the policy formulation stage, e.g, development of rules and standards than in their implementation and enforcement, which might explain this discrepancy. 


\section{Chapter 5}

\section{Conclusion}

The part-time citizen board was born out of a desire to regulate complex public policy issues through independent, objective, and representative institutions.

"Legislating" administrative rulemaking through part-time "citizen" boards was believed to protect rulemaking from undue influence from both regulated industries interested in minimizing their regulatory burden and overzealous bureaucrats with incentive to "overregulate." Instead, boards and commissions were viewed as a way to produce rational, balanced, and representative decisions on policy output. This form of governance was heavily utilized at the outset of the modern era of environmental regulation, and continues to maintain a strong presence in thirty-two states.

Demand for environmental regulation - and consequently state-level administrative capacity to address it -- has grown since the first environmental regulatory boards were implemented over fifty years ago, as has the popularity of participatory environmental governance strategies. Therefore, a primary emphasis of this project is to identify the role, if any, these institutions fulfill in the modern environmental governance paradigm, and whether their long experience as a deliberative governance body can offer insight into the efficacy of participatory strategies. To this end, I sought to answer three fundamental questions: Why are they formed? What are their contributions to contemporary environmental policy-making? And what are their implications for environmental outcomes?

In Chapter 2, I used Event History Analysis to study political and economic conditions surrounding regulatory agency design choices. From this analysis came two 
major findings: first, I found that, across the board, citizen ideology is a significant predictor of agency structure. Liberal states appear significantly more likely to prefer single-headed environmental agencies, and less likely to favor stakeholder, professional, or ex-officio boards.

I also found that that stakeholder boards are more likely in states where valueadded by manufacturing is higher, i.e., where their economic impact is greater. This suggests that lawmakers in these states are sensitive to the economic impacts of regulation, and prefer regulatory mechanisms that identify and incorporate societal effects into the decision-making calculus.

Taken together, these two findings suggest that states with more liberal citizenry are more comfortable with centralized environmental decision-making, while states with more conservative citizenry and/or economic prospects tied to regulated industries prefer to "check" agency expertise with quasi-external, citizen boards, particularly those granting input to affected stakeholder groups.

In the bigger picture, given what we know about liberals, conservatives, and business interests, it would appear this difference in preference for environmental policymaking boards is guided by variation in concern for the competing values that enter environmental policy decisions. On one hand, Liberals favor both centralized governance and enhanced environmental protection, both of which are more compatible with concentrated, expert-driven agency decision-making. Conversely, Conservatives are associated with preferences for less and decentralized government, enhanced sympathy for economic interests and less environmental concern and regulated industries bear most 
of the costs of regulation; both sets of interests are more compatible with the regulatory model that is more equipped to incorporate competing values.

Chapter Three explores theoretical claims made here and elsewhere concerning citizen boards through semi-structured interviews with current board members in several states. In accordance with proponents of participatory governance, most board members interviewed believe that the citizen board is the most appropriate form for governance of potentially intrusive regulation. This was commonly viewed as necessary to "vet" regulation and technical information produced by agency staff through the perspective of the general public, designated constituency, and/or field of expertise.

In chapter four, I attempted to test empirical implications of environmental policy boards by estimating their effects on three measures of environmental stringency of environmental stringency. Chapters 2 and 3, supplemented by existing literature helped shape expectations that citizen boards, by virtue of this commitment to balancing costs and benefits of regulation and other associated inefficiencies such as wasted staff time and inadequate expertise, would produce less stringent regulation, a competing theoretical story predicts a positive impact as a product of more thoughtful and deliberative decision-making.

In the models predicting regulatory stringency via the Levinson Index of actual to expected compliance costs, I find evidence of a significant positive relationship between citizen boards with no constituency representation requirements, but no discernible distinctions among the other board types. This suggests that boards can make a difference, but not in the expected direction. These findings instead imply that citizen 
boards without constituency requirements are capable of producing regulation that is relatively more stringent in terms of compliance costs.

\section{Implications}

These findings make significant contributions in several ways. First it begins to explore the role(s) and implication(s) of a prominent, but understudied, institution.

Scholars have debated the efficacy of the modern environmental regulatory paradigm and the value of participatory strategies, but few have tried to measure the contributions of environmental boards, which have connections to both worlds. Second, it adds depth to the deliberative governance literature by highlighting their role in facilitating participatory governance, and evaluating their impact on policy process and outcomes.

In the first two chapters, I attempt to identify the bases of preferences for the parttime board over the single-headed agency, and whether these preferences are justified in current policy output. To this point, it has been established that conservative ideology and manufacturing industry strength are strong predictors of agency structure, especially those that enable direct input from stakeholders. At least in the former case, this may be partially due to preferences regarding the role and power of government, but in both cases it is also likely due to stronger sensitivity to the costs of regulation via economic and other non-environmental impacts on society. Citizen boards, through appointment of members with diverse, relevant expertise are expected to evaluate proposed rules and/or other agency action through these various lenses, and identify their implications, where applicable, from these perspectives. In short, they are valued, in no small part, because they provide opportunity for pluralistic valuation of competing interests. 
Chapter 3 provides evidence that these expectations have largely been fulfilled. Board members overwhelmingly view their most important role as representing the public interest(s) (and to a lesser extent facilitating public input) in environmental policymaking. Whether actively engaged in policy-making or in more of an oversight role, board members view themselves as arbiters of competing interests. In some cases this entails direct and deliberate representation of designated stakeholder constituency groups, but in almost all cases this involves attempting to balance the various impacts on society. In sum, the board member interviews confirm expectations regarding their role by revealing a sense of responsibility to weigh these impacts and produce fair and representative regulation.

However, the board member interviews also noted several barriers to equal participation. First, the issues are frequently complex. Participation requires knowledge of process and subject-matter, which discourages the casual observer. Special interest groups have time, resources, and access to expertise that allows them to monitor and participate in the public policy process with greater ease and consistency. Second, special interests have the resources to provide information concerning agenda items. Several board members reported that the briefing materials they receive come from either agency staff or the regulated community. In some cases, resources also provide access to the board agenda, as standing to petition for rulemaking is determined by the petitioner's ability to pay the costs associated with the petition's review. Finally, board members also reported logistical barriers that limit ability to participate. Several states hold meetings in one location, normally the state capital, which makes participation more difficult for residents and board members in different parts of the state. In addition, 
meetings commonly take place over two day, further increasing the transaction costs of participation.

This study also provides some support for concerns about reliance on external sources for information. While some board members reported some initiative to research the issues in front of them, many acknowledged relying on briefings provided by environmental agency staff, as well as other stakeholder groups. Some members acknowledged that issue complexity and time constraints challenge their ability to independently gather and process information, and expressed want for independent legal, technical, and/or legal support. Most, however, reported trust in agency staff interest groups, and other board information to provide the necessary information and expertise, and member initiative to exercise independent critical thought.

As a consequence, I also find evidence of vulnerability to resource bias predicted by relevant literature. Board members commonly insisted that they provide opportunity for equal input, but also acknowledge that participation is commonly dominated by special interest groups, as they possess superior resources and consistent interest in participation. In most cases, business interest groups were perceived as overrepresented in board proceedings, as they are widely considered to hold a big advantage in terms of their capacity to remain engaged by monitoring board deliberations, lobbying between meetings, and producing briefing materials, etc. However, public interest advocacy groups were also cited as influential for their ability to galvanize media and the general public on certain issues. 
According to many board members, the general public is the most underrepresented in board deliberations. The general consensus is that while the general public is influential when they participate, it is hard to keep them interested, and they only get involved in a significant way if a problem becomes bad or controversial. As a consequence, the policy process model designed to channel public participation into policy-making is instead dependent on interest groups to represent the various interests and part-time board members to aggregate these interests to form representative public policy.

Another primary goal of this study was to identify the implication, if any, of composition differences between board types. To this end, I did find some indication composition matters. As previously noted, in chapter two I found that manufacturing industry strength significantly predicts a preference for stakeholder boards, presumably to institutionalize their representation in the policy process. As I have also previously mentioned, board members appear to view their roles differently depending on board type and individual role. Particularly, members from stakeholder boards viewed their individual role as representing their constituency group, ex-officio members considered themselves to be a source of administrative expertise, while non-affiliated members portrayed themselves as representing a more generalized notion of the state's best interests.

Chapter Four attempted to measure the implications of these distinctions in composition. While I found a significant distinction between unaffiliated boards and the other types, these findings did not extend to the enforcement or inspection-intensity models. Although these are compliance-related measures and thus tied to stringency, 
these activities are carried out by agency staff, which is only loosely accountable to rulemakers at this stage. It may then make sense that I find a weak connection between boards and enforcement-level indicators if their impacts are more significant elsewhere in the policy process. With respect to this stage in the policy process, it might be more instructive to examine administrative appeals of enforcement actions to determine whether boards influence outcomes at this juncture.

\section{Study Limitations}

The present study contains several additional limitations that challenge interpretation. Starting with Chapter 2, the primary weakness in the section is that the research design cannot account for "path dependence." In other words, agency reorganization decisions are influenced by previous reorganization decisions; states are more likely to make incremental changes than radical departures (Lindblom 1979). In addition, the small sample size (made smaller by the need to exclude Nebraska and its officially non-partisan legislature) limits the amount of significant results.

Sample size also presents a challenge in Chapter 3. Given the small sample size, it is difficult to identify systematic patterns in board member responses, especially among board types. Interpretation of results from this chapter is also challenged by the study's narrow sample. While instructive, presenting only board members' perceptions about their role in environmental policy-making offers only one perspective. Other stakeholders may hold different assessments of their role, but these perceptions are unrepresented in the sample. This introduces significant potential for biased results. 
As noted above, timing of board adoption and available data limits the selection of analytic methods suitable for the outcomes analysis presented in Chapter Four. While a fix-effects model would have more rigorous for its ability to control for state-level unobservable characteristics that do not vary over time, several boards were adopted before the required time-frame which precludes identifying within-state variation. As a consequence of being forced to use a random-effects model, the analysis is that much more vulnerable to omitted variable bias due to unmeasurable state-level characteristics. By including year dummy variables and several theoretically relevant control variables, it is hoped that omitted variable bias is minimal.

Second, the sources for these sections are admittedly not ideal for isolating board effects on environmental outcomes. While I can argue that citizens boards, as principal environmental decision-makers in their states, positively influence outcomes through rules and other regulatory decisions that they make, state-environmental policy-making is complicated, and the mechanism for this influence remains somewhat unclear.

\section{Future Research}

Therefore, future research will attempt to fill in the gaps by delving into the products of interaction between board members, agency staff, and stakeholders. The interviews in Chapter 3 revealed that, on average, queried board members believed they make significant modifications to approximately $10-15$ percent of proposed rules that come before them. Of course, this reportedly varies from as little as 5 percent to as much as 40 percent. An appropriate research question, therefore, might ask about the nature and impacts of these changes; are there systematic patterns in the types of changes 
requested? Who, if anyone, do they benefit? Can voting patterns be linked to the preferences of appointing political principals? Can these be predicted by board type? This type of study will entail reviewing board meeting materials to evaluate board vote outcomes and comments made by members.

An additional research project will assess quasi-judicial activities performed by boards in a similar fashion. Enforcement appeal briefs over time will be analyzed to identify whether systematic patterns emerge from board intervention in state enforcement decisions. Again, I am interested in determining whether boards systematically produce certain outcomes, whether they consistently benefit certain groups disproportionately, and whether their outcomes can be predicted by compositional features.

I also plan to expand the scope and sample of the interview protocol used to acquire data in Chapter 3 to gain additional leverage on the questions posed within. First, more board members will be added from more states to enhance confidence in results and likelihood of identifying systematic variation. Particular effort will be made to balance the sample on the basis of compositional type and individual expertise/constituency.

In addition, the sample will also be expanded to include additional stakeholders in the processes in which boards participate. These include agency staff and public and private interest groups that regularly participate in board affairs. These sub-populations will be queried to test the validity of claims made by board members, as well as gain a better understanding of their perspective on interaction with the board, their perceptions about boards' effectiveness in managing environmental policy, and particularly in the 
case of agency staff, the demands placed on them in terms of supporting the board and preparing for meetings.

Over the years, environmental scholars have debated the merits of collaborative environmental policy-making. Studying this in the context of citizen environmental boards, this study finds support for many of the benefits claimed by advocates of citizen boards and participatory modes of governance, but also reminds us of the pitfalls associated with the pluralist governance model. In a governance model that emphasizes participation, it is not enough to provide opportunity for participation, policy-makers also must also identify and minimize, to the extent possible, barriers to participation by underrepresented parties. Further research could go a long way toward accomplishing this goal by further identifying the factors and institutions that best promote balanced representation. 


\section{References}

Agranoff, R. (2007). Managing within networks: Adding value to public organizations Georgetown University Press: Washington, DC.

Alushin, M. S. (1991). Enforcement of the Clean Air Act Amendments of 1990. Environmental Law Journal, 21, 2217.

Ansell, C., and Gash, A. (2008). Collaborative governance in theory and practice. Journal of Public Administration Research and Theory, 18(4),543-71.

Archibald, KA. (1970). Three views of the expert's role in policy-making: Systems analysis, incrementalism, and the clinical approach." Policy Sciences, 1(1), 73-86.

Alter, C. \& Hage, J. (1993). Organizations working together. Newbury Park, CA: Sage.

Bacot A. H., and Dawes, R. A. (1997). State expenditures and policy outcomes in environmental program management." Policy Studies Journal, 25,355-370

Barkow, R. E. (2010) Insulating agencies: Avoiding capture through institutional design. New York University Public Law and Legal Theory Working Papers. Paper 240. http://lsr.nellco.org/nyu_plltwp/240

Bates, R. P. (2005) "Congressional authority to require state adoption of independent redistricting commissions.” Duke Law Journal, 55:.333 - 372 .

Bernstein, M. (1955). Regulating business by independent commission. Princeton: Princeton University Press. 
Bendor, J. and Moe, T. M. (1985) An adaptive model of bureaucratic politics. The American Political Science Review, 79(3), 755-774.

Bendor, J., and Hammond, T. (2010) Choice theoretic approaches in bureaucratic structure. in R. Durant (ed), The oxford handbook of American bureaucracy. New York: Oxford University Press.

Berry, W. D. (1984). An alternative to the capture theory of regulation: The case of public utility commissioners. American Journal of Political Science, 28, 534-58.

Bowling, C. J., and Ferguson, M.R., (2001). Divided government, interest representation and policy differences: Competing explanations of gridlock in the fifty states. Journal of Politics 63(1): 182-206

PL 95-95, (1977). Retrieved from http://history.nih.gov/research/downloads/PL95-95.pdf

Brace, P., Arceneaux, K. Johnson, M. \& Ulbig, S.G. (2004). Does state political ideology change over time? Political Research Quarterly 57:529-40.

Brace, Paul, Kevin Arceneaux, Martin Johnson, and Stacy G. Ulbig. (2006). "Reprint of Correction: Does State Political Ideology Change Over Time?" Political Research Quarterly 59:493-4.

Berry, W.D., Ringquist, E.J., Fording, R.C., \& Hanson, R.L. (2010). Measuring citizen and Government ideology in the United States: Revisited. State Politics and Policy Quarterly, 10(2), 117-135.

Black, M. L, \& Kohler, D. (2004). Diminishing Democracy: Review of public participation in Michigan's environmental decision-making. Wayne Law. Review, 50(2A), 308 .

Bingham, G. (1986). Resolving environmental disputes: A decade of experience” Conservation Foundation: Washington 
Binder, Sarah. (1999). "The Dynamics of Legislative Gridlock, 1947-96." American Political Science Review 93:519-33.

Bullwinkel, G. E. (1975). "Environmental Law - the Uneasy Accommodation between State and Federal Agencies." DePaul Law. Review, 25, 423

Breger M. \& Edles, G.J. (2000) Established by Practice: The Theory and Operation of Independent Federal Agencies, Admin. Law Review. 52, 1119.

Call, G.D. (1985). Arsenic, ASARCO and EPA: Cost benefit analysis, public participation, and polluter games in the regulation of hazardous air pollutants. Ecology Law Quarterly, 12, 618

Chubb, J.E. (1983). Interest Groups and the bureaucracy: The politics of energy. Palo Alto: Stanford University Press.

Coglianese, C. (1997). Assessing consensus: The promise and performance of negotiated rulemaking. Duke Law Journal, 46(6), 1255-1349.

Cohen, J., \& Sabel C. (1997). Directly deliberative polyarchy. European Law Journal, 3(4), 312-342.

Cope, S. \& Goodship, J. (1991). Regulating collaborative government: Towards joinedup government. Public Policy and Administration, 14(2), 3-16.

Culhane, P.J. (1981). Public lands politics: Interest group influence on the forest service and the Bureau of Land Management. Baltimore: Johns Hopkins University Press

Cushman, R.E. (1972). The Independent regulatory commissions. New York: Octagon 
Davis, C. \& Hoffer, K. (2011). Federalizing energy? Agenda change and the politics of fracking." Paper Prepared for Presentation at Western Political Science Association Conference.

De Figueiredo Jr, R.J.P., and Vanden Bergh, R.J. The Political economy of state-level administrative procedure acts. Journal of Law and Economics, 47(2), 569-588.

Devins, N. and Lewis, D.E. (2008). Not-so-independent agencies: Party polarization and the limits of institutional design. Faculty Publications. Paper 157. http://scholarship.law.wm.edu/facpubs/157

Duffy-Deno, K.T. 1992. Pollution abatement expenditures and regional manufacturing activity. Journal of Regional Science, 32(4), 419- 436.

Dunlap, R. E. (2008). The new environmental paradigm scale: From marginality to worldwide use. Journal of Environmental Education, 40(1), 3-18.

Edelman, S. (1968). "Air pollution abatement procedures under the Clean Air Act." Arizona Law Review, 10: 30-36

Endris, L.K. and Penrod, W.E. (1997). Judicial independence in administrative adjudication: Indiana's environmental solution. St. Johns Journal of Legal Commentary, 12, 144.

Environmental Protection Agency. (1990). FY 1989 enforcement accomplishments report. (20E-2001). Washington, DC: Government Printing Office.

Epstein, D., and O'Halloran, S. (1999). Delegating powers: A transaction cost politics approach to policy making under separate powers. Cambridge: Cambridge University Press.

Epstein, D., and O'Halloran, S. (1996). Divided government and the design of administrative procedures: A formal model and empirical test. American Journal of Political Science, 58(2), 373-397. 
Ernst, H.R. (2003). Chesapeake Bay blues: Science, politics, and the struggle to save the bay. Lanham: Rowman and Littlefield.

Estache, A., Martimort, D. (1999) Politics, transaction costs, and the design of regulatory institutions. Policy Research Working Paper 2073, World Bank

Farnsworth, S. J. (1999). Federal frustration, state satisfaction? Voters and decentralized governmental power. Publius: The Journal of Federalism, 29(3), 75-88.

Fiorino, D.J. 2006. The New environmental regulation. Cambridge: MIT Press.

Fredriksson, P.G., List, J.A. \& Millimet, D.A. (2003). Bureaucratic corruption, environmental policy, and inbound US FDI: Theory and evidence." Journal of Public Economics, 87, 1407-1430.

Gelpe, M.R. (1990). Citizens Boards as Regulatory Agencies. Urban. Lawyer., 22, 451.

Gelpe, M.R. (1985). Exhaustion of administrative remedies: lessons from environmental cases. Geoege. Washington. Law, Review, 53, 1.

Ginsberg, B., Sanders E. (1990). Theodore J. Lowi and juridical democracy. PS: Political Science and Politics, 23(4), 563-566.

Greenhouse, Linda. (2007, Apr 3). Environmentalists hail supreme court ruling on carbon. New York Times. Retrieved from http://www.nytimes.com/2007/04/03/world/americas/03ihtscotus.1.5124385.html.

Grossback, L. J., Nicholson-Crotty, S., \& Peterson, D.A.M. (2004) “Ideology and learning in policy diffusion.” American Politics Research, 32(5), 521-545.

Hall, B. and Kerr, M.L. (1991). 1991-92 green index: A state-by-state guide to the 
nation's environmental health. Washington, DC: Island Press

Harter, P. J. (2001). Assessing the assessors: The actual performance of negotiated rulemaking. NYU Envtl L.J. 9,32.

Havrilesky, T, \& Gildea, J. (1992). Reliable and unreliable partisan appointees to the board of governors. Public Choice, 73(4), 397-318.

Hays, S.P., Eisler, M. \& Hays, C.E. (1996). Environmental commitment among the states: Integrating alternative approaches to state environmental policy." Publius, 26(2), 41-58

Healy, M. P. (1997). Still dirty after twenty-five years: Water quality standard enforcement and the availability of citizen suits.” Ecology L.Q., 24, 393-460.

Hedge, D.M., \& Scicchitano, M.J. (1994). Regulating in space and time: The case of regulatory federalism. The Journal of Politics, 56(1), 134-153.

Helland, E. (1998). Environmental protection in the federalist system: The political economy of NPDES inspections." Economic Inquiry, 36(2), 305-19.

Herath, D.P., Weersink, A. J. \& Carpenter, C.L. (2004). "Spatial and Applied temporal changes in the US hog, dairy, and fed-cattle sectors, 1975-2000.

Economic Perspectives and Policy, 27,49-69.

Hillman, A.J., \& Dalziel, T. (2003). Boards of directors and integrating agency and resource dependence. The Academy of Management Review, 28 (2), 383-396.

Hoberg, G., Phillips, J. (2011). Playing defense: Early responses to conflict expansion in the oil sands policy subsystem. Canadian Journal of Political Science, 44(3), 507-527.

Heady, F. (1949). The Operation of a mixed commission The American Political Science Review, 43(5), 940-952 
Hoberg, G. \& Phillips, J. (2011). Playing defense: Early responses to conflict expansion in the oil sands policy subsystem. Canadian Journal of Political Science, 44(3), 507-527.

Howell, W. G., and Lewis, D. (2002) Agencies by presidential design, Journal of Politics, 64(4), 1095-1114

Huber, J. D., and Shipan, C.H., (2002). Deliberate discretion? The institutional foundations of bureaucratic autonomy. New York: Cambridge University Press.

Huber, J. D., Shipan, C.R., \& Pfahler, M. (2001). Legislative and statutory control over bureaucracy. American Journal of Political Science, 45(2), 330-345.

Huxham, C. (2003). Theorizing collaboration practice. Public Management Review, 5(3), 401-423.

Innes, J.E., Connick, S., Kaplan, L., \& Booher, D.E. (2006). Collaborative governance in the CALFED program: Adaptive policy making for California water. No. 2006, 01 Working paper///Urban and Regional Development.

Ipsen, H.W., \& Raisch, J.W. (1974). Enforcement under the federal water pollution control act amendments of 1972. Land \& Water Law Review, 9. 369.

Irvin, R.A. and Stansbury, J. (2004). Citizen participation in decision-making: Is it worth the effort? Public Administration Review, 64(1), 55-65

John, D. (1994). Civic environmentalism: Alternatives to regulation in states and communities. "Washington: Congressional Quarterly Press.

Jones, B. S., \& Branton, R. P. (2005). Beyond logit and probit: Cox duration models of single, repeating, and competing events for state policy adoption. State Politics and Policy Quarterly, 5(4):420-443

Johnson K. S. (2003) Modernity, Public Administration, and the Disappearance of the American States: A necessary development? Administration \& Society, 35,144 
Johnson K.S. (2010). The first new federalism and the development of the administrative state. in R. Durant (ed.), The Oxford handbook of American bureaucracy. New York: Oxford University Press.

Ka, S. and Teske, P. (2002). Ideology and professionalism : Electricity regulation and deregulation over time in the american states. American Politics Research, 30(3), 323-343.

Kaufman, H. 1956. Emerging conflicts in the doctrines of public administration. The American Political Science Review, 50(4), 1057-1073.

Keller, W., \& Levinson, A. (2002). Pollution abatement costs and FDI inflows to U.S. states. Review of Economics and Statistics, 84, 691-703.

Kettl, D. (2002). Introduction, In D. Kettl (ed.), Environmental governance a report on the next generation of environmental policy. Washington: Brookings Institution Press.

Kerwin, C., Furlong, S., \& West, W. (2010). Interest groups, rulemaking, and American bureaucracy" in R. Durant (ed.), The Oxford handbook of American bureaucracy. New York: Oxford University Press.

Kjaer, A.M. (2004). Governance. Cambridge: Polity Press.

Klyza, C. M. \& Sousa, D. (2008). American environmental policy, 1990-2006. Boston: MIT Press.

Koehler, B., \& Koontz T.M. (2008). Citizen participation in collaborative watershed partnerships. Environmental Management, 41(2), 143-154.

Konisky, D.M. (2007). Regulatory competition and environmental enforcement: Is there a race to the bottom? American Journal of Political Science, 51(4), 853-872.

Konisky, D.M. ( 2009). The limited effects of federal environmental justice policy on state enforcement. Policy Studies Journal, 37(3), 475-496. 
Konisky D. M., \& Woods, N.D. (2011). “Measuring state environmental policy.” Review of Policy Research, 29(4), 444-469.

Koontz, T.M., \& Thomas, C.W. (2006). What do we know and need to know about the environmental outcomes of collaborative management?" Public Administration Review. 66(s 1), 111-121.

Kraft, M. E., \& Vig, N.J., (1999). Environmental Policy from the 1970s to the 1990s: An overview." In M. E. Kraft \& N. J. Vig (eds.), Environmental policy from the 1970s to the 1990s. Washington: Congressional Quarterly.

Kramer, B. M. (1983). Transboundary air pollution and the Clean Air Act: An historical perspective." Kansas Law Review, 32, 181-213

Laffont, J., \& Martimort, D. (1998). Collusion and delegation. Rand Journal of Economics, 29, 280-305.

Langbein L. I., \& Kerwin, C.M. (2000). "Regulatory negotiation vs. conventional Rulemaking: Claims, counterclaims, and empirical evidence." Journal of Public Administration Research and Theory, 10(3), 599-632

Langbein L. I. (2002). Responsive bureaus, equity and regulatory negotiation: An empirical view. Journal of Policy Analysis and Management, 21(3), 449-466

Lester, J. P., \& Lombard, E.N. (1990). Comparative Analysis of State Environmental Policy, The. Natural Resources Journal, 30, 301.

Levinson, Arik. (2001). "An industry-adjusted index of state environmental compliance costs. In C. Carraro, and G.E. Metcalf (eds.), Behavioral and distributional effects of environmental policy. Chicago: University of Chicago Press.

Lisa, J.J. (2005). EPA administrative enforcement actions: An introduction to the consolidated rules of practice. Temple Journal of Science, Technology, and Environmental Law, 24, 1.

Lohr, L., Park T.A., \& Wetztein, M. (1998). Voluntary economic and environmental risk trade-off in crop protection decisions. Agricultural and Resource

Economics Review, 27, 108-116.

Lubell, M. (2004). Collaborative environmental institutions: All talk and no action? Journal of Policy Analysis and Management, 23(3), 549-573. 
Lubell, M., \& Fulton, A. (2008). Local policy networks and agricultural watershed management. Journal of Public Administration Research and Theory, 18(4), 673696.

Mayhew, D. (1991). Divided party control: Does it make a difference?" P S: Political Science and Politics, 24, 637-40.

McCloskey, M. (1999). Problems with using collaboration to shape environmental public policy, Valparaiso University Law Review, 34, 423.

Meinke, S.R., Staton, J.K., \& Wuhs, S.T. (2006)."State delegate selection rules for presidential nominations, 1972-2000. The Journal of Politics, 68(1), 180-193

McCubbins, M. (1985). The legislative design of regulatory structure. American Journal of Political Science, 29(4), 721-48.

McCubbins, M, \& Schwarz, T. (1984). "Congressional oversight overlooked: Police patrols versus fire alarms." American Journal of Political Science, 28(1), 165-79.

McCubbins, M., Noll, R., \& Weingast, B. (1987). Administrative procedures as instruments of political control. Journal of Law, Economics, and Organization, 3 , 243-77.

Moe, T. M. (1989). The politics of bureaucratic structure, in J. E. Chubb, and P.E. Peterson (eds.), Can the Government Govern? Washington, D.C.: Brookings Institution Press.

Muskie, E. (1968). Role of the federal government in air pollution control. Arizona Law Review. 10: 17-24

McGuire, M. (2006). Collaborative public management: Assessing what we know and how we know it. Public administration review, 66(s 1), 33-42.

Millimet, D. L., and Slottje, D. ( 2002). Environmental compliance costs and the distribution of emissions in the United States. Journal of Regional Science, 42(1), 87-105.

Middleton J. T. (1968). Summary of the Air Quality Act of 1967. Arizona Law. Review., 10, 25.

Moren, J. (1968). Organization theories and the study of boards, councils, and commissions in public administration. Acta Sociologica, 11(1/2), 63-81.

Nadeau, L.W. (1997). EPA effectiveness at reducing the duration of plant-level noncompliance." Journal of Environmental Economics and Management, 34, 54-78. 
Newig, J., \& Fritsch, O. (2009). Environmental governance: participatory, multi-level and effective?" Environmental Policy and Governance, 19(3), 197-214.

Nicholson-Crotty, S. (2004). The Politics and administration of privatization: Contracting out for corrections management in the United States." Policy Studies Journal, $32(1), 41-57$.

Nie, M. (2008). The underappreciated role of regulatory enforcement in natural resource conservation. Policy Sciences, 41, 139-164.

Nownes, A. J., Thomas, C.S., \& Hrebenar, R.J. (2008). Interest groups in the states.” In V. Gray and R. L. Hanson (eds.), Politics in the American states: A Comparative Analysis." Washington: CQ Press.

Office of the Vice President. (1993). "Improving regulatory systems: Accompanying report of the National Performance Review. ”Washington DC: Government Printing Office.

O’Leary, R. (1993). Environmental Change: Federal courts and the EPA. Philadelphia: Temple University Press.

Oliver, C. (1991). "Strategic responses to institutional processes." The academy of management review, 16(1), 145-179

Olson, M. (1965). The logic of collective action. Cambridge: Harvard University Press.

Ostrom, E.(1990). Governing the commons: The evolution of institutions for collective action. Cambridge: Cambridge University Press.

Paehlke, R. (2005). "Democracy and Environmentalism: Opening a Door to the Administrative State?" In R. Paehlke and D. Torgerson (eds.), Managing leviathan: environmental politics and the administrative state. Peterborough: Broadview Press

Petracca, M. (1986). Federal advisory committees, interest groups, and the administrative state. Congress and the Presidency, 13 (1), 83-114.

Pender, J. L. (1998). "Population growth, agricultural intensification, induced innovation and natural resource sustainability: An application of neoclassical growth theory." Agricultural Economics. 19 (1/2): 99-112.

Portney, P. (2000). "EPA and the evolution of federal regulation." in P. R. Portney \& R.N. Stavins (eds.), Public policies for environmental protection. Washington: RFF Press. 
Potoski, M. (1999). Managing uncertainty through bureaucratic design: Administrative procedures and state air pollution control agencies. Journal of Public Administration Research and Theory, 9, 623-40.

Potoski, M. (2001). "Clean air federalism: Do states race to the bottom?" Public Administration Review, 61(3), 335-342

Posner, P. (2009). Networks in the shadow of government: Keys to high performance government. In S. Goldsmith and D.F. Kettl (Eds.), Unlocking the power of networks. Washington: Brookings Institution Press.

The President's Advisory Council on Executive Reorganization. (1971). A New Regulatory Framework: Report on Selected Independent Regulatory Agencies. Washington: Government Printing Office

Rabe, B. G., Roman, M. \& Dobelis, A. (2005). State competition as a source driving climate change mitigation. New York University Environmental Law Journal, 14, $1-53$.

Rabe, B. \& Mundo, P. (2007). Business influence in state-level environmental policy. In M. Kraft and S. Kamieniecki, (Eds.), Business and Environmental Policy. Cambridge, MA: MIT Press.

Randolph, J. \& Bauer, M. (1999). Improving environmental decision-making through collaborative methods. Review of Policy Research, 16(3-4), 168-191.

Reenock, C. S., \& Poggione, S. (2004). Agency design as an ongoing tool of bureaucratic influence. Legislative Studies Quarterly, 29(3), 383-406

Repetto, R. C. (1995). Jobs, competitiveness, and environmental regulation: What are the real issues?" World Resources Institute, Washington, D.C.

Ringquist, E. (1993). Environmental protection at the state level: Politics and progress in controlling pollution. New York: M.E. Sharp.

Rogers, E. \& Weber, E. P. (2010). Thinking harder about outcomes for collaborative governance arrangements." The American Review of Public Administration, 40(5), 546-567.

Rossi, J. (1997). Participation run amok: The costs of mass participation for deliberative agency decision-making. Northwestern University Law Review, 92(1), 173-250.

Rudolph, Thomas J., \& Evans, J. (2005). Political trust, ideology, and public support for government spending. American Journal of Political Science, 49(3), 660-671 
Sabatier, P.A. (1977). Regulatory policy-making: Toward a framework of analysis. Natural Resources Journal, 17, 415.

Sabatier, P. A. (1975). Social movements and regulatory agencies: Toward a more adequate-and less pessimistic theory of "clientele capture." Policy Science, 6, 301-342.

Santos, R., Antunes, P., Baptista, G., Mateus. P., \& Madruga, L. (2006). "Stakeholder participation in the design of environmental policy mixes." Ecological Economics, 60, 100-110.

Schaller, L. E. (1964). Is the citizen advisory committee a threat to representative democracy? Public Administration Review 24(3), 175-217.

Scher, S. (1962). The Politics of agency organization. Western Political Quarterly, 15, 328-344.

Scholz J.T. (1986). Regulatory enforcement in a federalist system. American Political Science Review, 80(4), 1249-1270

Schrecker, T. (2005). "Class place and citizenship: The changing dynamics of environmental protection." In R. Paehlke \& D. Torgerson, (eds.), Managing leviathan: Environmental politics and the administrative state. Peterborough: Broadview Press

Sinclair, A. H. and Whitford, A.B. (2012) Separation and integration in public health: Evidence from organizational structure in the states. Journal of Public Administration Research and Theory: first published online April 18, 2012 doi:10.1093/jopart/mus005

Skelcher, C. (2000). Changing images of the state: Overloaded, hollowed-out, congested. Public Policy and Administration, 15 (3), 3-19.

Smith, D. A., \& Tolbert, T. (2004). Educated by initiative: The effects of direct democracy on citizens and political organizations in the American states. Ann Arbor: University of Michigan Press.

Smith, G. (2005). Democratic deliberation and environmental policy: Opportunities and barriers in Britain." In R. Paehlke and D. Torgerson, (eds.), Managing Leviathan: Environmental politics and the administrative state. Peterborough: Broadview Press

State of Minnesota Office of the Legislative Auditor.(1991). "Pollution Control Agency." St. Paul, Minnesota. 
Stenberg, C. W. (1972). Citizens and the administrative state: From participation to power. Public Administration Review, 32(3), 190-198.

Stern, A. C. (1982). History of air pollution legislation in the United States. Journal of the Air Pollution Control Association, 32(1), 44-61

Stigler, G. J. (1971). The theory of economic regulation. Bell Journal of Economics and Management Science, 2(1), 3-21.

Stivers, C. (1994). The listening bureaucrat: Responsiveness in public administration. Public Administration Review, 54(4), 364-369.

Teske P. (1991) Interests and institutions in state regulation. American Journal of Political Science, 35(1), 139-154.

Tett, L., Crowther J., and O'Hara, P. (2003). Collaborative partnerships in community education. Journal of Education Policy, 18(1), 37-51.

Tiebout, C. (1956). A pure theory of local expenditures. Journal of Political Economy, $64(5) .416-424$

Torgerson, Douglas and Robert Paehlke (2005). "Environmental Administration: Revising the Agenda of Inquiry and Practice." In R. Paehlke and D. Torgerson, (eds.), Managing leviathan: environmental politics and the administrative state. Peterborough: Broadview Press

Torgerson, Douglas. (2005). “Obsolescent Leviathan: Problems of Order in Administrative Thought.” In R. Paehlke and D. Torgerson, (eds.), Managing leviathan: environmental politics and the administrative state. Peterborough: Broadview Press

U.S. Census Bureau, Annual Survey of State Government Finances and Census of Governments (1977-2005)

Vaughn, R. (1971). State Air Pollution Control Boards: The Interest Group Model and the Lawyer's Role. Oklahoma. Law Review, 41, 25.

Verkuil, P. R. (1988). The Purposes and Limits of Independent Agencies. Duke Law Journal, 1988(2/3): 257-279

Volden, Craig. 2002. "Delegating Power to Bureaucracies: Evidence from the States." Journal of Law, Economics, and Organization 18(1): 187-220.

Waller, C. J. (2000). Policy boards and policy smoothing. The Quarterly Journal of Economics, 115(1), 305-339. 
Whitford, A. B. (2005). The pursuit of political control by multiple principals. The Journal of Politics, 67(1), 29-49.

Weber, E.P., and Khademian, A. (1997). From agitation to collaboration: clearing the air through negotiation." Public Administration Review 57 ( 5 ): 396 -410.

Weber, E. P. (1998). Pluralism by the rules: Conflict and cooperation in environmental .regulation. Washington, DC: Georgetown University Press.

Weible C., and Sabatier, P.A. (2009). Coalitions, science, and belief change: Comparing adversarial and collaborative policy subsystems. Policy Studies Journal, 37(2), 191-212.

Walker, J. L. (1969). The diffusion of innovations among the american states. The American Political Science Review, 63(3), 880-899

Weber, E. P. (1998). Pluralism by the rules: Conflict and cooperation in environmental regulation. Washington, DC: Georgetown University Press.

Weimer, D. L. (2006). The puzzle of private rulemaking: Expertise, flexibility, and blame avoidance in U.S. regulation.” Public Administration Review, 66 (4), 569.

Wilson, J. Q. (1989), Bureaucracy: What government agencies do and why they do it. New York: Basic Books.

Wilson, J.Q. (1980). The politics of regulation. New York: Basic Books.

Wise, C., and O'Leary, R. (1997). Intergovernmental relations and federalism in environmental management and policy: The role of the courts. Public Administration Review, 57(2), 150-159.

Wood, B. D. (1988). Principals, bureaucrats, and responsiveness in clean air enforcements. American Political Science Review, 82, 213-34.

Wood, B. D. (2010). Agency theory and the bureaucracy." in R. Durant (ed.), The oxford handbook of American bureaucracy. New York: Oxford University Press.

Wood, B. D., and Bohte, J. (2004). Political transaction costs and the politics of administrative design. Journal of Politics, 66: 176-202.

Wood, B. D., and Waterman, R.W. (1991). The dynamics of political control of the bureaucracy. American Political Science Review, 85(3), 801-28.

Wood, B. D., and Waterman, R.W..(1993). The dynamics of political bureaucratic adaptation. American Journal of Political Science, 37(2), 497-528.

Woods, N. D. (2006). Interstate competition and environmental regulation: A test of the race to the bottom thesis. Social Science Quarterly, 87, 174-89. 
Yackee, J.W., and Yackee, S.W. (2006). A bias toward business? Assessing interest group influence on the bureaucracy. Journal of Politics, 68, 128-139.

Zaring, D. (1996). Agriculture, Nonpoint Source Pollution, and Regulatory Control: The Clean Water Act's Bleak Present and Future. Harvard Environmental Law Review., 20, 515. 
Matthew B. Arbuckle was born and raised Washington D.C. He earned a B.A. in Political Science from St. Mary’s College of Maryland, a Master of Public Administration from the School of Public Affairs at the University of Colorado Denver, and Ph.D. in Public Affairs from the Harry S Truman School of Public Affairs at the University of Missouri. Before beginning doctoral work, he spent several years working in a variety of roles in the public sector or its periphery. During this time, he worked in various positions on political campaigns for candidates and initiatives on all levels; worked for the City and County of Denver to help implement several large-scale events such as the Group of Eight Economic Summit, and the US Department of Energy's International Conference on Geologic Repositories; and performed research for a public affairs consulting firm. Matthew's research primarily examines issues at the intersection of policy, management, and politics, and their implications for environmental governance. His research agenda has specifically focused on the structure of state-level environmental decision-making, particularly the efficacy of negotiated, stakeholderengagement approaches to environmental policymaking. 